\title{
Evolution of New Variants/Mutants of JE Virus, Its Effect on Neurovirulence, Antigenicity, Host Immune Responses and Disease Transmission in Endemic Areas
}

\author{
Ravi Kant Upadhyay \\ Department of Zoology, D. D. U. Gorakhpur University, Gorakhpur 273009, India \\ Correspondence should be addressed to Ravi Kant Upadhyay; rkupadhya@yahoo.com
}

Received 4 October 2013; Accepted 11 January 2014; Published 25 March 2014

Academic Editor: Piet Maes

Copyright (C) 2014 Ravi Kant Upadhyay. This is an open access article distributed under the Creative Commons Attribution License, which permits unrestricted use, distribution, and reproduction in any medium, provided the original work is properly cited.

\begin{abstract}
This paper highlights various reasons of evolution of new mutants/variants of JE virus and its effects on neurovirulence, antigenicity, host immune responses, and disease transmission in endemic areas. Virus is reorganizing its genome by making sequence alterations, single site mutations, cluster specific reversions, and amino acid substitutions in neutralizing antigenic sites mainly in $\mathrm{N}^{\prime}$ glycosylation sites and epitopic regions of $\mathrm{S}$ and $\mathrm{E}$ proteins. Virus is regularly changing gene order, gene density by making substitution point mutations in important structural genes which make virus envelope proteins. Further, JE virus acquiring new genetic variations and adaptabilities through genetic recombination of wild strains with vaccine strains and assimilating new lethal genes that lead to emergence of molecular variants/mutants. These newly emerged JE virus genotypes have attained the ability to escape the immune defense and show wider resistance against vaccines and therapeutic agents. Thus new strains did significant elevation in the level of neurovirulence, antigenicity and pathogenesis. It is causing very high mortalities in various infant groups and imposing lifelong irreversible disorders in survivors and showing a regular trend of emergence and reemergence in endemic areas. The present review article emphasizes methods to suppress virus replication, reversion of neurovirulence, attenuation and an utmost need of more potential vaccines against cross reactive heterologous genotypes of JE virus to control disease transmission and mortalities occurring in endemic areas.
\end{abstract}

\section{Introduction}

Flavivirus, Japanese encephalitis (JE) virus, is the leading cause of acute viral encephalitis syndrome of central nervous system and mortalities of patients throughout Asia [1]. Though a large number of flaviviruses, such as Dengue virus and West Nile Virus Murray Valley encephalitis virus, are capable of giving rise to encephalitis, but, among all flaviviruses, JEV is proved highly dreadful because it severely invade many tissues and cells to establish an acute epidemic encephalitis syndrome in patients. Virus invasion generates severe inflammatory responses inside host, which later on spreads throughout the brain and results in necrosis of neurons and causes perivesicular cuffing, thrombosis, and variable degree of meningitis. Virus imposes very high neurovirulence and hemorrhage that give rise multiple disorders and lethality in various infant groups. Moreover, severity of infection with flaviviruses usually results into long lasting immunity and virus antigens boost the existing immune response. Further, cross-reactiveness between various antigenic components of different arboviruses also reinforces immune response to display variable pathogenic symptoms and etiology based on genetic relatedness. It also coincides with antigenic relatedness that is responsible for generation of hemorrhagic manifestations and immune hypersensitivity reactions in patients most similar to Dengue infections (Dengue shock syndrome). Virus that multiplies in cycles in different hosts is transferred by Culicinae mosquito species and generates repeated subclinical infections in endemic areas.

Current literature and clinical investigations reveal that climate induced genotypic variations are emerging in molecular variants of flaviviruses mainly related to encephalitis. Further, vaccine attenuated sequence alterations are also 
significantly increasing which not only are changing the etiological features of virus but also are inducing high neurovirulence and host immune responses and affecting disease transmission in endemic and nonendemic population. However, other than JE virus endemic strains, new vaccine derived recombinant strains of JE virus have been evolved which are detected in serum samples of patients from endemic regions. There is an observable finding that virus transmission from host to host is providing extra assistance to virus to adjudge the neutralizing molecules/machinery inside human host and making possible modifications in antigenic structures accordingly. This is an important issue to be discussed and requires prompt and essential solution. However, no information is available about decrease in virus pathogenicity by natural means, but JEV generated pathogenicity is increasing day by day due to mutations occurring in crucial amino acids in strains of JE virus [2]. However, flaviviruses are acquiring single amino acid changes or point mutations in domain III of the E protein [3] and attaining new molecular and ecological adaptations [4]. Thus, environment induced antibody resistant mutants are emerging with significant changes in genotypes [5]. These antibody resistant mutants also show the serotype reactivity and slow down immune protection [6]. However, vaccine strains of many viruses like rabies [7], West Nile Virus [8], Vaccinia virus [9], Influenza [10], Yellow fever virus [1], and JE virus [11] are also acquiring similar changes in genome and developing new mutant forms which are antibody resistant and environmentally adapted. These environmentally adapted new variants/mutants are proved to be more lethal than normal strains because of production of high neurovirulence and pathogenesis in human hosts mainly in various infant groups.

Further, it is also well known that viruses not only seek mutations inside host body or through artificial means in the laboratory by transfection methods but also vaccine strains generate mutations during storage. Therefore, due to mutations occurring in antigenic sites of viruses, there become regular trends of emergence and reemergence of viral diseases of the central nervous system [12]. However, single site mutations versus multiple mutations, cluster specific reversions, or amino acid substitutions that occurred in neutralizing antigenic sites or $\mathrm{N}^{\prime}$ glycosylation sites of structural proteins are well known established reasons for the formation of new variants. But gene rearrangements, reversions, additions, deletions, and duplications occurring in native viral strains of JEV including other flaviviruses also seem to play its role in formation of new variants of JEV.

In addition, changes in gene order and virus specific $\mathrm{NS}$ and $\mathrm{S}$ proteins and $\mathrm{pH}$-induced rearrangements in the envelope glycoprotein gene are also assisting in formation of antibody resistant mutants with variable genetic stability and molecular plasticity. More specifically, microevolution of new lethal amino acid sequences within the E protein in ecological and vaccine strains has significantly increased the severity of pathological effects in patients, and such isolates are found to be under directional evolution and/or coevolution. There are few important questions regarding host-to-host transfer and gain of variable antigenicity. Whether it is only possible through mutations and how long recombination play active role in generation of genetic diversity in JE virus are important questions. Further, occurrence of natural mutations and incorporation of new sequences in JE virus genotypes is a continuous evolutionary process that will give rise formation of neuroadapated antibody resistant viruses having more neuro-virulent protein genes. However, after attaining all required significant alterations in genome, new strains of JE virus may foil different immunological and molecular defense strategies in the future. Thus, environment induced genetic changes may alter the antigen profile very rapidly that will make flaviviruses more infective. Hence, it seems to be very difficult to control this virus by ordinary treatment and its control needs years of time. However, highly sophisticated molecular, biochemical, and immunological tools are to be required to control JE virus within and outside the boundaries of endemic area. However, from studies, it is clear that single site mutations and ecoclimatic, demographic, and clinical reasons are responsible for advent of new antibody resistant JE virus strains in endemic areas. These are considered as real cause of endemic expansion, disease transmission, and prevalence of Japanese encephalitis virus. Hence, in the present paper, all possible reasons of enhancement of neurovirulence, antigenicity, host immune responses, and transmission of JE have been discussed with the due emphasis on development of most appropriate and potential vaccine.

\section{Role of Mutation in Evolution of New Genetic Variations}

Genomes of both DNA and RNA viruses show different rates of mutations. More specifically, DNA viruses show near similar mutation rate, as it occurs in DNA of eukaryotes and prokaryotes. More commonly, these mutational changes or errors are estimated to occur at $10^{5}$ and $10^{10}$ per incorporated nucleotide per base pair per replication. However, the genetic information in eukaryotes does not reside in RNA; hence, no comparison can be made between the mutation rate in RNA viruses and eukaryotic cells. However, error rate in RNA viruses is observed much higher than in DNA of other organisms. Further, this rate in some of the RNA viruses such as vesicular is nearly $1: 1000$ to $1: 10,000$ per incorporated nucleotide. This rate is thus million times greater than mutation rate in DNA viruses. Further mutation induced in a virus does not manifest phenotypic changes in same way in all the hosts. Hence, there is much possibility that viable mutations that are neutral or deleterious in one host may provide a selective advantage in a different host. As it is clear from evolutionary studies that existing virus genomes were evolved over a very long periods. For over all established changes mutations and recombination both seem to be equal partners. But appearances of induced variations have been evolved only by different types of gene mutations. However, due to long evolutionary period, changing ecoclimatic conditions, mainly temperature, association of virus with different types of hosts and therapeutics used against virus have played important role in evolution of new mutant strains of flaviviruses. Further, during long evolution, 
TABLE 1: Evolutionary mechanisms involved in formation of new JE virus variants/mutants.

\begin{tabular}{|c|c|c|c|c|c|c|c|}
\hline Mechanism & Mutation type & $\begin{array}{c}\text { Possible genomic } \\
\text { change }\end{array}$ & Antigenicity & Neurovirulence & Endemicity & Therapeutics & References \\
\hline \multirow{6}{*}{ Natural } & Substitutions & Epitope/specific & Positive/high & High & Increase & $\begin{array}{l}\text { Live attenuated } \\
\text { vaccines }\end{array}$ & $\begin{array}{c}{[1,22,79,} \\
80]\end{array}$ \\
\hline & Deletions & Epitope/specific & Positive/high & High & Decrease & $\begin{array}{l}\text { Live attenuated } \\
\text { vaccines }\end{array}$ & {$[39,172]$} \\
\hline & Reversions & Epitope/specific & Negative/low & Low & Mild & Chimeric vaccines & {$[1,171]$} \\
\hline & Duplications & Nonspecific & Negative/low & Low & Increase & $\begin{array}{l}\text { RNA/Degenerated } \\
\text { vaccines }\end{array}$ & \\
\hline & Rearrangements & Nonspecific & Negative/low & Low & Constant & $\begin{array}{l}\text { RNA/Degenerated } \\
\text { vaccines }\end{array}$ & {$[97,109]$} \\
\hline & Reassortment & Nonspecific & Negative/low & Low & Constant & $\begin{array}{l}\text { RNA/Degenerated } \\
\text { vaccines }\end{array}$ & [110] \\
\hline \multirow{8}{*}{ Artificial } & $\begin{array}{l}\text { Site directed } \\
\text { mutagenesis }\end{array}$ & Epitope/desirable & Positive/negative & High & Increase & $\begin{array}{l}\text { Live attenuated } \\
\text { vaccines }\end{array}$ & {$[1]$} \\
\hline & $\begin{array}{l}\text { Fusion of } \\
\text { proteins }\end{array}$ & Epitope/desirable & Positive/negative & High & Increase & $\begin{array}{l}\text { Live attenuated } \\
\text { vaccines }\end{array}$ & $\begin{array}{c}{[61,62,} \\
175]\end{array}$ \\
\hline & Chimerization & Epitope/desirable & Positive/high & High & Increase & Chimeric vaccines & {$[174,179]$} \\
\hline & cDNA clones & Epitope/desirable & Positive/negative & High & Increase & $\begin{array}{l}\text { Recombinant } \\
\text { vaccines }\end{array}$ & {$[83,87]$} \\
\hline & VLPs & Epitope/desirable & Positive/high & High & Increase & $\begin{array}{l}\text { Recombinant } \\
\text { vaccines }\end{array}$ & {$[61,62]$} \\
\hline & $\begin{array}{l}\text { Recombinant } \\
\text { viruses }\end{array}$ & Epitope/desirable & Positive/high & High & Increase & $\begin{array}{l}\text { Recombinant } \\
\text { vaccines }\end{array}$ & {$[101]$} \\
\hline & Vaccines strains & Epitope/desirable & Positive/low & Mild & Increase & $\begin{array}{l}\text { Live attenuated } \\
\text { vaccines }\end{array}$ & [167] \\
\hline & $\begin{array}{l}\text { Synthetic } \\
\text { antigens }\end{array}$ & Short peptides & Positive/negative & High & Increase & $\begin{array}{l}\text { Attenuated } \\
\text { vaccines }\end{array}$ & \\
\hline \multirow{3}{*}{ Recombination } & Homologous & Epitopic/nonspecific & Positive/high & High & Increase & $\begin{array}{l}\text { Recombinant } \\
\text { vaccines }\end{array}$ & $\begin{array}{c}{[101,104,} \\
108]\end{array}$ \\
\hline & Intertypic & Epitopic/nonspecific & Positive/mild & High & Increase & $\begin{array}{l}\text { Recombinant } \\
\text { vaccines }\end{array}$ & {$[111]$} \\
\hline & Intratypic & Epitopic/nonspecific & Positive/mild & High & Increase & $\begin{array}{l}\text { Recombinant } \\
\text { vaccines }\end{array}$ & {$[105]$} \\
\hline Replication & Shared & Epitopic/nonepitopic & Positive/high & High & Increase & $\begin{array}{c}\text { Attenuated } \\
\text { vaccines }\end{array}$ & {$[39,41]$} \\
\hline
\end{tabular}

gene rearrangements and mutations were assimilated in the genome most related to virus survival and environmental susceptibility. Later on, these antigenic binding regions greatly differed in diverse orders of genes that not only influence gene activity but also give rise to counter resurgence in new viruses against any therapeutic agent and climatic change. Thus, virus during incubation, storage, or either inside host could develop new closely related strains. It presents a clear evidence of their phylogenetic evolution and can assist in finding relationship of origin of mutant strains of various flaviviruses [13-15]. These changes work as signals, which can be used to reconstruct the evolutionary history or phylogeny of a set of organisms including viruses. However, reversions, additions, and deletions may affect phylogenetic reconstruction of gene order in natural strains that may provide information regarding positive negative impacts of mutation in JE virus mainly about virulence and pathogenesis. Further, gene ordering could be changed due to evolutionary events such as transpositions or by substitutions. Thus, chromosome or genome can be represented by a signed permutation of genes. However, due to their short genome, chances of assimilation of new sequences from other viruses are lesser and lesser. But chances of increase in copy number of harmful signaling molecules cannot be declined. Viruses may adopt all these changes accordingly which make them more resistant to any drug or any vaccine. Further, host to host transfer may lead to an increase in antigenicity that may result in high genetic load in human host for carrying new harmful genes causing severe neuropathogenesis. Hence, all nonessential genes are ablated from the main chain as they have no requirement in virus replication and establishment of infections inside a host (Table 1).

Further, viruses show four different types of recombination mechanisms, that is, intramolecular, reassortment, reactivation, and marker response. All these mechanisms occur either simultaneously or in separate viruses whenever a host 
cell is infected by two virions. Mostly intramolecular recombination occurs in double stranded DNA viruses and retroviruses, or between two closely related viruses, but it never occurs in single stranded DNA viruses, while reassortment occurs in segmented genome of viruses such as Arenaviridae and Birnaviridae, Birnaviridae to Arenaviridae, and Birnaviridae and Bunyaviridae. More specifically, reassortment takes place in influenza A viruses which is known to affect viability, replication efficiency, antigenicity, host range, and virulence and can generate pandemic strains [10]. However, an exchange between various viruses or between two different viruses results in genetic variations that also affect neurovirulence and pathogenesis. In case of reactivation, two virions of same strain infest host and its formed corecombinants result in lethal mutations. Poxviruses, orthomyxoviruses and reoviruses are examples of reactivation. Marker rescue occurs when an infectious virion and an inactivated virus infect a host cell simultaneously. Sometimes virus gets active genes from a low pathogenic strain and high pathogenic strain that are proved more lethal. Further, viral gene products also interact to each other by mechanism of complementation, phenotypic mixing, and polyploidy. However, major reasons of genetic variations are deletions, reversions, and reassortment processes, which are responsible for creation of new variations in viruses in the nature (Table 1).

2.1. Mutations in Virus Envelop Proteins. Virus envelope protein is a major structural protein that contains many antigenic variants [16] or neutralizing epitopes. It make surface of the viruses [17] and mediate attachment to host cells. However, mutations that occurred in the envelope protein in Japanese encephalitis virus play important role in a putative receptor-binding domain that induces the host immune response $[18,19]$ and affect virus entry into cells and virulence [20]. However, mutations occurred in genome of JE virus are widely concerned to changes in conformational structures of structural and nonstructural virus proteins. If single amino acid changes occur within antigenic domain of virus, it confers resistance to virus neutralization [21] and develops antibody-resistant mutants with reduced neurovirulence [5]. Similarly, one, two, or multiple nucleotide changes in $\mathrm{E}$ genes are responsible for loss of neuroinvasiveness in Japanese encephalitis virus neutralization-resistant mutants [22]. Most commonly, both natural and synthetic peptides of E-glycoproteins of encephalitis virus elicits anti-viral antibody responses [23]. Mutations occur in internal fusion peptides of flavivirus envelop protein E [24]. These antigenic epitopes [25] also occur on fusion protein of viruses and are found to be involved in neutralization of antibody responses [26]. Moreover, fusion protein contains dominant antigenic site having only three amino acid changes which are detected by using anti-F monoclonal antibody (MAb). However, single amino acid change at position 73 was found responsible for its nonreactivity with the anti-F MAb. With the same MAb, antibody-resistant mutants were prepared from the vaccine strain [26]. Similarly, human Fab (gammal/kappa) library of human polyclonal antibodies shows similar neutralization potency against Japanese encephalitis virus [27].
Similarly, bovine respiratory syncytial virus nonstructural proteins NS1 and NS2 cooperatively antagonize alpha/ beta interferon induced antiviral response by generation of single and double gene deletions [28]. However, treatments of cells with recombinant universal IFN-alpha A/D or IFNbeta revealed severe inhibition of single and double deletion mutants, but it could not affect the growth of full-length BRSV. Surprisingly, all NS deletion mutants were found equally repressed, indicating an obligatory cooperation of NS1 and NS2 in antagonizing IFN-mediated antiviral mechanisms [28]. Whereas in MDBK cells the lack of either or both NS genes resulted in a 5,000- to 10,000-fold reduction of virus titers, in Vero cells a moderate (10-fold) reduction was observed [28]. It will help in generation of live recombinant vaccines.

Single amino acid changes in virus antibody resistant mutant show reduced neurovirulence [5] and poor undetectable hemagglutinating activity in comparison to parent virus [5]. However, a change from the aspartate to asparagine at amino acid 308 in Scottish strain of louping ill virus represented a potential glycosylation site and acted as strong determinants of virus generated virulence [5]. Similar neutralization resistance is also developed in immune escape mutants with an amino acid substitution in transmembrane protein due to alteration of a conformational epitope in HIV virus, mostly in envelope glycoprotein gp 120 [29]. This is the main reason that sera for many HIV-1 infected individuals contain broadly reactive specific neutralizing antibodies [29] and its mutant strains were found resistant to neutralization antibody effect that also target the CD4 receptor attachment site [30]. It is also possible that point mutations may affect the serotype reactivity [6] and may have a major impact on the design of live recombinant vaccines [28]. These mutations in nonstructural proteins result in virus escape from cytokine mediated host cell responses or show inhibitory effects to type I interferons [28] (Table 1).

Similarly, potent antibody mediated neutralization and antigenic escape was also detected in new variant of SIV strain SIV Mac 239 [31]. Such changes in HIV induced type 1 monovalent and trivalent envelope glycoproteins result in induction of neutralizing antibody responses in host animals [32], while $\mathrm{N}$ terminal substitutions in HIV-1 gp 41 reduce the expression of envelope glycoprotein on the virus [33]. Thus, mutations that occur at individual codons in the glycoprotein gene of the geographically diversified infectious hematopoietic necrosis virus give rise to more molecular adaptations to viruses [4]. More importantly, removal of single $\mathrm{N}$ linked glycan in HIV type 1 gp 120 results in an enhanced ability to induce neutralizing antibody responses [34]. Similarly, mutations are generated within potential glycosylation sites in the capsid protein of hepatitis E virus, which prevent the formation of infectious virus particles [35] but N-linked glycosylation of E2 glycoprotein of swine fever virus influences virulence in swine [36].

Similarly, HCV E2 glycoprotein mutagenesis of N-linked glycosylation sites has effects on E2 expression and processing [37], while a single site for N-linked glycosylation in the envelope glycoprotein of feline immunodeficiency virus and PRRSV (porcine reproductive and respiratory syndrome 
virus) modulates the virus-receptor interactions and generates immune responses $[38,39]$. Similarly, single $\mathrm{N}$ glycans play important role in proteolytic process and cell surface transport of glycoprotein in viruses [40]. However, N-linked deletions made in new fusogenic viruses showed an increase in replication, virulence, and immunogenicity [41]. Further, mutations caused due to replacement or deletion of these sites affect epitope determinant that results in resistance to monoclonal antibodies or neutralization antibodies as well [42]. Similarly, NS1 glycoprotein generates dramatic antibodyenhanced dengue viral replication in normal outbred mice resulting in lethal multiorgan disease [43]. Heparan sulphate binding by natural eastern equine encephalitis viruses promotes neurovirulence [44].

The antibody resistant mutants are generally formed due to either change in single amino acid codon [5] or due to an amino acid substitution in the transmembrane protein [29]. Such mutations do significant alteration in conformational structure of epitope that is recognized by neutralizing antibodies directed against receptor binding site [29]. For example, single amino acid substitution (A281V) within conserved region of the envelope glycoprotein gp 120 confers neutralization resistance against broadly reactive neutralization antiserum from a seropositive individual [29]. Similarly, mutation in fusion peptide affects antigenic site in globular region that also affects the binding of monoclonal antibody [45]. For example, in case of influenza virus, a monoclonal antibody (Y8-10C2) binds to the globular domain of hemagglutinin monomers or an epitope that is located at the interface of adjacent subunits [45]. Similar neutralization epitopes are also detected on VP7 surface protein serotype G11 porcine virus [46], pandemic influenza H1N1 hemagglutinin, and other respiratory viruses [47]. Similar reactive epitopes are also characterized on dengue 3 virus envelope protein domain III [48, 49], influenza A virus variants (Humberd et al., 2007 [50]), and a linear epitope on the enterovirus 71 VP2 protein which generates antigenicity and neurovirulence [51]. It is also true that antibodies generated in response to different viral antigens show broad reactivity. But, at the same time, various virus resistant neutralization antibodies may circulate in the blood stream, even then virus escapes the immune defense [29]. Therefore, mutation analysis of the cross-reactive epitopes of Japanese encephalitis virus envelope glycoprotein is highly essential and important to improve the accuracy of clinical diagnosis of flavivirus infections [52].

Thus, mutations generated in virus genome not only affect epitope conformational structure in antigenic binding region of protein but also affect protein folding [53]. These more promptly generate conformational flexibility in hemagglutinins which affect also its antigenicity [45] and molecular plasticity [54]. For example, removing of flexible loop of conformational structure of HIV 1 gp 120 proteins significantly changes its structure and function [55]. Hence, there seems to be a correlation between genetic variation and phenotypic fluctuations [56] and immune responses generated by envelope glycoproteins of viruses or vaccine strains [57]. As in eukaryotes, genotypic variants also show different phenotypes but in viruses phenotypic variations are much more while genetic variations are very less. It provides them extra molecular plasticity to recombine with any other virus or any other host and assists in generation of new genetic variations. Though, in eukaryotes, it is possible by spontaneous amplification of large chromosomal segments [58]. Further, changes, which are made by substitution mutation, seem to be good enough to enhance immune responses. But gene rearrangements induce antineutralization potential of viruses, which also led to altered neuroinvasiveness and neuropathogenesis [59]. However, amino acid residues that contribute to the neutralizing and enhancing epitopes localized into two regions and show partial overlaps in the homologous antigenic sites. Mainly these are designated like $\mathrm{A} 1$ and $\mathrm{A} 2$ in $\mathrm{S}$ glycoprotein of feline infectious peritonitis virus (FIPV) [60]. These antigenic sites are responsible for eliciting both neutralization and antibody dependent enhancement of immune responses [60]. Similarly, induction of $\mathrm{G}$ alpha (q) signaling cascade by HIV virus envelope is required for virus entry [61].

Similarly, single site mutation in the flavivirus envelope protein hinge region increases neurovirulence for mice and monkeys but decreases viscerotropism for monkeys [62]. However, few amino acids in the stem loop region were found to be involved in intracellular retention of envelope protein. It may affect antigenicity and neurovirulence [63]. However, secretion of noninfectious dengue virus like particles and Japanese encephalitis virus peptide present on Johnson grass mosaic virus-like particles induces virusneutralizing antibodies and protects mice against lethal challenge [64]. Similarly VSV glycoprotein displaying retrovirus like particles induce a type 1 IFN receptor dependent switch to neutralizing IgG antibodies [65], while HIV 1 envelope proteins trigger polyclonal Ig class switch recombination through a CD 40 independent mechanism [66]. When these envelop proteins are used as antigens to prepare a vaccine, these could elicit a functional complex human CD+ T cell response and induce cytotoxic T lymphocytes [67]. Contrary to this, other virus gene products that inhibit ATP binding (Hewitt et al., 2001 [68]) express a restricted repertoire of T-cell receptors [69], and induce multicentric lymphomas [70] and multiple pathogenic symptoms [69, 71]. Similarly, antigenic variations are also detected in glycosylation sites of hemagglutinin protein of $\mathrm{H} 5 \mathrm{~N} 1$ strain due to single mutations [72] and Influenza virus induced yeast cell surface proteins [73]. However, for knowing replacement based antigenic variabilities in JE virus, complete genomic characterization is highly essential and needful [17].

In addition, viruses also show property of immune escape to keep away themselves from action of neutralizing antibodies [29] and opt for multiple pathways [74]. However, due to occurrence of single site mutations in nucleotide sequence of the envelope glycoprotein gene, virus escape mutants showed resistance to polyclonal antiserum [75] and antilogous neutralizing antibodies [75]. Sometimes these neutralizing epitopes showed reduced neurovirulence in comparison to parent virus and failed to induce protective immune responses against lethal challenge in mice. In addition, these mutants with the lowest virulence remain less effective, show poor and undetectable hemagglutinating activity. However, 
cross-neutralization tests and sequence analysis should be performed to locate antigenic sites. However, such intratypic variations account for selection of mutation at different positions in virus envelope proteins [46] (Table 1).

2.2. Single Site Mutations in $N^{\prime}$ Glycosylation Sites. Single site mutations occurred in hemagglutinin-neuraminidase glycoprotein of different viruses affect antigenic specificity, functionality, and differentiation of a number of genotypes. However, amino acid substitutions done by creating single site mutations in hemagglutinin-neuraminidase glycoprotein showed different antigenic properties. These not only alter the antigenic structure and function of glycoproteins but also affect virus penetration in the cells [76]. These antigenic mutants selected with monoclonal antibodies delineate four nonoverlapping antigenic sites (I-IV) and separately inhibit hemagglutinating, neuraminidase, and hemolysis activities [77]. The temperature-sensitive (ts) neuraminidase (HN) glycoprotein of Sendai virus was found defective in its ability to agglutinate erythrocytes and infect host cells, while its neuraminidase activity was normal [77]. Similarly, glycosylation of the hemagglutinin-neuraminidase glycoprotein of human parainfluenza virus type 1 affects its functional but not its antigenic properties [78]. More specifically, antibody blocks only hemagglutination, but mutants selected with it showed a decrease in neuraminidase activity. It shows that neuraminidase site is close to, but distinct from, the hemagglutination site. Similarly, migration of the swine influenza virus $\delta$-cluster hemagglutinin $\mathrm{N}$-linked glycosylation site from N142 to N144 results in loss of antibody cross-reactivity [79].

The flavivirus E protein is the viral haemagglutinin, which induces protective immunity and mediates receptor specific virus attachment to cell surfaces [80]. The E protein plays major role in determining viral pathogenicity by defining cellular tropism and affecting penetration into susceptible cells $[81,82]$. The mutations in these proteins affect viral attenuation. These proteins are responsible for antigenicity in most of the viruses mostly infectious. However, antigenic variants of flaviviruses (Murray Valley encephalitis virus) showed altered hemagglutination properties and reduced neuroinvasiveness in experimental animals. It is only propagated by amino acid substitutions that lead to a significant change in virus envelope protein [16]. Similarly, single amino acid change within antigenic domain confers resistance to virus neutralization in spike protein of coronavirus [21]. Further, similar mutants of BCV were found resistant to the selecting group A MAb and sensitive to neutralization, but showed loss of reactivities [21]. The A528V mutation that occurred in domain II into the wild-type spike protein resulted in the loss of MAb binding of the mutant protein, confirming that the single point mutation was responsible for the escape of $\mathrm{BCV}$ from immunological selective pressure [21] (Table 1).

Similarly, human parainfluenza virus type 3 hemagglutinin-neuraminidase protein showed N-linked glycosylation [83]. This hPIV-3 hemagglutinin-neuraminidase (HN) protein is a multifunctional protein that mediates hemadsorption (HAD) and neuraminidase (NA) and shows fusion promotion activities, each of which affects the ability of $\mathrm{HN}$ to promote viral fusion and entry [83]. This protein contains four potential sites (N308, N351, N485 and N523) for Nlinked glycosylation whose systematic elimination in various combinations from $\mathrm{HN}$ to form a panel of mutants affect cellular immunity [83]. But removal of individual or multiple $\mathrm{N}$-glycans on the hPIV-3 HN protein had no effects on transport to the cell surface, expression, and neutralization activity [83]. However, few important amino acids found in E protein are considered to be located on E0 beta strand in domain I of E protein [84] but have shown presence of such amino acids at E-138, which upon mutation in JEV from Glu to Lys inhibits viral spread from cell to cell [3]. More specifically, mutations occurred in external loop region of domain II of dengue virus type 2 envelope protein showed serotypes specific binding to mosquito but not mammalian cells [19]. However, low-pH-induced rearrangements and mutations that occurred in flavivirus E protein [85] affect its structure. These also affect conformational structure of $\mathrm{E}$ protein derived peptides and change them from dimer in to trimer $[19,86]$. This structural transition of E protein is found responsible for viral cell binding and entry into the host cells, $[1,19,86,87]$. Thus, viral cell binding seems to be affected by mutations occurred in the E protein. Moreover, it is also confirmed that E-138 mutation is not located in domain III of $\mathrm{E}$ protein, but it is responsible for virus cell attachment under acidic conditions [5]. In addition, every mutant protein retained F-interactive capability may be equal to the wildtype protein capability. It shows that single or multiple $\mathrm{N}$-glycosylation site mutations that inhibited fusion at the earliest stages and $\mathrm{N}$-glycosylation of hPIV-3 HN were found to be critical to its receptor recognition activity, cleavage of the $\mathrm{F}$ protein, and fusion promotion activity. It is also possible that it might have no influence on its interaction with the homologous F protein and NA activity [83]. Similarly, HCV E2 glycoprotein: mutagenesis of N-linked glycosylation sites affects E2 expression and processing [37] (Table 1).

Flaviviruses are internalized after binding to glycosaminoglycan (GAG) residues on cells, and other molecules are involved in virus entry for some viruses such as lectins [88]. Single glycosylation site mutants (G1, G2, and G4) not only impaired fusion promotion activity but also reduced HAD activity of $\mathrm{HN}$ protein, which was even more obvious for all three double mutants (G12, G14, and G24) and the triple mutant (G124) [83]. Entry of HIV-1 into cells is mediated by interactions between the envelope (Env) gp120 and gp41 proteins with CD4 and chemokine receptors or via formation of an intermediate called the viral fusion complex (vFC) [89]. The Ab binding to the epitopes that appeared during viral membrane fusion might reinforce the appearance of the target epitopes for effective neutralization activity [89]. Similarly, Hepatitis $\mathrm{C}$ virus genotype 3a hypervariable region 1 in patients showed rapid virological response to alpha interferon and ribavirin combination therapy [90].

\subsection{Changes in Gene Order and Virus Specific Proteins.} Changes in gene order in virus genomes evolve over very long times that also affect the linear order in position of genes and its activity. However, comparison of gene order in different 
mutants developed form single endemic strain of virus could explore about all future possibilities of mutations. However, if all possible mutations and permutations are calculated based on sequential changes one can theoretically predict the valuable shifts in glycosylation and antigenic site in single epitope of a RNA fragment. Further, all such predictions obtained from in silico studies could be experimentally proved in various biological systems. However, all possible gene order per-mutated genomes of JE virus could also help to predict future infectious progenies of virus. Furthermore, it will also provide primary information about most possible/suggestible mutation types, its existing mutation rate, and ongoing effect in present time. However, sum total of genetic variabilities generated may show initial multiplicity of infection. It can be used for correlation of genome organization of each strain with its progeny production. However, shifts and reshifts occurred in location of specific genes in new strains if compared with wild strains. These could also build up the most suitable antigenic profile that is required for generation of suitable vaccine(s). But overexpression of any protein could inhibit virus growth, or permutations may reduce expression of gene $\mathrm{N}$ which codes for the nucleocapsid protein wild-type genome (Table 1).

JEV contains positive single stranded RNA genome, approximately $11 \mathrm{~kb}$ in length. Virus genome contains a single open reading frame with a well-arranged gene order as $5^{\prime}$ C-prM-E-NS1-NS2A-NS2B-NS3-NS4A-2K-NS4B-NS5 $3^{\prime}$ $[90,91]$. It encodes viral proteins $[92,93]$, mainly a precursor polyprotein having three structural proteins $(\mathrm{C}, \mathrm{prM}$, and E) and seven nonstructural proteins (NSI, NS2, NS2B, NS3, NS4A, NS4B, and NS5) [94]. Among nonstructural proteins, NS3 is a multifunctional protein having 619 amino acid residues and shows enzymatic activities like serine protease, helicase, and nucleoside triphosphatase. NS3 plays important role in the processing of the viral precursor polyprotein and the replication of viral genomic RNA [95]. In infected cells, NS3 is associated with microtubules and tumor susceptibility gene 101 protein and plays essential role in viral packing and intracellular trafficking of various viral components. In general, structural proteins $\mathrm{C}$, prM, and $\mathrm{E}$ are in a greater demand than the enzymatic protein (NS3) during the viral infection cycle $[96,97]$. However, simulated virus can show position effect of all genes, which can be experimentally proved for various ranges of infection. These could also elucidate alternate patterns of gene expression and enzymatic requirements for virus replication. However, there must be suitable selection of a cellular microenvironment inside specific cell types. For example, neuronal cells are most suitable sites for establishing and replication for JE virus. Because virus finds availability of all necessary enzymes, factors, cofactors, ionic fluxes, and proteins in the cell cytoplasm. But it should need a close association with host genome for replication and making working transcripts and phenotypes. Further, transcription and replication cycle need readymade contents of proteins that has to be adequately synthesized and its supply is maintained regularly during this period. Interestingly, if this gene for most essential protein is rearranged it would lead to a change in level of transcription, as it is located at position much differently in the wild-type genome. Similarly, N-gene rearrangement strains engineered by Wertz et al. [98] gave positive results in experimental and simulation studies. Therefore, structural proteins remain in a greater demand than the enzymatic protein during the viral infection cycle. Further arrangements are also possible with the movement of structural protein genes toward the $5^{\prime}$ end that may possibly reduce its level of transcription (Table 1).

There is a possibility that mutation in transcripts induce changes in gene expression related to cellular signaling pathways of signal transduction; transcriptional regulation may also affect carbohydrate, lipid, and protein metabolism [99]. However, alternative patterns of gene expression, achieved by changing the linear sequence of genes in the viral genome and its confirmation in various biological systems, could affect the growth of virus. Comparatively, defective mutant strains might show reduced expression of these genes, while high expression resulted from wild-type mutant strains of JE virus. It is also possible that virus growth can be exquisitely sensitive to perturbations in expression of some of structural genes while at the same time it may remain insensitive to perturbation in the expression of other genes. For example, Simian immunodeficiency virus targets central cell cycle functions through transcriptional control of an E2F regulated cell cycle program that does repression in vivo [100]. It shows massive and selective loss of CD4+ memory $\mathrm{T}$ cells that occurs during the acute phase of immunodeficiency virus infections. However, gene expression of purified $\mathrm{T}$ cells in Rhesus Macaques during acute SIVmac239 infection transcriptional program of over 1,600 interferon-stimulated genes was induced in all $\mathrm{T}$ cells by the infection. With this, all transcriptional changes were found specific to virally infected cells. It is due to striking downregulation of several key cell cycle regulator genes, which shared promotor-region $\mathrm{E} 2 \mathrm{~F}$ binding sites in downregulated genes. In addition, the upregulation of the gene for the fundamental regulator of RNA polymerase II, TAF7, displays that viral interference with the cell cycle and transcriptional regulation programs may be critical components during the establishment of a pathogenic infection in vivo [101]. Further, high mutant frequency was observed in populations of a DNA virus evasion from antibody therapy in an immune deficient host [102].

More specifically, influenza virus subpopulations show exchange of lethal $\mathrm{H} 5 \mathrm{~N} 1$ virus NS for $\mathrm{H} 1 \mathrm{~N} 1$ virus. It triggers de novo generation of defective interfering particles and enhances interferon induced particle efficiency [10]. Here, reassortment plays important role as influenza A viruses are known to affect viability, replication efficiency, antigenicity, host range, and virulence and can generate pandemic strains. There was observed a specific exchange of the NS gene segment from highly pathogenic A/HK/156/97 (H5N1) [E92 or E92D NS1] virus for the cognate NS gene segment of $\mathrm{A} / \mathrm{PR} / 834$ (H1N1) [D92 NS1] virus that did not cause a significant change in the sizes of infectious particle subpopulations [10]. Similarly, interaction of the HIV-1 nucleocapsid protein with SL3 RNA felt some real changes, which are attributed to loss of function of the H5N1-NS gene products [10]. Most notably, the NS exchange obliterated the usual IFN-induction-suppressing capacity associated with 
expression of full-size NS1 proteins, and hence functionally mimicked deletions in the NS1 gene. The loss of NS1-mediated suppression of IFN induction, de novo generation of DIPs, and the concomitant enhancement of IFN-inducing particle efficiency suggests that in an attenuated background the H5N1-NS could be used to formulate a self-adjuvanting live attenuated influenza vaccine similar to viruses with deletions in the NS1 gene [10]. Similarly, stability of the $1: 1$ complex of NCp7 with a 20mer mimic of stem-loop 3 RNA (SL3, also called psi-RNA, in the packaging domain of genomic RNA) is strongly affected by changes in ionic strength [103]. Similarly, strain specific induction of IL-6 and CCL5 in respiratory epithelial cells by clinical isolates of respiratory virus strain is also identified [104].

\section{Recombination Is a Source of Genetic Diversity and Therapeutic Resistance}

In a phylogenetic hierarchy, viruses share common properties to recombine and replicate very simply; they even possess complex antigenic structural and nonstructural proteins that generate neurovirulence in human and animal hosts (Table 2). Viruses possess many natural disease genes, which are easily rearrangeable and mutable after sensing the environmental changes and media available. Viruses in animal hosts recombine with the virulent and nonvirulent viruses or associate with more complex animal host genomes. Thus, viruses insert highly pathogenic lethal genes into new strains through recombination, for which they harbor the immune cells, tissues, and organs and try to destroy structuralfunctional attributes of virus recognizing molecules on the surface of immune surveillance cells. These give rise to either temporary or permanent severe pathogenic changes and lastly kill the host. More often, there are experimental evidences that RNA recombination occurs in the Japanese encephalitis virus within host cells only, [101] but PCR based methods are also used for generation of recombinant virus [105]. It is another factor associated with generation of genomic variations in viruses in laboratory setups. Normally, during recombination, two strains of a virus having different genotypes recombine inside host transfer their lethal genes and infect the host or cells in such a manner that both strains may infect the host cells simultaneously. Thus, liberated progeny virus particles may be actual recombinants, most likely to parental combination which occurs in viruses. It leads to basic changes in viruses, which help to increase the host range, virulence, and cause mixed infections. However, resulting progeny virus may show high recombination frequency in host, when one pathogenic and one nonpathogenic virus recombine, either frequency will be affected, or there may be some chances of decrease in RF. If it happens so, then viruses more exclusively reject retrogression and it will not recombine with a nonvirulent strain. It is assumed theoretically that a fatal decrease in virus recombination may decline the virulence forever. However, it can be assumed that antagonistic RNA viruses will become real solution for so many infectious diseases. Further, it seems to be impossible due to natural selection and avidity principle of biomolecules.
The most critical thing is that two interacting lines of viruses are not available on near genetic distance; however, path of infection, mutations, and reemergence are self-proclaimed in viruses that solely depend on the natural environment and host availability. Another important question is that if deletions take place single time for single amino acid and no replacement is being made available second time, what may be the fate of a low recombining strains in artificial and natural medium? Since duplications can happen easily, parental strain undergoes duplication many times and gives rise to hundreds of virions from a single infected cell. However, it is true that every recombinant product shortly after infection may undergo further exchange at later times so that several rounds of exchange become possible within the host before cell lyses. Postrecombination events can also modify mode of infection, latency, persistence, and neurovirulence in flaviviruses.

In addition, recombination also occurs between genetically similar viruses as well as between dissimilar viruses (Table 2). If intragenic intra-allelic recombinations occur, it may lead to formation of wild-type mutants in F1 progeny of a heterozygote for two mutant alleles. Viruses may possess autonomous elements, which can confer excision of any specific change in any position in the virus genome; contrary to this, no nonmutable virus is known until the date. Still there is no information available on elimination of defective mutants generated in virus progenies. In addition, integration host factors (IHF), interacting virus proteins, and associating genes may play an important role in nonchoice selection of mutants. They can generate environmentally adapted revertants against any therapeutic drug or a vaccine. It is the replication system which makes viruses more powerful by generating ecologically adapted mutants not only of filoviruses but also of other infectious viruses. If production of both integrase and repressor is inhibited, it will stop multiplication and act as an important switch to make off the virus pathogenicity. In addition, in case of enveloped viruses, ribosomal binding sites may have important role in control of virus framework and envelope protein synthesis. More importantly, mutant strains are also formed due to the lack of a proofreading function and error-repairing ability of genomic RNA. Hence, accumulated mutations work as a driving force for viral evolution in the genus Flavivirus, including the Japanese encephalitis (JE) virus. RNA recombination generates genetic diversity in the JE virus, which is an ancestral feature that worked in viral evolution, and effects epidemiology, and possibly vaccine safety (Table 2).

Further, it is also proved by genomic analysis of postrecombination strains that virus isolates established independently have shown significant increase in neurovirulence in comparison to their parents even they show close similarity to them. It is true that viruses have been evolved from common ancestry from which other microbes come out in existence. These viruses infect different hosts, but sustain in inside hosts due to molecular changes at amino acid and enzyme levels even after common evolutionary origin. Further, different diverging lineages also emerged among different clinical isolates of JEV; they show both collective and individual differences. Reemergence of clinical viral strains is 
TABLE 2: Theoretical prediction of formation of most possible single site revertants (mutations) through recombination and its effect on neurovirulence.

\begin{tabular}{|c|c|c|c|c|c|c|}
\hline \multirow{2}{*}{$\begin{array}{l}\text { E protein } \\
\text { Amino acid }\end{array}$} & \multirow{2}{*}{$\begin{array}{l}\text { Residue(s) in clusters } \\
\text { Epitopic region }\end{array}$} & \multicolumn{3}{|c|}{ Recombination } & \multicolumn{2}{|c|}{ Level of neurovirulence } \\
\hline & & Within the group & Out of the group & $\mathrm{M}-/ \mathrm{M}+$ Ratio & $\%$ Rec. & Increase/decrease \\
\hline & $12345(\mathrm{M}+)^{*}$ & 1.0 & 1.0 & 1.0 & 1.0 & Similar to PS \\
\hline & $678910(\mathrm{M}-)$ & 1.0 & 1.0 & 1.0 & 1.0 & Similar to PS \\
\hline & 12365 & 0.266 & 1.36 & 0.195 & 1.3 & $\uparrow<$ PS \\
\hline & 12645 & 0.337 & 1.50 & 0.224 & 1.2 & $\uparrow<$ PS \\
\hline & 16345 & 0.367 & 1.58 & 0.232 & 1.1 & $\uparrow<$ PS \\
\hline & 62345 & 0.388 & 1.636 & 0.237 & 1.1 & $\uparrow<$ PS \\
\hline & 12346 & 0.414 & 1.70 & 0.243 & 1.0 & $\uparrow<$ PS \\
\hline & 12347 & 0.303 & 1.436 & 0.211 & 1.26 & $\uparrow<\mathrm{PS}$ \\
\hline & 12375 & 0.375 & 1.60 & 0.234 & 1.10 & $\uparrow<$ PS \\
\hline & 12745 & 0.421 & 1.72 & 0.244 & 1.00 & $\uparrow<$ PS \\
\hline & 17345 & 0.450 & 1.81 & 0.248 & 1.00 & $\uparrow<\mathrm{PS}$ \\
\hline & 72345 & 0.466 & 1.87 & 0.249 & 0.97 & $\downarrow>$ PS \\
\hline & 12348 & 0.414 & 1.70 & 0.243 & 1.06 & $\uparrow<$ PS \\
\hline & 12385 & 0.466 & 1.87 & 0.249 & 0.97 & $\downarrow>$ PS \\
\hline & 12845 & 0.500 & 2.00 & 0.250 & 0.90 & $\downarrow>$ PS \\
\hline & 18345 & 0.521 & 2.09 & 0.249 & 0.86 & $\downarrow>$ PS \\
\hline & 82345 & 0.533 & 2.14 & 0.249 & 0.84 & $\downarrow>$ PS \\
\hline & 12349 & 0.504 & 2.01 & 0.250 & 0.90 & $\downarrow>$ PS \\
\hline & 12395 & 0.375 & 1.60 & 0.234 & 0.83 & $\downarrow>$ PS \\
\hline & 12945 & 0.566 & 2.30 & 0.246 & 0.78 & $\downarrow>$ PS \\
\hline & 19345 & 0.583 & 2.40 & 0.242 & 0.75 & $\downarrow>$ PS \\
\hline & 92345 & 0.592 & 2.45 & 0.241 & 0.74 & $\downarrow>$ PS \\
\hline & 123410 & 0.75 & 2.36 & 0.317 & 0.769 & $\downarrow>$ PS \\
\hline & 123105 & 0.84 & 2.52 & 0.333 & 0.719 & $\downarrow>$ PS \\
\hline & 121045 & 0.91 & 2.65 & 0.343 & 0.684 & $\downarrow>$ PS \\
\hline & 110345 & 0.96 & 2.74 & 0.350 & 0.662 & $\downarrow>$ PS \\
\hline & 102345 & 0.99 & 2.80 & 0.353 & 0.649 & $\downarrow>$ PS \\
\hline \multicolumn{7}{|c|}{ Prediction of formation of most possible multiple site revertants through recombination and its effect on neurovirulence } \\
\hline & 12345 & 1.0 & 1.0 & 1.0 & 1.0 & $\uparrow<\mathrm{PS}$ \\
\hline & 16365 & 0.367 & 1.58 & 0.232 & 1.14 & $\uparrow<\mathrm{PS}$ \\
\hline & 12646 & 0.408 & 1.69 & 0.241 & 1.07 & $\uparrow<$ PS \\
\hline & 16346 & 0.438 & 1.78 & 0.240 & 1.02 & $\uparrow<$ PS \\
\hline & 16265 & 0.636 & 1.85 & 0.343 & 0.98 & $\uparrow>$ PS \\
\hline & 62365 & 1.0 & 2.0 & 0.50 & 0.90 & $\uparrow>$ PS \\
\hline & 62346 & 0.455 & 1.83 & 0.248 & 0.90 & $\uparrow>$ PS \\
\hline & 16645 & 0.517 & 2.07 & 0.249 & 0.877 & $\uparrow>$ PS \\
\hline & 62645 & 0.529 & 2.12 & 0.249 & 0.854 & $\uparrow>$ PS \\
\hline & 72375 & 0.595 & 2.47 & 0.240 & 0.840 & $\uparrow>$ PS \\
\hline & 17347 & 0.556 & 2.25 & 0.245 & 0.806 & $\uparrow>$ PS \\
\hline & 17275 & 0.570 & 2.32 & 0.245 & 0.781 & $\uparrow>$ PS \\
\hline & 17375 & 0.586 & 2.36 & 0.248 & 0.787 & $\uparrow>$ PS \\
\hline & 72347 & 0.566 & 2.30 & 0.246 & 0.751 & $\uparrow>$ PS \\
\hline & 12747 & 0.537 & 2.16 & 0.248 & 0.735 & $\uparrow>$ PS \\
\hline & 17745 & 0.607 & 2.54 & 0.238 & 0.714 & $\uparrow>$ PS \\
\hline & 72745 & 0.615 & 2.60 & 0.236 & 0.699 & $\uparrow>$ PS \\
\hline
\end{tabular}


TABLE 2: Continued.

\begin{tabular}{|c|c|c|c|c|c|c|}
\hline \multirow{2}{*}{$\begin{array}{l}\text { E protein } \\
\text { Amino acid }\end{array}$} & \multirow{2}{*}{$\begin{array}{c}\text { Residue(s) in clusters } \\
\text { Epitopic region }\end{array}$} & \multicolumn{3}{|c|}{ Recombination } & \multicolumn{2}{|c|}{ Level of neurovirulence } \\
\hline & & Within the group & Out of the group & $M-/ M+$ Ratio & $\%$ Rec. & Increase/decrease \\
\hline & 12848 & 0.630 & 2.70 & 0.233 & 0.671 & $\uparrow>$ PS \\
\hline & 18285 & 0.651 & 2.87 & 0.266 & 0.632 & $\uparrow>$ PS \\
\hline & 18348 & 0.642 & 2.82 & 0.227 & 0.649 & $\uparrow>$ PS \\
\hline & 82348 & 0.649 & 2.85 & 0.227 & 0.636 & $\uparrow>$ PS \\
\hline & 18385 & 0.662 & 2.96 & 0.223 & 0.613 & $\uparrow>$ PS \\
\hline & 82385 & 0.668 & 3.01 & 0.221 & 0.602 & $\uparrow>$ PS \\
\hline & 18845 & 0.766 & 3.09 & 0.247 & 0.588 & $\uparrow>$ PS \\
\hline & 82845 & 0.682 & 3.14 & 0.217 & 0.578 & $\uparrow>$ PS \\
\hline & 12949 & 0.699 & 3.32 & 0.210 & 0.546 & $\uparrow>$ PS \\
\hline & 19349 & 0.707 & 3.41 & 0.207 & 0.531 & $\uparrow>$ PS \\
\hline & 92349 & 0.270 & 3.47 & 0.207 & 0.523 & $\uparrow>$ PS \\
\hline & 19295 & 0.713 & 3.49 & 0.204 & 0.508 & $\uparrow>P S$ \\
\hline & 19395 & 0.712 & 3.58 & 0.198 & 0.507 & $\uparrow>$ PS \\
\hline & 92395 & 0.725 & 3.63 & 0.199 & 0.500 & $\uparrow>$ PS \\
\hline & 19945 & 0.730 & 3.70 & 0.197 & 0.490 & $\uparrow>$ PS \\
\hline & 92945 & 0.738 & 3.818 & 0.193 & 0.476 & $\uparrow>$ PS \\
\hline & 1103105 & 0.765 & 4.27 & 0.179 & 0.425 & $\uparrow>$ PS \\
\hline & 1101045 & 0.757 & 4.4 & 0.172 & 0.423 & $\uparrow>$ PS \\
\hline & 1023105 & 0.768 & 4.3 & 0.187 & 0.420 & $\uparrow>$ PS \\
\hline & 1021045 & 0.775 & 4.45 & 0.174 & 0.408 & $\uparrow>$ PS \\
\hline & 1210410 & 0.751 & 4.01 & 0.187 & 0.452 & $\uparrow>$ PS \\
\hline & 1103410 & 0.756 & 4.10 & 0.184 & 0.442 & $\uparrow>$ PS \\
\hline & 1023410 & 0.759 & 4.16 & 0.182 & 0.436 & $\uparrow>$ PS \\
\hline & 1103105 & 0.765 & 4.27 & 0.179 & 0.425 & $\uparrow>$ PS \\
\hline
\end{tabular}

$\uparrow<$ PS Increasing but higher than the parental strain, $\uparrow>$ PS increasing but lower than parental strain.

(1) All sequential changes in antigenic sites with in the group $=\mathrm{Sncv}-\mathrm{Snv} / \mathrm{Sncv}$.

${ }^{*}$ Total no. of shifts in antigenic sites in circulating virus, ${ }^{* *}$ No. of probable shifts generated in newly emerged virus.

(2) All sequential changes in antigenic sites out of the group $=$ Sncv - Snv/Spv.

${ }^{*}$ No. of sequences in antigenic sites in parental virus.

(3) Possible \% recombination frequency in mutants/variants of JE virus $=1 /$ Square values of total shifts due to recombination in new progeny virus X100.

(4) Number of sequences in antigenic sites of $M+$ and $M-$ recombining viruses are 5.

(5) Possible alternate triplet codons 3, amino acids 2.

(6) Revertants mutations occur at single and more than two sites.

a hot area to decide the reasons of emergence and increase in severity of disease, whether these are genetic, clinical, or ecological reasons. Naturally, it may never be selective to occur in preferential recombination sites and these are not very precise hotspots, but it is very common theme that viruses share recombination between different groups that imply common ancestry. However, high sequence diversity generating through recombination is evolutionary in nature, also implies common ancestry and shows long chain of replication in one or more human hosts. Each of these events had to have occurred in single individual although not necessarily the same one.

However, RNA recombination occurred in the JE virus by using two local pure clones (T1P1-S1 and CJN-S1) which were, respectively, derived from the local strains, T1P1 and CJN [101]. It showed a C/preM junction comprising a fragment of 868 nucleotides (nt 10-877). Further, it was found that 9 of 20 recombinant forms of the JE virus had a crossover in the nt 123-323 region. However, in most of the recombinants, no nucleotide deletion or insertion identified in the region that may favor crossovers but precisely homologous recombination was involved. However, using site-directed mutagenesis, three stem-loop secondary structures were recognized to destabilize or restabilize in sequence, leading to changes in the frequency of recombination. It shows that the conformation, not the free energy, of the secondary structure is important in modulating RNA recombination of the virus [101]. Besides this, intratypic recombination was observed among lineages of type 1 vaccine derived poliovirus emerging during chronic infection of an immunodeficient patient [105]. Interestingly, some vaccine progeny, reverted to wild phenotype, showed only 2-3 nucleotide substitutions differences [106] and high neurovirulence [107]. Similarly, circulating poliovirus also frequently recombine with genomes of the polio and other nonpolio enteroviruses, either in primary or subsequent hosts, and show reversion 
effects [108-110]. When these strains were analyzed for its genetic analysis, the recombination junctions were found clustered in particular subgenomic regions of new serotype of the clinical isolates [111]. Similarly, circulating JE virus also frequently recombines with genomes of other flaviviruses and nonflaviviruses in primary and subsequent hosts $[112,113]$. More often, this recombination may occur in subgenomic regions and/or on the associations of genomic segments in recombination $[105,109,114]$ (Table 2).

However, if intratypic recombination takes place between two flavivirus strains, one with normal genome and another having a single site point mutation in genome, will give rise a new mutant strain with a single site mutation or any other non-useful nucleotide substitution throughout the genome [105]. It will lead to synthesis of defaulted enzymes or proteins that may promote neurovirulent susceptibility in host cells after having a close interaction to membrane receptors of immune defense cells. Thus, the number of shared identical recombinations and types of mutations occurring (amino acid substitutions) in neutralizing antigenic sites of $\mathrm{E}$ glycoprotein genes or proteins is major reason of formation of ecoclimatic variants of JE isolates. Thus, two viruses recombine intratypically, in progeny viruses its neutralizing antigenic sites may differ or remain similar is an important issue for molecular immunobiologists. It is much possible that new mutant/variants of virus may acquire altered neutralizing antigenic sites that may slightly differ from their parents. If we compare first strain with last to last newly emerging mutant strain of JEV, three important questions arise, what will be the exiting mutation rate and possible change in antigenic and recombination sites (Table 2). It may be equal to the induction in rate of infestation. However, all minor changes occur in complementarity determining regions or antibody-binding sites may display the evolution of lineage and changes that occurred in recombining region. Then what will be the fate of newly emerging ambiguous strains with defaulted genotypes evolved from noninfective strains, or those, which arise after recombination of a noninfectious virus to an infectious virus. In such a condition what may be the possible impact on host-to-host transmission of disease in a population with low to high immunity bearing individuals and between unimmunized and immunized human hosts. Similarly, if exotic strains of viruses are used to prepare a live attenuated vaccine for immunization of endemic population. Further, it is very difficult to identify possible start sites for reversion and re-reversion in the genome of vaccine derived virus strains. However, reemergence is not only due to natural reasons but due to vaccination, hence in order to solve this problem new replacing strains with ecologically adapted strains are upcoming. These are recombining with some common viruses and passing through a phase of reverse mutation, coadaptation, acclimatization, and fixation of postrecombination genetic factors rapidly to achieve its ecological survival. Hence, deletion methods are proved efficient to characterize the type of virus and mutations established in the genome.

However, theoretical prediction of formation of most possible single site reversion through recombination or any substitution mutation displays susceptibility of virus proteins to various hosts. However, to prove it, two hypothetical recombining strains with nucleotide/amino acid sequence like $12345(\mathrm{M}+)$ strain and $678910(\mathrm{M}-)$ strain recombine inside host; the new progenies may possess following order of \% recombination frequency $\uparrow<\mathrm{PS}, \uparrow<\mathrm{PS}, \downarrow$ PS, $\uparrow \downarrow$ similar to PS. These might be $0.699-1.33$, which is a clear-cut deviation form 1.0. However, strains which will show \% RF more than 1.0 will be highly virulent, 1.0 will be equal to their parent strain, and less than 1.0 recombinant frequency will be of low virulent type (Table 2). There will be rising trend in recombination frequency and neurovirulence in future progenies either similar or more than the parental strains. More exceptionally mutants with less than $1.0 \%$ recombination frequency might be temperature sensitive and hence eliminated in the nature or recombine at very slow rate, which can be said as bottom dwellers, but they might be improved when any highly virulent strain recombine in the future. Therefore, cluster specific reversions may slow down the rate of neurovirulence for a very short period but they take a lead after having possible reversions/mutations at a much proper site. However, it can be assumed that the changes, which occur in $5^{\prime}$ upstream of virus genome mutations, will be more effective and lead to both genotypic and phenotypic expression in host systems. More specifically whether changes occur in right side of amino acids in epitopic region or in core amino acids in structural proteins will be more significant according to the viewpoint of neurovirulence and antigenicity in newly emerging mutants/variants of JE virus. Further, changes in half-overlapping cluster or a common amino acid for two clusters will be more susceptible site for a significant alteration in the genome for genesis of high antigenicity and neurovirulence; that is why in a set of 5 sequences of cluster, amino acid number at position 3 might have major role in antigenicity determination (Table 2). However, substitution mutations are considered as important candidate molecule inside a structural protein or the RNA genome of JE virus that essentially acts as a complete antigenic determinant. Further, these sites are found highly flexible which is why these can gain assess of any type of shifting due to any type of mutation and allow positioning of a much appropriate and most required amino acids in the epitopic region. It is a common happening in all the pathogenic viruses. Further, when these sites undergo recombination with a less virulent virus, they maintain its own recombination frequency more intact or for say they never recombine between or on these sites. If anyhow recombinations occur, they never adapt \% recombination frequency half of the parental strain ( 0.5 of PS) and remain in the main stream to advance or increase its recombination frequency by transferring low virulent regions out of the group function or excluded out during replication. Further, copy editing in base sequences might be corrected inside amplifying host amplification. It is the main reason that GI and GIII are evolving new strains by recombining through near overlapping sites of structural genes, which are generated by various mutations (Table 2). However, newly emerging variants are showing heterologous genotypes with variable phenotypic expressions in different hosts. However, number type of amino acids in antigenic sites, protein folding, order of placement, and its possible effect on structure of 
virus structural proteins are the real cause of high virulence. Hence, certain amino acids, which act as live virulent switches, positioned in $\mathrm{E}$ and prM proteins, which effect $3 \mathrm{D}$ structure of virulent proteins and express differently in different host systems, are quite valuable and important for generation of most appropriate vaccines. Similar trend will be followed if reversions occur in more than two sites, but these will give rise to low recombination frequency genotypes that will be eliminated by repression effect by virus itself.

\section{JE Therapeutics}

It is a well-known fact that viral proteins elicit pathogenesis in hosts by establishing attachment with receptors of healthy cells and entry into the host. Therefore, to obstruct the infection at initial stage vaccination of infants and children is highly essential. It may stop cellular attachment of virus and nullify its effect. However, numerous options of JE vaccine preparation are available for prevention of Japanese encephalitis, but vaccine having a good molecular design with many antigenic determinants could be found more efficacious and may provide high safety profile against JE virus. However, for achieving high protection efficacy and feasibility for an effective JE control, new vaccines are designed by construction of chimeric viruses. These cDNA infectious clones and synthetic virus strains are generated by incorporating sequences most essential for viral antigens using site directed mutagenesis [72]. However, selective and strong viral antigens with a varied structure may stop attachment of virus and its replication inside host cells. It could also desirably stop reversion of neurovirulence. Thus, it can be considered more suitable for vaccination purposes. Furthermore, induction of differential enhancement of virus immune complex formation and eliciting of strong immune responses may increase the protective efficacy of vaccines. Therefore, designing better antigenic epitopes and genetic profiling of infectious DNA clones, plasmid incorporated mutations, genetically engineered chimeric viruses, VLPs, and synthetic viruses are widely in use for making necessary changes in genome by using site directed mutagenesis. However, more suitable vaccine candidates are needed for development of new potential vaccines against flaviviruses.

4.1. Use of Potential Viral Antigens. Virus possesses a protein coat called capsid which is made up of protein subunits, whose arrangement is virus specific. In some viruses, it is covered by an envelope made up of lipids, proteins, and carbohydrates. Contrary to this, some of the animal viruses are released from the host cells by an extrusion process that coats the virus with a layer of host's plasma membrane. Later on it becomes the viral envelope. Viruses are also covered by spikes, a carbohydrate protein complex that project from the surface of envelope virus; it helps the virus to attach with a host cell. For example, by means of spikes influenza, virus clump red blood cells and form bridges between them [115]. This clumping is called hemagglutination and is an important laboratory test [45]. Contrary to this, nonencapsulated viruses protect the nucleic acid from nuclease enzymes in biological fluids and promote the virus attachment to susceptible host cells. In response to viral infection, host immune system is stimulated and produces virus-neutralizing antibodies, which could inactivate the virus. However, viruses much cleverly escape antibodies because of significant alterations incorporated in the structure of envelop or surface proteins. Thus, altered surface proteins of viruses and host antibodies do not remain able to react to each other [116]. This is the main reason that influenza virus infects the same host repeatedly and every time mutates to defy action of antibodies [117].

4.2. How to Stop Viral Replication. Plants possess enormous power to synthesize phytochemicals to counteract different microorganisms because they remain in direct exposure of environment. However, to make a strong counter attack, plants synthesize so many broad-spectrum antimicrobials against various groups of microbes. However, to make an early defense, plants synthesize natural products of diverse nature and activity most similar to antibodies generated by animal hosts. Among them, few important plant products such as Glycorrhizin, a triterpinoid glycoside and licorice isolated from Glycyrrhiza glabra, and an ammonium salt of glycorrhizic acid showed antiviral activity against Japanese encephalitis virus [118]. Similarly, isoquinoline alkaloids and other constituents isolated from Amaryllidaceae were found effective against JE virus, yellow fever and dengue virus, alphavirus, and lentivirus [119]. Lucidone, a phytochemical isolated from fruits of Lindra erythrocarpa Makino, significantly suppressed HCV RNA levels at 50\% effective concentrations of $15+0.5 \mu \mathrm{M}$ and $20+1.1 \mu \mathrm{M}$ in $\mathrm{HCV}$ replication [120]. However, lucidone and alpha interferon, the protease inhibitor telaprevir, the NS5A inhibitor BMS-790052, or the NS5B polymerase inhibitor PSI-7977, synergistically suppressed HCV RNA replication [121]. Similarly, Glycyrrhiza uralensis extract showed antiviral properties against several viruses mainly rotavirus [122], while Euphorbia neriifolia triterpenoids and flavonoid glycoside were found to be antihuman coronavirus [123]. Further, galantamine and lycorine alkaloids isolated from Amaryllidaceae showed antitumor properties [124]. More specifically, Croton crassifolius that contains clerodane diterpenoids showed antiviral activity against herpes simplex virus type 1[125]. Green tea leaves possess catechins which showed immune-stimulatory and antiviral activity against human papillomavirus [126] while Cimicifugin from Cimicifuga foetida against human respiratory syncytial virus [127]. The roots of Wikstroemia indica contain dilignans that showed in vitro antiviral activities against respiratory syncytial virus (RSV) [125]. Algal sulphate polysaccharides showed anti-HIV, antiherpes, and antihepatitis activity [123]. Similarly, bioactive phenolic compounds from Egyptian Red Sea Seagrass Thalassodendron ciliatum showed antiviral activity against herpes simplex and hepatitis A virus [128] while Azadirachta indica polysaccharides were found antiviral to poliovirus [129]. Oral administration of Astragali radix showed protective effect against JEV in mice [130].

Similarly, houttuynoids A-E, a new type of flavonoids isolated from the whole plant of Houttuynia cordata, exhibited 
potent anti-HSV (herpes simplex viruses) activity [131]. Phenolic glycosides such as hedyotoides A-E including a new cyanogenic glycoside isolated from the whole plants of Hedyotis scandens showed in vitro antiviral activity against respiratory syncytial virus (RSV) [127]. Cimicifuga foetida was found antiviral against Human respiratory syncytial virus (HRSV) and inhibited the cytopathic effects of HRSV by a plaque reduction assay in both human upper (HEp2) and lower (A549) respiratory tract cell lines [125]. Similarly, triterpenoids from leaves of Euphorbia nerifolia showed antiviral activity against human coronavirus [123]. Moreover, herbal products from green tea and turmeric contain bioflavonoids, that is, Curcumin and catechins, which exhibit virucidal and virustatic actions [132]. Similarly, polyphenolic compounds such as catechins occur in green tea are known to have strong anti-influenza activity [132, 133] while Pokeweed antiviral protein (PAP), a plant-derived N-glycosidase, exhibits strong antiviral activity against several viruses including HIV-1 [134].

Silymarin, extracted from the milk thistle plant, Silybum marianum (L) Gaertn. (Asteraceae) showed antiviral activity against chronic hepatitis C [135]. Similarly, water-soluble chromone derivatives, including chromone-2-carboxylic acids, 2-methyl-chromones, and their structural hybrids, isolated from aerial tissues of Halenia elliptica (Gentianaceae), exhibit a strong inhibitory effect towards hepatitis B virus (HBV) in vitro [136]. Xanthone derivatives isolated from the EtOAc-soluble extract of Polygala karensium showed strong inhibitory effects on neuraminidases from various influenza viral strains, H1N1, H9N2, and novel H1N1 (WT) [137]. Similarly, tannins, flavonoids, saponins, coumarins, and terpenes isolated from leaves of Brazilian medicinal plants showed antiviral activity [138]. Similarly, phytochemicals isolated from marine algae possess novel functional ingredients and show antiherpes virus therapy [139].

Viruses are intracellular obligate parasites and need host body cells to replicate and express their genes. Viruses usually replicate in six different phases, that is, attachment of virus to host cell, its penetration or entry inside cell, uncoating, replication and expression, assembly, and release. Very simple viral replication produces many progeny that, when complete, leave the host cell to infect other cells in the organism. Interestingly, process of RNA viral replication differs in viruses having double and single stranded DNA and RNA viruses. For example, double-stranded DNA viruses typically must enter the host cell's nucleus before they can replicate. Single-stranded RNA viruses, however, replicate mainly in the host cell's cytoplasm. Interestingly, a single virus particle or virion remains inert because it lacks replication and proteins synthesis machinery. However, all viruses more essentially use host cell systems for replication and its survival. After cell invasion, virus infects a cell and it marshals the cells ribosome, enzymes, and much of the essential cellular components for replication purpose. The nucleic acid in a virion contain only a few of the genes needed for synthesis of new viruses. These include genes for the virions structural components, such as the capsid proteins and genes for a few of the enzymes used in the viral life cycle. These enzymes are synthesized and become functional only when the virus resides inside the host cell. The virus enzymes are almost entirely concerned with replication or processing of viral nucleic acid. But these are also needed for synthesizing viral proteins, including viral enzymes; ribosomes, tRNAs, and energy production are also supplied by the host cell, although smallest nonenveloped virions that do not contain a few enzymes, which usually function in helping the virus, penetrate host cell or replicate its own nucleic acid. Thus, for their own multiplication, viruses invade a host cell, use its metabolic machinery for multiplying its genome, and make several or even thousands of similar viruses in a single host in multiple cycles. This process drastically changes the structure and functions of host cells and usually causes its death. More exceptionally, in few viral infections, infected body cells survive for longer period that produce viruses infinitely. However, sudden invasion of host cells, tissue, and organs, largely by pathogenic viruses, could not make an effective defense because of the very short incubation period and the short life span of JE virus. It causes high mortality and morbidity in JE patients.

Flavivirus RNA genomes encode one long open reading frame flanking $5^{\prime}$ - and $3^{\prime}$-untranslated regions $\left(5^{\prime}-\right.$ and $3^{\prime}$-UTRs) which contain cis-acting RNA elements playing important roles for viral RNA translation and replication. As it is known, encephalitis virus is a positive $(+)$ sense strand RNA that encodes synthesis of a single polyprotein, which processes into three structural proteins and seven nonstructural (NS) proteins. The regions coding for the seven NS proteins are sufficient for replication of the RNA [140]. These linear RNA genomes of flaviviruses are polycistronic and act as mRNA that is translated into a viral polyprotein that is subsequently cleaved into individual viral polypeptides, one of which is a RNA dependent RNA polymerase. This polymerase uses the $(+)$ sense input RNA as a template for the transcription of $(-)$ sense RNA which in turn can act as a template for the production of nascent $(+)$ sense RNA [141]. This newly transcribed (+) sense RNA acts as mRNA and is used as a template for production of additional (-) strands or packaged as progeny virus. The replication of viral RNA genomes is unique considering that the host cell does not contain a RNA dependent RNA polymerase [142]. To overcome this constraint, the majority of RNA viruses encode their own RNA polymerase that is either packaged with the virus genome or is synthesized shortly after infection. In the first step of viral replication, early proteins or viral replicase is synthesized. This is an RNA-dependent RNA polymerase (RdRp that uses RNA as a template to make more RNA). In next step RdRp copies the original positive-sense RNA strand to make a double-stranded RNA replicative complex [143]. The newly made negative-sense RNA strand is used as a guide to make more single strands of positive-sense RNA. Then, single strands of positive-sense RNA can be used as mRNA to make the structural proteins, which are packaged into the final virions. But assembly of viral capsid is a natural and spontaneous nonenzymatic process. In next step the structural proteins and the positive-sense single strands of RNA are packaged together to bud out or exit the cell when it lyses (explodes). More exceptionally, virus titer decreases when there are no infectious particles present 
during replication process. Therefore, virus is detected in external medium only when it is released [144].

More exceptionally, virus infection starts with the attachment and entry of virus inside cell, and after establishment, virus starts replication and performs mRNA production, processing, and expression or translation. Then small virions get assembled and exit for cause of pathogenesis. More exceptionally, host membranes play an important role in $(+)$ RNA virus replication, as the RNA replication complexes released from membranes during purification generally lose the ability to catalyze true RNA replication, although a limited activity may be retained. In general, the intracellular membranes of cells infected with $(+)$ RNA viruses rearrange to form anchor sites for viral RNA replication complexes [145]. Nonstructural proteins with hydrophobic sequences that enable membrane integration or interaction facilitate membrane tethering of the replication complexes. In picornavirus-infected cells, viral RNA replication occurs on the cytoplasmic surfaces of double-membrane vesicles derived from the endoplasmic reticulum (ER). However, there are some proteins that directly inhibit virus replication. For example, antiviral protein viperin inhibits hepatitis $\mathrm{C}$ virus replication via interaction with nonstructural protein 5A [146]. More possibly, some specific molecules may inhibit viral replication by inhibiting activity of RNA dependent RNA polymerase [120, 142].

Similarly, secondary metabolites from endophytic fungi of desert plants showed inhibition of HIV-1 replication [147] while plant derived polyphenols were found to exert antiviral effects against influenza virus and showed inhibitory effect on neuraminidase activity [148]. Similarly, xanthone derivatives from Polygala karensium inhibit neuraminidase activity in influenza A virus [137] while alkaloids such as arvelexin and other compounds isolated from Isatis indigotica showed anti-viral activity against the influenza virus A/Hanfang/359/95(H3N2). Arvelexin has shown an IC (50) values of $3.70-12 \mu \mathrm{M}$, and inhibits Coxsackie virus B3 replication with an IC (50) of $6.87 \mu \mathrm{M}[120,131]$. Similarly, South American plants Limonium brasiliense, Psidium guajava, and Phyllanthus niruri and algae extracts showed antiviral activity and inhibited HSV-1 replication in vitro with $50 \%$ effective concentration (EC (50)) values of 185 , 118 , and $60 \mu \mathrm{g} / \mathrm{mL}$, respectively [149]. Moreover, aqueous dandelion extract showed anti-HIV-1 activity and inhibitory effect to HIV-1 replication and reverse transcriptase activity (Han et al., 2011). Similarly, 3-hydroxy caruilignan C (3HCL-C) isolated from Swietenia macrophylla stems exhibited high anti-HCV activity at both protein and RNA levels. It interfered with HCV replication by inducing IFN-stimulated response element transcription and IFN-dependent antiviral gene expression [150].

4.3. Stop Attachment of Virus Proteins. Just after attaching with a host cell, virus gets its entry inside the cell by three types of endocytosis, phagocytosis, receptor-mediated endocytosis, or pinocytosis. Most of the flaviviruses associate with CD46 receptors, which are glycoproteins. More exceptionally, viruses also use clathrin mediated endocytosis for its entry into host cells that is major route for endocytosis in most cells. Clathrin is a large protein that helps in the formation of a coated pit on the inner surface of the cell's plasma membrane. A coated vesicle formed in the cytoplasm of the cell when pit buds into the cell; it sucks in a small volume of fluid from outside the cell and carries it into the cell [151]. Most importantly, Dengue virus bind to heparan sulphate that is a glycosaminoglycan but uses the clathrin mediated endocytosis for its entry in to the host cells. Animal viruses possess attachment sites that binds to complementary receptor sites on the host's cell surface. The attachment sites of animal viruses are distributed over the surface of virus that varies from one group of viruses to other group. However, cells surface molecule or receptor sites of animal cells are proteins, glycoproteins, and glycolipid of the plasma membrane [152]. Glycoprotein possess sugar group attached to the protein, and glycolipids have fat or lipid group attached to it. There are many receptors with different functions for many different viruses. These help in attachment of virus to the host cell and gain entry into the cell for invasion [153]. Similar receptor sites inherited characteristic of every host, which varies from person to person, and show different binding to various virus-associating proteins. That is why, to a particular virus, different host shows variable susceptibility and this could account for differences in susceptibility to a particular virus. Following attachment entry and uncoating, the viral DNA/RNA is released into the nucleus of host cell. During bursts, new progeny of virus are gathered and all are instantaneously released.

However, virus attachment protein (VAP) assists in virus attachment to the receptor located on membrane which enables virus to gain entry into the host cell. Thus, viruses can enter the host cells through different routes; either virus may gain entry by direct penetration, fusion, or endocytosis [154]. Human cells do not have particular receptors for virus (Jolly and Sattentau 2013 [155]). Following attachment, virus enters into the host cells by pinocytosis and fuses with the plasma membrane forming a vesicle. Enveloped viruses enter the host cell by fusion with plasma membrane and release its capsid into the host cell's cytoplasm. The capsid digests the vesicle's contents or the nonenveloped capsid is released into the cytoplasm of host cell. Therefore, virus makes use of receptors to attach, if attachment is restricted by using antiviral drugs or other pharmaceutical agents viral infection can be prevented more successfully. However, monoclonal antibodies are generated to combine with a virus attachment site or the cells' receptor site. Uncoating also takes place that specify separation of virus nucleic acid from its protein coat once the virion is enclosed with the vesicle.

4.4. Stop Reversion of Neurovirulence. Among all flaviviruses, Japanese encephalitis (JE) virus is the leading cause of acute virus encephalitis syndrome. Virus just after inoculation multiplies its number and invades neuronal cells and causes heavy neurovirulence and pathogenesis. More specifically, amino acids existing in $\mathrm{E}$ protein were found neurovirulent determinants. These make highly specific antigenic site in the epitopic regions of viral proteins. If changes are made in these 
amino acids, antigenic specificity in viruses will change. It is possible after single amino acid substitutions/replacements in domain I of E protein or due to cluster specific reversions. There is a possibility that vaccine progeny can revert to wild phenotype if 2-3 nucleotide substitutions are created between the two phenotypes [106]. This reversion of neurovirulence may occur during primary infection inside host body [107]. However, to cut down the neurovirulence, more effective virus neutralizing antibodies are to be prepared against most appropriate antigenic determinants located in E proteins. Similarly, genetically engineered chimeric viruses are also used as vaccination candidates to stop the neurovirulence. However, to unfold the mystery of possible changes and nonselectivity of certain E protein sequences, humanized monoclonal antibodies can play important role. There is a possibility that composite herbal preparations may cut down virus generated neurovirulence by inhibiting DNA/RNA replication and prolonging the virus multiplication. Besides NS1, peptides derived from JEV E protein contain virus neutralizing epitopes that could be used to generate JEV neutralizing antibodies [64]. However, by analyzing isolate specific crucial amino acid substitutions, more clear evidences could be generated for confirmation of neurovirulence/neuroinvasiveness and antigenicity available today as well its possible enhancement in the future. Further, it may help in assessment of immunogenicity/antigenicity required against future progenies of virus that might influence the outcome of vaccines [2].

\subsection{Differential Enhancement of Virus Immune Complex.} Antibody-mediated immunity is critical for protection against many virus diseases, although it is becoming more evident that coordinated, multifunctional immune responses make most effective defense. However, specific antibody $(\mathrm{Ab})$ isotypes were found more efficient to provide protection against pathogen invasion in different locations in the body [156]. For example, antibody isotype, immunoglobulin (Ig) A, provides more protection at mucosal areas. It is known from the use of cationic lipopolymer (liposome-polyethylene glycol-polyethyleneimine complex [LPPC]) adjuvant that it strongly adsorbs antigens or immunomodulators onto its surface to enhance or switch on immune responses. More specifically, LPPC enhances uptake ability, surface marker expression, proinflammatory cytokine release, and antigen presentation in mouse phagocytes [156]. Antibody-dependent enhancement (ADE) of dengue virus (DENV) infection is mediated through the interaction of viral immune complexes with $\mathrm{F} c \gamma$ Rs, with notable efficiency of Fc $\gamma$ RII. Most human dengue target cells coexpress activating ( $\mathrm{F} c \gamma$ RIIa) and inhibitory (Fc $\gamma$ RIIb) isoforms. More specifically, both Fc $\gamma$ RIIa and Fc $\gamma$ RIIb isoforms comparably bind dengue immune complexes. Moreover, class II Fc $\gamma$ receptors found abundantly distributed which deferentially influence $\mathrm{Ab}$ mediated DENV infection under ADE conditions at cellular level $[132,157]$.

Similarly, differential enhancement of dengue virus immune complex infectivity mediated by signaling-competent and signaling-incompetent human Fcgamma RIA
(CD64) or FcgammaRIIA (CD32) [158]. It is assumed that Fcgamma receptor (FcgammaR)-mediated entry of infectious dengue virus immune complexes into monocytes/ macrophages is a key event in the pathogenesis of complicated dengue fever. Further, abrogation of FcgammaRIIA signaling competency was also associated with equally impaired phagocytosis but had no discernible effect on dengue virus immune complex infectivity. It shows fundamental differences between FcgammaRIA and FcgammaRIIA with respect to their immune-enhancing capabilities. Interestingly, there might be different mechanisms of dengue virus immune complex internalization that may operate between these FcgammaRs [158].

However, it is clear from antibodies interaction that virus neutralizing antibodies neutralize the DENV (Dengue virus) attack on monocytes by either preventing virus attachment to cellular receptors or inhibiting viral fusion intracellularly [159]. However, whether the antibody blocks attachment or fusion, the resulting immune complexes are expected to be phagocytosed by Fc gamma receptor ( $\mathrm{F} c \gamma \mathrm{R})$-bearing cells and cleared from circulation. This suggests that only antibodies that are able to block intracellular fusion would be able to neutralize DENV upon Fc $\gamma$ R-mediated uptake by monocytes whereas other antibodies would have resulted in enhancement of DENV replication. But in dengue patients, neutralization of the homologous serotypes occurred despite $\mathrm{Fc} \gamma \mathrm{R}$ mediated uptake. Contrary to this, Fc $\gamma$ R-mediated uptake appeared to be inhibited when neutralized heterologous DENV serotypes were used instead. It shows that inhibition occurred through the formation of viral aggregates by antibodies in a concentration-dependent manner. Aggregation of viruses enabled antibodies to cross-link the inhibitory Fc $\gamma$ RIIB, which is expressed at low levels but which inhibits Fc $\gamma$ R-mediated phagocytosis and hence prevents antibodydependent enhancement of DENV infection in monocytes [159].

4.6. Construction of Infectious DNA Clones. cDNA clones are used to characterize mutation in viruses [3] and to know the coupling between replication and packaging of flavivirus RNA [160]. These are used for generation of new vaccines against dengue fever and JE [161]. However, infectious cDNA clone of so many viruses, that is, tick borne encephalitis virus [162], duck Tembusu virus emerging as a flavivirus [163], west Nile virus [164], Omsk hemorrhagic fever virus [165], Brazilian prototype strain of dengue virus type 1 [166], dengue virus type 2, strain Jamaican 1409, [167], Japanese encephalitis virus [168], infectious dengue 2 virus cDNA [169], and Kunjin virus [170], were prepared to use them as candidate for generation of new vaccines [171]. However, cloning DNA segments in plasmid vector is useful to study behavior of incorporated genes and sequences in expression systems. But it is a limitation that a plasmid containing a donor DNA has the DNA segment of interest; therefore, confirmatory analysis of such inserts is essential to ensure presence of desirable DNA segment. There may be demarcation line between each one of the natural and artificial systems that is the rate of incorporation of new nucleotides. Interestingly, in natural 
conditions, during formation of new mutants, whether rate of elimination of defective or nondesirable nucleotides will be very high in comparison to artificial system is an important question to answer. Further, artificially generated mutants that did not face any environmental alteration must revert sooner or later to normal strain, or may precisely improve with the time. There is possibility that such strains may remain unsuccessful to show the host genome integration if used. In natural system, viruses derived from infectious clones may retain neuroinvasiveness and neurovirulence properties of original virus very soon [164]. At the same time it is not mandatory in artificial methods that defaulted copies of mutants be corrected soon; possibly it will depend on the chance of elimination of old nucleotides and fixation of new nucleotides at replacement sites. It may help to reduce the cryptic bacterial promoter activity of virus genome because pathogenic viruses rarely use bacterial hosts or use them in highly unfavorable conditions [172]. Therefore, the regulatory mechanism of virus control certainly possesses triangular reasons. First use nonspecific antigenic sites for advent of new amino acids, cut and cleave the new positions, and apply refixation of favorable amino acids in old replacement sites by upholding old confirmatory translational switches. It helps the virus to read the new genes fetched from human hosts as well as from nonpathogenic viruses and transfect bacterium host. However, new progenies possess triple factors to make its survival more successful and induce high neurovirulence in immune deficient human hosts. With this all further corrections could be made inside amplifying host or any alternate host that might possess nearly similar strains of viruses and bacteria as well.

However, generation of expression-ready ORF cDNA clones of infectious viruses often requires multistep cloning processes as well as lengthy verification and sequence analysis. Besides this, infectious transcripts are also generated by RT-PCR methods [173] or are derived as stable full length cDNA clone of virus [174] or by transcription of virus DNA from full length cDNA template [175]. These can be generated in both ways by transcription and reverse genetic system [176] or are artificially designed [167]. Infectious JE virus RNA can be synthesized in vitro ligated cDNA templates [177] by using high copy number plasmids [178]. Similarly, infectious JE virus clone was made on cDNA template of the attenuated live vaccine production strain [179] while infectious cDNA clones of dengue 2 virus were made by using strain 16681 and its attenuated vaccine derivative strain PDK-53 [180]. Furthermore, a new strategy was followed to design positive RNA virus infection clones by enabling their stable propagation in E. coli [179] and in mammalian cell culture systems [180]. Defective interfering RNAs of JE virus are found in mosquito cells responsible for persistence of infection [181].

However, a DEN3-DEN4 chimera (intertypic chimeric dengue viruses) was constructed that contains DEN3 CPreM-E genes, which express DEN3 antigenic specificity. It bears Thr-435 $\rightarrow$ Leu substitution mutations, which ablates the potential glycosylation site sequences, produced in virus E protein identical in size to that of wild-type DEN3 $\mathrm{E}$, indicating that the glycosylation site is normally not used. Further, its intracerebral inoculation in suckling mice revealed that the mutant chimera containing the Glu-406 $\rightarrow$ Lys substitution was neurovirulent, whereas its wild-type counterpart or parent DEN3 was proved nonvirulent [182]. Similarly, intertypic chimeric dengue viruses are also constructed by substitution of structural protein genes [183]. The RNA transcripts made from these templates were found infectious when transfected into permissive cells in culture. The type 2/type 4 chimera retained the mouse neurovirulence of the dengue 2 virus, which was the source of its structural protein genes. When mice inoculated intracerebrally with the chimera they died, but survival time was prolonged due to retardation of replication in the type 2/type 4 chimeric virus. However, these intertypic dengue virus chimeras could be used for attenuation in primates and possible usefulness in a live dengue virus vaccine for humans [183].

4.7. Plasmid Incorporated Mutations and Vaccine Development. Plasmid incorporated mutations are highly useful in generation of good viral antigens which can be used for generation of novel vaccines. These mutation based new antigens induce strong antibody responses to the viral envelope glycoprotein (Env) and possess the capacity to neutralize a broad range of viral strains. For example, mutations created in membrane proximal external region of the envelope glycoprotein of human immunodeficiency virus significantly increased the target specify and antibody responses to the virus [184]. Further, neutralizing monoclonal antibodies synthesized target the short and hidden membrane proximal external region (MPER) of the gp41 transmembrane protein. However, mice immunized with VLPs containing the MPER mutants produced MPER-specific antibodies, whose levels could be increased by the trimerization of the displayed proteins as well as by a DNA prime-VLP boost immunization strategy [184]. Similarly, virus glycoprotein display retrovirus like particles induce type 1 IFN receptor dependent switch to neutralizing antibodies [185]. Similarly, coimmunization with an optimized IL15 plasmid adjuvant enhances humoral immunity via B cells induced by genetically engineered DNA vaccines expressing consensus JEV and WNV E DIII [186]. Contrary to this, human respiratory syncytial virus nucleoprotein and inclusion bodies antagonize the innate immune response mediated by MDA5 and MAVS [187].

Similarly, immunity level in pig to Hog cholera vaccine was improved by using recombinant plasmid with porcine interleukin-6 gene and CpG motifs [188]. However, in order to observe the dosage-effect of recombinant pig interleukin6 gene and $\mathrm{CpG}$ motifs on the immune responses of swine to vaccine, a novel recombinant eukaryotic VPIL6C plasmid was packed with chitosan nanoparticles (CNP). This VPIL6C entrapped with CNP was found to be a novel effective adjuvant to boost the humoral and cellular immunity of pig to Hog cholera, implying its potentiality to enhance the resistance of pig against infectious diseases [188]. Furthermore, induction of such antibodies represents an important goal in the development of a preventive vaccine against the infection. For which most conserved virus specific complex-reactive antigenic sites would be selected for antibody production [189]. 
Similarly, attenuated mutants of Venezuelan equine encephalitis virus containing lethal mutations in the PE2 cleavage signal combined with a second-site suppressor mutation in E1. [190]. The PE2 cleavage signal in a full-length cDNA clone of the alphavirus Venezuelan equine encephalitis virus (VEE) was ablated by site-directed mutagenesis. There was observed a close functional association of the E2 and E1 proteins in the alphavirus spike [190]. Similarly, recombinant plasmid expressing a truncated dengue-2 virus $\mathrm{E}$ protein without coexpression of prM protein induces partial protection in mice [191]. A nucleic acid vaccine candidate against dengue- 2 virus was constructed to express a truncated dengue-2 E glycoprotein without concomitant expression of prM. The truncated E protein was properly expressed even in the absence of prM [191]. But an imperfect secretion of $\mathrm{E}$ protein due to lack of the prM protein generates lower grade protection and does weak activation of the immune system. It clears that prM is important for the processing of the $\mathrm{E}$ glycoprotein and that it should be incorporated in candidate vaccines engineered by recombinant DNA technology [191].

4.8. Construction of Chimeric Viruses for New Live Vaccines. Viruses not only seek mutations inside host body or through artificial means in the laboratory by transfection methods but also avail mutations during storage of vaccines. Many viruses like rabies [7], West Nile Virus [140], Yellow fever Virus [1], Vaccinia virus [9], and JE virus [8] grow in vaccine fluid or admixtures. These mutations in vaccine strains of encephalitis virus impose risks in development of new vaccines. However, to overcome this problem, more stable mutants or artificial recombinants of two different viruses such as a wildtype flavivirus (Kunjin) and a live chimeric vaccine flavivirus (ChimeriVax-JE) [192] are fused to prepare a new stable strain that can be used for generation of more potential vaccines. It may possess a different genotype and broad spectrum antiviral activity against Japanese encephalitis virus [193]. Similarly, a yellow fever virus (YFV)/Japanese encephalitis virus (JEV) chimera was also prepared by replacement of structural proteins prM and E of YFV 17D, replaced with those of the JEV SA14-14-2 vaccine strain to generate a candidate vaccine against Japanese encephalitis. This chimera (YFV/JEV SA14-14-2, or ChimeriVax-JE) was found to be less neurovirulent than YFV 17D vaccine in mouse and nonhuman primate models $[194,195]$. However, ten amino acid differences have been identified between the $\mathrm{E}$ proteins of ChimeriVax-JE and the YFV/JEV Nakayama virus, four of which are predicted to be neurovirulence determinants based on various sequence comparisons. Similarly, a series of intratypic YFV/JEV chimeras containing either single or multiple amino acid substitutions were engineered and tested for mouse neurovirulence [1]. However, to restore the neurovirulence typical of the YFV/JEV Nakayama virus, reversions in at least three distinct clusters were made and these were found highly useful to make different combinations of cluster-specific reversions to confer neurovirulence [1]. Finally, amino acid number 138 of the E protein (E (138)) exhibited a dominant effect. More often, no single amino acid reversion produced a phenotype significantly different from that of the ChimeriVax-JE parent was detected. When these mutant strains were allowed to grow in prolonged cell culture and mouse brain passages, virus showed genetic stability and was found suitable for generation of a novel live-attenuated viral vaccine against Japanese encephalitis [1].

However, Yellow fever 17D virus, a safe and effective live, attenuated vaccine, was used as a vector for genes encoding the protective antigenic determinants of a heterologous member of the genus Flavivirus. Since the prM and E proteins contain antigens conferring protective humoral and cellular immunity, the immune response to vaccination seems to principally target JE virus. Though, it is true that a single $\mathrm{M}$ protein mutation affect the acid inactivation threshold and growth kinetics of a chimeric flavivirus [196]. However, upon immunization in animals, it has shown no detectable viremia after challenge in tests in comparison to unimmunized controls that became viremic [197]. Further, histopathological examination, performed 30 days after virus challenge, has shown no minimum evidence of encephalitis in immunized animals. It confirms the very high protective efficacy of ChimeriVax-JE against virus intracerebral challenge that also induces a rapid humoral immune response in experimental animals. More exceptionally, it causes lesser neuronal damage in virus targeting areas and lower inflammation and neurovirulence in monkeys infected with wild-type JE virus [195]. Similarly, full-length RNA transcripts of the YF/JE chimaera were used to transfect Vero cells.

Similarly, ChimeriVax-JE, a live, attenuated recombinant $J E$ virus vaccine, was prepared by replacing the genes encoding two structural proteins (prM and E) of yellow fever 17D virus with the corresponding genes of an attenuated strain of Japanese encephalitis virus (JE), SA14-14-2 [197]. The prME genome sequence of the ChimeriVax-JE is identical to that of JE SA14-14-2 vaccine and differed from sequences of virulent wild-type strains (SA14 and Nakayama) at six amino acid residues in the envelope gene (E107, E138, E176, E279, E315, and E439) [197]. A well-tested attenuated live JEV vaccine provides better preclinical safety and efficacy requirements for a human vaccine. It was found more suitable for JE susceptible animals, and its single dose is well tolerated and highly immunogenic to human hosts [60]. It was tested for neurovirulence in mice, monkeys, hamsters, and athymic nude mice in which attenuated virus strain was found avirulent to these animals by intracerebral inoculation (i.c.) or intraperitoneal inoculation (i.p.) [60]. It was tested safer than yellow fever $17 \mathrm{D}$ vaccines but has a similar profile of immunogenicity and protective efficacy. It shows significantly almost no detectable viremia after challenge in immunized animals. Only 1 of $6(17 \%)$ vaccinated monkeys has shown symptoms of encephalitis [1]. When compared, ChimeriVaxJE was found more appropriate and suitable than commercial yellow fever 17D vaccine (YF-Vax) because it successfully cut down lethal effects of JEV generated pathogenesis. Further, reduction in pathogenesis was obtained in JE virus prone histological regions. Moreover, lesion scores in brains and spinal cord were significantly higher for monkeys inoculated with YF-Vax, but there was no symptom in ChimeriVaxJE immunized animals. Similarly, chimeric novel vaccines against dengue fever and tick borne encephalitis and Japanese 
encephalitis are constructed for immunization purpose [198]. Similarly, chimeric human antibodies are also generated by using antibody encoded recombinant gene. It is a mouse human chimera known as chimeric antibody. Its antigenic specificity is determined by variable region that is derived from mouse DNA, while its isotype, which is determined by the constant region, is derived from human DNA.

Similarly, a IMOJEV (ChimeriVax-JE), a novel recombinant chimeric virus vaccine, was developed by using the Yellow fever virus (YFV) vaccine vector YFV17D, by replacing the cDNA encoding the envelope proteins of YFV with that of an attenuated JEV strain SA14-14-2. It was found much safer, highly immunogenic, and capable of inducing long-lasting immunity in both preclinical and clinical trials. Moreover, a single dose of IMOJEV was sufficient to induce protective immunity [199]. Its single intramuscular injection induces protective immunity and prevents JE virus infection in mice [200]. But unfortunately reversion of normal vaccine strains to more wild strains is a leading cause of increase in neurovirulence and pathogenesis [201]. Therefore, formalin inactivated vaccines seem to be important because they enhance the potency of injectable vaccine produced from serotypes that never reverted to a more neurovirulent strain [202].

\subsection{Use of Virus-Like Particles for Making Safer Vaccines.} For effective treatment and prevention of virus diseases, virus-like particles (VLPs) are constructed/assembled and expressed in different cell systems for its secretion [203]. These recombinant VLPs are shell-like viruses that lack virus-specific genetic materials but contain JEV peptide sequence and induce production of anti-peptide and anti-JEV antibodies when injected in the mice [64]. However, these naturally assembled or recombinant VLPs, which possess JEV peptide sequences, are used to evoke production of virus neutralization antibodies in immunized mice that might show significant protection against lethal viral challenge [64]. It also depends on recognition of the peptides in demand and its binding to antipeptide antibodies. Similarly, autoassembled fusion proteins or virus like particles (VLPs) were prepared by fusing JGMV and coat protein (CP) in $E$ coli [64]. Normally, a peptide is fused to a large protein as JGMV that binds to CP and possess some constraints on the conformation imposed by the protein and may affect neutralization potential. Thus, many viral-structured protein(s) or its components are assembled into VLPs, which can mimic the overall structure of virus particles and can elicit strong immune responses in a host. Similarly, chimeric virus-like particles were also prepared from tick-borne encephalitis virus and mosquito-borne Japanese encephalitis virus for immunization purpose [204]. Moreover, for mass production of recombinant VLPs, various expression systems such as lepidopteran insect cells $[205,206]$ and mammalian and plant cells are used [207].

In addition, efforts are also made to generate a tetravalent dengue subunit vaccine by mixing recombinant VLPs, corresponding to all four dengue virus serotypes, for which a Pichia pastoris (P. pastoris) expression system was used for production of dengue virus type 1 (DENV-1) VLPs. These secreted VLPs induce both humoral and cellular immune response in mice [208]. Similarly, in vitro assembly was done for the capsid protein to construct nucleocapsid-like particles (recNLPs) that induce cell-mediated immunity and generate wider protection in immunized mice [209]. Further, virus like particles and aggregates of capsid proteins devoid of viral genetic material are also used for development of promising vaccines [210]. These virus-like particles spontaneously selfassemble after heterologous expression of viral structural proteins and are safe and easy to produce. Further, these can be loaded with a broad range of diverse cargos and can be tailored for specific delivery or epitope presentation [210]. However, to display neutralizing epitopes and T-cell epitopes of fusion protein of different viruses, chimeric virus like particles are generated which are used as vaccine candidate [211]. This system could be used for presentation of B and T-cell epitopes. However, the morphological and antigenic similarity between VLP and native virions represents a promising approach to the new type of vaccines [207].

More exceptionally, these VLPs are formed from Johnson grass mosaic virus (JGMV) coat protein after self-assembly and form rod shaped virus like particles VLPs in the absence of the viral RNA [212]. Besides this, JGMV system can be used for production of variety of VLPs with different activity by using different $\mathrm{E}$ protein derived peptides and different mixing of CP fusion protein. Thus, different protein parts are autoassembled to form VLPs. This system is also proved much safer because both $\mathrm{N}$ and $\mathrm{C}$ terminal regions of JGMV are not required for an autoassembly to form VLPs [64]. However, virus-like particles (VLPs) emerged as promising elements or candidates for making new subunit vaccines [208]. These viruses derived VLPs have broader applications in diagnostics, vaccine development, and gene delivery [209]. Further, after seeing the instant increase in endemicity of viruses and threat imposed by them, advanced technology is used to produce a new generation of safe and effective nonembryo culture vaccines by making good antigenic VLPs in various expression systems [207]. This provides great advantages in comparison with existing methods of vaccine production. Such vaccines induced full humoral and cellular immune response in animals and humans.

Further, landmark efforts have been made to prepare better quality of vaccines against JEV. For this purpose, novel epitope mapping strategies were followed by using combining phage display with VLPs. However, generation of more functional and stable epitopes could help to make potential therapeutic antibodies or neutralization antibodies which might be capable of providing broad protection against different viruses such as JEV, WNV, and DENV-2 infections without enhancing activity in humans. However, mutations in the prM protein can reduce or eliminate secretion of WN VLPs and show lesser effects [213]. This difference may be due to the quantity of prM in WN VLPs compared to $\mathrm{WNV}$ or to differences in maturation, structure, and symmetry of these particles [214]. Similarly, methylotrophic yeast Pichia pastoris was used to develop a chimeric vaccine candidate displaying the dengue virus type-2 (DENV-2) envelope domain III (EDIII). These VLPs displayed good host receptor binding and proved highly immunogenic to mice 
and induced production of virus-neutralizing antibodies. These could specifically recognize virus, lower down its number by inhibition of replication, and neutralize virus infectivity [213].

Similarly, nanoparticles based on E. coli-expressed recombinant Hepatitis $\mathrm{B}$ virus core antigen ( $\mathrm{HBcAg}$ ) were designed to display EDIII moiety of DENV on the surface [213]. It was designed specifically as a synthetic gene construct encoding $\mathrm{HBcAg}$ containing an EDIII insert in its c/el loop [213]. The fusion antigen HBcAg-EDIII-2 was expressed in E. coli, purified to near homogeneity using $\mathrm{Ni}+2$ affinity chromatography, and demonstrated to assemble into discrete 35-40 nm [213]. More specifically, HBcAgderived nanoparticles display DENV EDIII. The EDIIIdisplaying nanoparticles may have potential applications in diagnostics/vaccines for dengue [213]. Similarly, VLPs DIII were found capable of inducing specific neutralizing antibodies against DENV and WNV in mice [215]. These were obtained in form of chimeric proteins, DIII-DENV1RIgE, and DIII-WNVKun-RIgE by replacement of CD16 ectodomain of CD16-RIgE by the envelope glycoprotein domain III (DIII) of dengue virus serotype 1 (DENV1) or West Nile virus Kunjin (WNVKun [215]. Similarly, bionanoparticles (NLPs) most similar to VLPs, consisting of recombinant viral structural polypeptides, are also designed and constructed. These new formulation of nucleocapsid-like particles (NLPs) obtained from the recombinant dengue2 capsid protein protect the experimental host against homologous and heterologous viral challenge. These are also used to measure the cytotoxicity and cytokine-secretion profiles induced upon heterologous viral stimulation [216]. However, these nucleocapsid-like particles (NLPs) work as an attractive vaccine candidate against dengue virus. They induce a functional immune response mediated by $\mathrm{CD} 4(+)$ and $\mathrm{CD} 8(+)$ cells in mice, which protects against viral lethal challenge. These are potentially safe because of induction of serotype specific cell-mediated immunity and antiviral antibodies [216].

\section{Increasing the Protective Efficacy of Vaccines}

A vaccine must be a cause of an active infection in recipient and it induces an immunity which is both rapid in onset and long lasting after single dose [194]. However, a protein that contains critical neutralizing antibody determinants $[195,217]$ can be used to raise protective immune response largely against JEV. However, before preparing an appropriate vaccine, possible mutations in antigenic epitopes, its effect on neurovirulence efficacy of antigenic amino acid sequences of virus proteins must be explored. More importantly, a vaccine strain must be stable and proteins with single and multiple antigenic determinants are most commonly used for immunization to develop wider protection against flaviviruses. Hence, identification of amino acid residues in the E protein which are proved to be best antigenic sites is responsible for neurovirulence. These must be tested in different animal models and in human hosts to have the most appropriate vaccine design. Further roles of amino acid substitutions on structure and function of antigenic sites must be explored in newly emerging JEV strains during the attenuation. Attenuated vaccines show their capacity for transient growth; such vaccines provide prolonged immune system exposure to the individual epitopes on the attenuated organisms resulting in increased immunogenicity and production of memory cells. Further, mutations occurred in JEV genome during attenuation process that may find a novel virus vaccine not only against JE but also against other pathogenic viruses. More often, these vaccines require only a single immunization, eliminating the need for repeated boosters.

More importantly, before immunization, safety testing for neurovirulence of novel live attenuated flavivirus vaccines is highly essential in infant mice and in monkeys [218]. Further, its dose-response effectiveness, safety standards [219], and biological properties must be evaluated [197]. Similarly, biological characterization of artificial recombinants formed by fusion of a wild type flavivirus (Kunjin) and a live chimeric flavivirus vaccine strain (ChimeriVax-JE) is highly essential to decide [192]. Further, for obtaining better infectious clones, its biological properties, immunogenicity, and protection against disease are to be tested [197]. However, cloning and expression of mutated envelope proteins of Japanese encephalitis virus are also highly essential in different cell systems to have desirable attenuation for developing a good vaccine [220]. Further, to raise the protective efficacy of attenuated vaccines, chimeric proteins consisting of a protein of interest covalently linked to a naturally fluorescent protein can be designed. These proteins can be used for knowing its cellular behavior and possible impact on host cells mainly related to necrosis, pathogenesis, cellular entry, and its movement in living cells. Thus, smaller peptides of high attenuation potential incorporated in virions of pathogens that generate no symptom can be prepared for immunization purposes. Further, these can be used in combination by recruiting all the component parts of the adaptive immune system. Hence, such live attenuated vaccine can elicit strong immune responses and raise the level of protective antibodies. Further, these could help in finding postvaccination effects of vaccines, in retaining over all structure function changes in mutated and reemerged virulent strains of viruses. These could also decide the route of infection and its therapeutic solution in in vivo studies. Similarly, chimeric monoclonal antibodies are also prepared genetically which are humanmurine hybrids. The variable part of the antibody molecule including the antigen-binding site is murine while the remainder of the antibody molecule, the constant region, has been derived from a human source. These MAbs are about $66 \%$ human; example is rituximab.

\section{Molecular Basis of Attenuation of Neurovirulence}

RNA genomes of flaviviruses show high rates of mutations both in natural and artificial conditions. However, it became highly important to understand the molecular basis of attenuation of live virus vaccines and multiple genetic determinants, 
which govern this property. Therefore, to generate candidate vaccines against viruses, both natural and artificial methods are used for attenuation so that they lose their ability to cause significant disease/pathogenicity, but retain their capacity for transient growth with in inoculated host. When these attenuated strains are used for immunization, more often, they elicit life-long immunity after having few doses. Nevertheless viruses like other micro-organisms keeping on changing their genetic properties by acquiring significant alterations in genome through recombination. It could develop acquisition of new adaptations in viruses against fluctuating climatic conditions in endemic areas/habitats. It also results in significant increase in antibody resistance in viruses that may cause high mortality and morbidity in patients. There are multiple pathways to the attenuation of viruses [221]; hence, both natural and artificial methods can be applied to attenuate the viruses for immunization purposes. Flaviviruses are also attenuated by multiple passages in animal tissues and cell cultures [222]. Besides this, some traditional methods are also used to develop vaccines against other flavivirus diseases, such as dengue. There are natural and artificial methods available to attenuate the virus. For natural attenuation of viruses, these are allowed to grow in different host cells and in cell lines or passage regularly in mice. These are used to immunize the host to raise the immunity and protective efficacy against disease, but it is very difficult to isolate them in pure form. In artificial methods for attenuation, viruses are grown for prolonged periods under abnormal culture conditions to make them inactive or make their growth very slow and its mutants are selected. These are better suited to grow in the abnormal culture conditions. These become less capable of growth in the natural host. By using such methods, many live attenuated vaccines have been generated mainly against measles, mumps, Polio, Rotavirus, Rubella, Tuberculosis, Varicella, and Yellow fever viruses. These show that strong immune response often generates lifelong immunity after prescription of few doses. More than this, many attenuate vaccines show ability to replicate with in host cells and make them more suitable for inducing a cell mediated response. Further, attenuated vaccines are also associated with more complications similar to those seen in neural disease. Therefore, it is also important to understand the molecular biology of attenuation.

Today, it is a great challenge for vaccine developers as most of the virus serotypes have attained high mutation rates $[223,224]$ and were found to accumulate mutations during passage in human hosts. Further, due to misincorporation of nucleotides into the viral genome, new strains are originating at constant rates $[225,226]$ which are highly virulent $[226,227]$. More specifically, host-to-host transfer becomes a critical problem to solve its molecular biology which is mainly related to elevation in neurovirulence [228]. It is a major problem to solve. More caution that defaulted attenuation is developing in JE virus strains in mouse brain and other experimental animal models and animal cell lines might be the main reason of positive-negative mutation selection in virus in endemic areas. But it is certain that always virus may seek self-favorable genes which assist in generation of high neurovirulence in human hosts. This is the main reason that attenuated strain merely shows low neurovirulence in the experimental animal but gain assesses high neurovirulence in human host. In addition, vaccine should be free of any detectable adventitious microbial agents that would render these materials unsafe for human immunization [229].

However, for generation of appropriate vaccine, molecular characterization [230] of viral attenuation in flaviviruses is highly essential and important. Hence, desirable changes are made by using site-directed mutagenesis in infectious cDNA clones [231], or by production of Chimeric viruses [1], and have deletions in the $3^{\prime}$ untranslated regions of genomes [232]. However, new artificial infectious constructs of viruses were found more appropriate for immunization and to use them as candidate strain for generation of new live attenuated vaccines. If single base substitutions, replacements, rearrangements, or selective deletions are being made in the $3^{\prime}$ untranslated regions [232], these may attain most desirable antigenic sites in proteins. When these chimeric viruses (Chmiera-Vax WNV live attenuated vaccine) are injected in the animals, they showed better efficacy and antigenicity in comparison to inactivated vaccines [1]. Contrary to this, some notable failures have also been observed; for example, reversion in Sabin Polio Vaccine (OPVP) caused its reemergence that resulted in subsequent paralysis disease in about one case in 2.4 million doses of vaccine. This reversion implies mutations in pathogenic forms of the virus that is passed in to a few immunized individuals. Next, these may reach the human host through contaminated water supply especially in areas where sanitation standards are very poor or where wastewater is recycled for drinking purpose. This is one of the major possibilities of failures of attenuation and generation of new mutant strains from immunized strains of virus. Hence, it leads to the extensive use of inactivated vaccines. In addition, genetic engineering techniques provide a way to attenuate a virus by selectively removing genes that are necessary for virulence for growth in the vaccine. Example is Herpes virus vaccine for pigs in which the thymidine kinase gene was removed. However, removal of this gene rendered the virus incapable of causing disease. But there is a major disadvantage that attenuated viruses revert to a virulent form that show higher neurovirulence and pathogenicity [62].

Moreover, to improve existing vaccines, rational approaches are also used to prepare attenuated flavivirus vaccines. These are employed only after allowing introduction of specific mutations into wild-type viruses and chimerization between two different viruses. With this, novel methods for delivery of live vaccines, such as inoculation of infectious DNA or RNA, construction of protein subunit, expression vector-based, and naked DNA vaccines, have been used to create alternate vaccine candidates [233]. Other than natural strains, mutated vaccine strains are also produced in animal models by generating selected mutations in the genes of structural proteins. Naturally, virus also develops ecologically adapted strains (NS3 gene and $3^{\prime}$ NCR of Japanese encephalitis) and shows natural attenuation of virus [234]. Thus, small changes in nucleotide sequences of envelope protein of Japanese encephalitis virus could enhance the protective efficacy of vaccines $[235,236]$. Contrary to this, natural mutations that occurred 
in viruses enhance the neurovirulence and pathogenicity [237]. Moreover, to cut down the rate of infection and neurovirulence generation, cluster specific reversions are the only solution to restore the antigenicity [1]. Besides, it was also found that reversions in at least three distinct clusters are required to restore the neurovirulence typical of the YFV/JEV Nakayama virus. It is known that prolonged cell culture and mouse brain passage of JE virus increase the genetic stability of the virus and support candidacy for generation of a novel live-attenuated viral vaccine against Japanese encephalitis [1].

Thus, attenuation can be done by serial passages of virus in experimental animals or generated by growing virus in artificial cell cultures such as Vero cells [238], primary canine kidney cell cultures [229]. However, live-attenuated JE vaccine virus clones SA14-14-2 were grown in primary canine kidney (PCK) cell culture and vaccine seeds to adapt them [203]. Thus, PCK-grown virus indicates and displays that passage in PCK did not result in detectable phenotypic or genome changes for this virus clone. Similarly, a live attenuated Japanese encephalitis (JE) virus SA(14)-14-2 was produced in primary dog kidney cells (PDK) and adapted to Vero cells [236]. However, it was found that Lys and Val (a.a. 138 and 176) responsible for attenuation and are still conserved in SA(14)-14-2(Vero). Animal testing showed that SA(14)-14-2(Vero) has an attenuation phenotype similar to that of the parent SA(14)-14-2(PDK) strain in mice [235]. Further, attenuation of JE virus is also made by selection of its mouse brain membrane preparation escape variants.

Similarly, mutations created in the NS3 gene and $3^{\prime}$-NCR of Japanese encephalitis virus showed natural attenuation [234]. It was found circulating in T1P1 strain of Japanese encephalitis (JE) virus. When these mutant strains (T1P1) were grown in mouse neuroblastoma-derived Neuro-2a cells, they have shown significantly lower virus productivity than another local isolate, $\mathrm{CH} 1392$ [234]. It implies that this new isolate possesses a characteristic viral replication pattern other than that of $\mathrm{CH} 1392$. Further, lower neurovirulence obtained in T1P1 also reflected by a significantly higher $\mathrm{LD}_{50}$ than $\mathrm{CH} 1392$. This may be due to abnormal enzymatic activity generated after mutations in NS3 gene (especially position 364) located on $3^{\prime}$-NCR [234]. Similarly, six variants of Japanese encephalitis (JE) virus strain P3 were selected for resistance to binding to mouse brain membrane receptor preparations (MRP) [239]. All but one of these MRP escape (MRPR) variants were significantly attenuated in mice for both neuroinvasiveness ( $>200$-fold) and neurovirulence ( $>500$-fold) compared to their parent virus. Immunization of mice with MRPRs induced neutralizing antibodies and protected mice against challenge with wild-type JE virus [239]. A common amino acid mutation was found in the envelope (E) protein gene of all attenuated mouse brain MRPR variants at residue E-306 compared to P3 virus grown in mosquito C636 cells or plaque purified and amplified in monkey kidney Vero cells [239]. This E-306 amino acid residue was found putatively responsible for attenuation due to alteration in binding of JE virus to its cell receptor in mouse brain [239]. Most possibly, it may help in attenuation of virulence if its binding is inhibited by viral attachment of a protein(s).
Most possibly, it interacts with cell receptors which can be blocked by using an inhibitor [239]. Similarly, four wild-type strains (Nakayama-original, SA14, 826309, and Beijing-1) of Japanese encephalitis (JE) virus that were passaged six times in HeLa cells (HeLa p6), two normal strains (Nakayamaoriginal and 826309) were attenuated for immunization in mice. In the case of strain Nakayama-original, the virulence for mice was markedly reduced and attenuation was retained on passage in primary chicken embryo fibroblast, LLC-MK2 and C6/36 cells [240]. Both of the attenuated viruses can be distinguished from the virulent non-HeLa-passaged parental viruses by examination with $\mathrm{E}$ protein reactive vaccine and wild-type-specific monoclonal antibodies (MAbs). The vaccine-specific MAb V23, which is only reactive with the SA14 series of live vaccine viruses, recognized the HeLa cellattenuated Nakayama-original and 826309 viruses, whereas two wild-type-specific MAbs (MAbs K13 and K39) lost reactivity [240]. Comparison of the nucleotide sequences of the structural protein genes of the 826309 and Nakayamaoriginal virulent parent and attenuated HeLa p6 viruses revealed that the viruses differed by 37 and 46 nucleotides coding for eight and nine amino acid [240]. It shows role of few amino acids as attenuation determinant [240].

Further, molecular determinants for attenuation of wildtype Japanese encephalitis (JE) virus strain SA14, the RNA genome of wild-type strain SA14, and its attenuated vaccine virus SA14-2-8 were made known by using reverse transcription, amplification, and sequencing [237]. However, comparison of the nucleotide sequence of SA14-2-8 vaccine virus with virulent parent SA14 virus and with two other attenuated vaccine viruses derived from SA14 virus (SA14-142/PHK and SA14-14-2/PDK) revealed that only seven amino acids in the virulent parent SA14 had been substituted in all three attenuated vaccines. Four were in the envelope (E) protein (E-138, E-176, E-315, and E-439), one in nonstructural protein 2B (NS2B-63), one in NS3 (NS3-105), and one in NS4B (NS4B-106). The substitutions at E-315 and E-439 arose due to correction of the SA14/CDC sequence [236]. Similarly, mutations are also observed in NS2B and NS3 nonstructural proteins in functional domains of the trypsin-like serine protease. However, attenuation of SA14 virus may be due to alterations in viral protease activity, which could also affect replication of the virus [237]. Similarly, attenuated SA14-14-2 strain of Japanese encephalitis (JE) virus has been used to immunize the people [236]. However, oligonucleotide fingerprints of the parent SA-14 and vaccine strain indicate that multiple genetic changes occurred during attenuation of the virus and a silent nucleotide change occurred in the prM gene sequence while M-protein remained unchanged [236].

There are certain markers of attenuation including small plaque size, lack of intracerebral virulence for weanling mice, minimal neurovirulence for rhesus monkeys, and a distinct nucleotide pattern compared to the parent nonattenuated virus [229]. Further, it is highly important and much cautious to prove the attenuation on the basis of right selection, right sequence order, and gene arrangement in viruses available in endemic areas. There must be certain correlation between stabilization of new variations and neurovirulence in different hosts. This may vary with the age and protective efficacy of 
host immune system. It is also observed that most of the modifications occurred in viruses remain silent in amplifying hosts but exclusion of low neurovirulent genes may take place more promptly. However, similar doses of vaccine immunization may generate different responses in different hosts. The main causes are variations in immune molecules and cells of hosts and modifications geared up by virus strain in antigenic sites. However, it cannot be denied that the vaccine safety is merely a subject of nonadaptability in viruses. Because soon after vaccination, virulent strain start identification of vaccine strain and associate to make significant changes in its genome more consistently. I modifies, the non-virulent virus into a virulent strain by incorporation of new sequences through multiplication, substitutions and copy reading and by corrections in the antigenic binding sites. Thus by acquiring new variations vaccine strain become infectious and it start affecting overall efficacy of concerned vaccine/s. However, vaccine strain may be a subject of modification whether it may be due to molecular or ecological reasons. There are so many possibilities of recombination among vaccine and wild strains, but changes stabilize in them only after completion of two-three cycles of replication, recombination, and multiplication. Thus, vaccine viruses may also recombine to a less virulent to high virulent strain available in the ecological area.

Most possibly, these mutations that occurred due to substitution or replacement may not affect the gene sequence and gene order but alter the expression of second nearby gene that remains silent for some reason. More importantly, ecological genetics suddenly altered virus's genomic constitution by incorporating new base sequences which start synthesizing completely different antigenic sites in a protein that conceal the neutralization of epitopes by monoclonal antibodies. It may also lead to conformational changes in second structural protein with new shifts in amino acid sequences. If significant deletions are made in the most important structural framework of a virulent protein, it will certainly cut down the virus replication and multiplication that alternatively reduce the neurovirulence and pathogenesis is human host. However, it seems correct that no visible mutation may occur in virus gene. But it may induce a more visible change in a protein due to deletion. But whether such changes are also possible due to amino acid rearrangements during incubation period that may restructure epitope in antigenic sites is still unanswered. Such changes also defy the neutralizing potential of MAbs and may increase the neurovirulence in hosts. However, it can be concluded that environment specific silent mutations occurred in virus genes either readable or not but they show some definite expression in host cells and impose permanent morbidity, immune disability, and finally death in patients in endemic areas. There are some associating effects of secondary mutations which change the conformational structure of a second protein either it may be structural or nonstructural. Further, virus can remove errors by copying the right orders during recombination in association to other viruses that belong to the same group by undergoing high multiplication and replication inside human host. Thus, multiplication in virus generates neurovirulence geometrically in form of additions that is a real factor to succumb to the nonantigenic sequences from attenuated vaccines, denatured vaccines, or any therapeutic and other antiviral agent. Oppositely, when two strains of pathogenic viruses interact simultaneously with nonpathogenic virus, chance of fixation of genes, gene order, and antigenic sites may stabilize after correction in second proof. Further, these may essentially make the virulent proteins more antigenic after expression of structural genes in concerted manner. It not only stabilizes the generation of copy number of virus but also is simultaneously involved in corrections in base sequences to raise the pathogenesis. Therefore, virus opts, waits, and watches policy to acquire new expression system. However, there occurs an important exchange of virulent specific genes which upon attenuation may remain intact and when they pass through a more susceptible host, they give rise to new intertypic or intratypic viruses, which are hard to challenge by any antibody to neutralize.

\section{Control of Disease Transmission and Endemicity}

Different patterns in the molecular epidemiology and evolution of various mutant strains of flaviviruses are known. However, from genetic, molecular, and bioinformatic analysis, it become clear that JE virus was originated in the Indonesia-Malaysia region from an ancestral virus. From that ancestral virus, GV was diverged, followed by GIII, GII, and GI [241] (Table 3). Genotype IV appears to be confined to the Indonesia-Malaysian region as GIV has been isolated from mosquitoes in China and South Korea [215] while GI-III virus circulates throughout Asia and Australia from a variety of hosts. Moreover, GIV isolates from Java, Mali, and Sumatra showed six amino acid substitutions with in the E protein (Table 3). However, microevolution lead to incorporation of new lethal amino acid sequences in ecological and vaccine strains of JE virus. It has significantly increased the severity of pathological effects in patients manifold. Besides this, several amino acids with in the E protein of the Indonesian isolates were found to be under directional evolution and/or coevolution. Such naturally occurring evolution is likely to affect the disease profile and the vaccine efficacy against circulating JEV genotype I in Eastern [2] and G III in Northern part of Asia [242]. Thus, different JE genotypes showed close genomic relationships and displayed very little differences in their antigenic sites, but these were found much larger in potential to generate acute encephalitis syndrome in infant groups. Based on molecular epidemiological study of JEV in different Southeastern Asian countries, different subgroups of genotypes of I, II, and III are largely circulating and all are chronologically related to one another and more frequently cause JE disease. Further, JEV has recently changed from genotype III (G III) to GI (GI) and imposes life threatening situations for both human and animal populations in Asian countries [120] (Table 3). However, advent of heterotypic genotypes has reduced the vaccine efficacy and raised emergence of antibody resistant mutants with new lethal and neurovirulent genes which are circulating in the endemic population of this region. This is the main reason that, despite 
TABLE 3: Japanese encephalitis virus genotypes isolated from different parts of South East Asia and other countries.

\begin{tabular}{|c|c|c|c|c|c|}
\hline Genotype & Location & Epitope & Method used & JEV surveillance & References \\
\hline GI & Japan & $\begin{array}{c}\text { E327 Glu 20.2-21.2 } \\
8.5-9.9\end{array}$ & Multiplex RT-PCR & Mosquito based & [256] \\
\hline GI & $\begin{array}{c}\text { China, Korea, } \\
\text { Cambodia, Thailand, } \\
\text { Australia }\end{array}$ & $\begin{array}{l}\text { prM and E glycoprotein } \\
\text { genes }\end{array}$ & RT-PCR & Mosquito based & {$[252]$} \\
\hline GII & $\begin{array}{l}\text { Australia, Malaysia, } \\
\text { Indonesia }\end{array}$ & $\begin{array}{l}\text { prM and E glycoprotein } \\
\text { genes }\end{array}$ & RT-PCR & Pigs & {$[254]$} \\
\hline GIII & Taiwan & E protein & Multiplex RT-PCR & Mosquito based & {$[255]$} \\
\hline GI-III & Asia and Australasia & $\mathrm{E} 176,177,227,244,264$ & Amino acid sequencing & Mosquito based & [257] \\
\hline GIII & West Bengal India & Envelope proteins & Mac-ELISA and RT-PCR & Human & {$[2]$} \\
\hline GIII & Northern India & $\begin{array}{c}\mathrm{E} 176,177,227,244,264 \\
279\end{array}$ & Gene sequencing & Human & {$[242]$} \\
\hline GIII & $\begin{array}{l}\text { CQ11-66 strain } \\
\text { Chongqing, China }\end{array}$ & E-genes & Nested PCR & Human & {$[251]$} \\
\hline GIII & $\begin{array}{l}\text { Shanghai, China, } \\
\text { Wuhan, Nepal, Taiwan, } \\
\text { Japan, Philippines, } \\
\text { Korea, Sichuan, Yunan }\end{array}$ & E-genes & Multiplex RT-PCR & Human & \\
\hline GIV & $\begin{array}{l}\text { Indonesia-Malaysia } \\
\text { region, Indonesia }\end{array}$ & Six AA substitutions & Amino acid sequencing & Mosquito based & {$[257]$} \\
\hline GV & $\begin{array}{l}\text { Malaysia China and } \\
\text { South Korea }\end{array}$ & Six AA substitutions & Amino acid sequencing & Mosquito based & {$[257]$} \\
\hline GV & Singapore, Australia & Structural genes & $\begin{array}{l}\text { Nucleotide and AA } \\
\text { sequencing }\end{array}$ & Mosquito based & {$[258]$} \\
\hline GV & Japan & Structural genes & Nucleotide sequencing & Mosquito based & [253] \\
\hline
\end{tabular}

the availability of vaccines, JE related mortality rate is still high in India and its neighboring countries [1]. It indicates failure of vaccines or partial work of it. Therefore, a vaccine must possess enough potential to work against JE virus during initial phase of virus infections and might show long lasting effect after administering a single dose [194]. However, a protein that may contain the critical neutralizing antibody determinants $[195,217]$ and can elicit high protective immune response should be used for vaccination purpose against JEV. However, before preparing an appropriate vaccine, possible mutations and its most possible effect on antigenic amino acid sites mainly on epitopes of virus proteins should be assessed in silico and in experimental animals and correlated with neurovirulence and pathogenesis. Thus, it is assumed that vaccine strain must be stable and viral proteins with single and multiple antigenic determinants should be tested for its susceptibility for any future conformational change that occurs due to single site mutations that may have most commonly occurred in the flaviviruses. Further roles of amino acid substitutions in JEV strains in the attenuation process and neurovirulence must be tested in different animal models and in human hosts to have an appropriate vaccine design.

Moreover, favorable climate exists in South East Asia, assisting the JE virus in multiplication cycling and circulation of virus during summer and rainy season. Thus, due to rapid globalization and gradual shifts in climate flaviviruses are increasing its endemicity and virus is continuously spreading in new areas [243]. Further, availability and co-habitation of many hosts (both wild and domesticated) in the same locality and exchange of virus among different hosts by disease transmission vectors are assisting the virus to create new variations. Hence, both wild and domesticated animals are working as hotspots for the emergence and evolution of JEV. More often, open farming of pigs, poultry birds, rabbits, and goats in the middle of human habitation is responsible for rapid amplification of virus or creation of new amino acid substitutions in virus $\mathrm{E}$ protein. It gives rise to new mutants and serotypes in local habitations. However, beside encephalitis virus, some other viruses like FMDV also showed outbreaks in the endemic areas. This confirms interrelationship between both the viruses. In nature, there might be some viruses which may infect both animals and plants; they inoculate ordinarily in plant hosts and maintain their replication rate very high, and possibly they may also find their way inside a suitable animal host. There are examples of largest outbreak of hand, foot, and mouth disease (FMDV) in Singapore in 2008 that was caused by enterovirus 71 and coxsackievirus A strains [244]. With this, in recent years, virus has also expanded its geographic range from Indonesia to Australia.

In addition, both climate and enzootic biology showed that viral proteins are highly susceptible to changing conditions of climate and host-immune interactions in the endemic areas. These are responsible for both summertime and annual precipitation seroconversion rate in JE virus infection [245]. 
Therefore, virus infection is directly correlated with various climatic factors and presence of virulent proteins [246]. Besides this, other important factors, which are responsible for reemergence of JE virus, are geographic and epidemiological location, physical environment, presence of uncontrolled virus vectors, clinical patterns followed, and presence of alternate vertebrate hosts, circulating JE virus serotypes, international travels, and ongoing rapid climatic changes [247]. Further, disturbances in ecological niche of water birds and their forced migration to nonendemic areas lead to wider spread of JE V in nonendemic regions. Similarly, human migration is also supporting the expansion of endemicity. Further, locally adapted mutant strains are finding their way through virus vectors and different types of migratory water birds to newer area. Infected water birds are working as flying cargos of JE virus, which land anywhere in similar ecoclimatic areas. From these virus genotypes are distributed by the virus vector and finally to the human. Further, in new locations, water establishing accordingly by making most required necessary changes in epitopic region, which govern the neurovirulence. Therefore, strength of vaccines should be improved for disease control and prevention, with wider immunization coverage and control of secondary hosts of JE virus. It must be reevaluated from time to time to lower down the risk for occurrence and reemergence of JE virus in rural pockets.

Most of the JE cases and positive serotypes are circulating in clusters in Tarai region of India and Nepal and also in other similar ecoclimatic zones. However, a spatial heterogeneity was observed between Japanese encephalitis induce destruction and environmental variables [248]. However, positive mutants of virus circulate more and more in rainy season, because mass breeding of mosquitoes gives rise to significant increase in virus vector that results in an increase in MIR (minimum infection rates) in Culex tritaeniorhynchus and Culex gelidus during transmission seasons. This MIR is significantly declined in winter and summer seasons [247]. Other factors which are related to JEV infection in human are cultural differences, that is, type of living, sanitation standards, vector control, healthy animal breeding houses, proper surveillance, routine immunization, and Coordinated Disease Controlling System and Networking in rural areas. Further, reemergence of genotype $\mathrm{V}$ in Asia has increased the risk of JEV transmission, mortalities, and morbidities more significantly. This is one of the major reasons that JEV transmission occurs in rural agriculture areas [249] but recently its transmission was also identified in Delhi [250]. However, to control the disease transmission, virus vector must be minimized either by direct control of pesticides or by using repellent coated mosquito nets, clothes, safe window mesh, and regular treatment of water storage tanks. Further, efforts should be made for good surveillance, immunization, and JE awareness at national and international level.

\section{Evolutionary Biology of JE Virus}

Complete nucleotide and amino acid sequences of different Japanese encephalitis virus strain show intragroup divergence in $\sim 10-20$ of nucleotide sequences and that all isolates fell into 5 different genotypes which are circulating in South East Asia, Australia, Europe, and USA. However, high nucleotide homologies were obtained among isolates collected from different countries with few significant variations in genotypes. Furthermore, molecular variations observed among isolates from same region and same time between two different genotypes III and I were due to point mutations occurred. When these were analyzed for phylogenetic analysis, these different isolates of JEV fell into different clusters and showed different epitopic determinants in antigenic sites. However, intergroup genetic distances were larger and seem to be diverging more. These are most possible associating reason of rising of neurovirulence and infection in the host population. When compared, both inter- and intragroup clusters showed a net difference in epitopic determinants and such variations lead to sever pathogenesis. The origin of virulent strains of JE is through recombination between far distantly placed virus isolates whose clustering shows antigenic cross-reactivity. There were observed climate-induced differences among JE isolates, for example, genotypes identified in temperate countries differed from genotypes of subtropical countries such as India, Nepal, Bangladesh, Bhutan, and Tibet. It has been proved from phylogenetic studies that at least three genotypes of JEV are circulating in Malaysia, two in India [2], three in China [251, 252], and two both in Japan [253] and Australia [254]. However, to find close genetic relationship among JE genotypes, rates of genetic evolution, and genotype replacement [255] molecular phylogenetic and evolutionary analyses are highly important [256]. Further, corelationships of mutations and climatic factors [257] are also responsible for emergence of JE Genotypes [258]. It is not necessary and mandatory that it is the virus genetics, which is changing the virus, but there is possibility that one of the ecoclimatic factor(s) may have significant role in conversion of low virulent virus to high virulent virus and significant increase in lethality. However, climate induced minor significant changes occurring in the JE virus genome are due to point mutations which seems to be major reason of epidemiological changes in JE virus in Southeast Asia [253].

For testing minor differences between two structurally related strains serological tests such as hemagglutination inhibition and neutralization are performed. However, parental strains have shown a rooted tree with many diverging lines of the JE virus. Thus, five genotypes G1-GV, of Japanese encephalitis virus have been identified and each one of it has distinct geographical distribution and epidemiology [215]. JEV shows extensive genetic diversity among JEV isolates. Because of parental sequences and modifications that occurred in JEV genome, it is speculated that JEV was originated in the Indo-Malaysian region from where it has spread in all surrounding countries by birds and international human travelling. However, emergence and divergence are widely related to subtropical climate as main factor, as well as virus genetics and together with vast floral and faunal diversity existing in the area. However, ecological, demographical, molecular, and geographical factors are equally responsible for emergence and evolution of JEV. It is further correlated with increasing rate of neurovirulence and infection with antigenically different JE strains in different climatic regions. 
However, naturally occurring evolution is likely to affect the disease profile and vaccine efficacy [2]. All these are specifically related to ongoing changes in epitopic antigenic sites that are differing in different genotypes, that is why vaccines are showing partial coverage or low protection against JEV. To fight against this problem, immunoinformatics and mutations in silico will help to evaluate the infectivity and pathogenicity of JEV. Further, it is mostly observed that only E proteins are highly susceptible to climate and natural mutations going on in JEV strains. Those substitutions, which can disrupt T-cell epitope antigenicity, might largely influence the outcome of vaccine derived from JEV genotypes specifically using SA-14-14-2 strain. Phylogenetic analysis based on the genomic sequences can confirm which particular isolate belongs to which JEV genotype, which may be consistent with phylogenetic analysis based on the premembrane (prM) and glycoprotein genes. However, identification of residues in the E protein, which govern neurovirulence, is an important issue. Mutagenesis of clinical determinants and surrounding residues in conjunction with molecular clone technology can be used to generate additional live attenuated viral vaccine candidates in the Chimeri-Vax background. Further, stability of the virus can be verified by making serial passages in vivo and in vitro while confirmation of the vaccine genotypes could be achieved by using molecular methods. It will assist in manufacturing quality vaccines that may possess wider protection coverage against virulence revertants inside hosts.

Thus, there seems to be a high correlation between genetic variations that occurred in antigenic sites and neurovirulence. It is equivalent to mutations adopted or established in the virus in all odds or favors from the environment and geographic conditions prevailed in that area. All these variations are due to ecoclimate fluctuations and host and vector density in the endemic area. However, net differences in climate-induced changes within the body are not only useful for pathogen survival but also significantly affect incubation period and virus cycling in different hosts. They assist the virus to make locality specific changes in antigenic sites that is why individual differences are noted in the expression of each genotype of JE virus. Further, it is possible due to genetic difference between hosts; it is either an amplifying or a reservoir host. More specifically, birds have high body temperature that may give rise to new shifts in protein structures, if these are transferred directly from birds to operate by mosquito vector, it may be more lethal, because chances of substitutions become possible due to increasing temperature. However, potential expression of GIII seems to be more than the others. It may be possible due to endemicity and homing of virus genes due to prevailing environmental conditions. Though, strain-to-strain quantitative differences are very narrow but the show imposes serious impact in different hosts in an invasive manner. However, such changes in phenotype or structural proteins may be much larger in viruses than other microbes. It is the main reason that both virulence and infection rates are constantly increasing with few essential changes in the $\mathrm{E}$ proteins or in prM proteins. Therefore, role of structural genes may be far ahead and responsible for generation of neurovirulence than the regulatory genes. With this, there are lesser chances of changes occurring in the activity of regulatory genes because viruses may seek this regulation partially from host genome that is most stable. Thus, viruses much cleverly invade host cells and use genetic machinery for their multiplication, invasion, and establishment of disease. Therefore, for generation of pathogenesis inside host body viruses structural genes are largely responsible because mutation susceptible genes make mutation susceptible proteins. It is much favorable for virus but against the survival of host. Further, unfavorable ecoclimatic variabilities prevailing in different geographic ranges affect hosts and help to establish the virus after precondition during incubation. Hence, virus genetics, microadaptations to ecoclimate, host body environment, and swapping of host genetics are the main reasons that vaccines are not working well and fail to check the onset of disease. It is mainly due to biological differences in different genotypes, which never remain stable and face rapid changes occurring in virus genome. Further, overlapping between genotypes leads to failures of attenuated vaccines or vaccines are showing partial coverage after immunization. Therefore, it seems as a hard fact that eradication of virus is very tedious job, and one cannot find an absolute solution until and unless vaccines must be prepared against local strains. It could help to stop endemicity and disease transmission. Therefore, JE vaccines, which may have cross protective efficacy to JEV, are to be prepared for finding a solution of severe infection, caused by circulating heterologous genotypes $[225,259]$. There is a possibility that some minor differences exist in water borne strain of JEV and virus circulating in the endemic population and vaccine strains. It cannot be denied that differences existing in amino acids in antigenic epitopes are more pertinent to virulence and disease severity. These may differ from host to host and type of genotype infected the patient.

It has been commonly seen that artificial mutations induce quantitative traits in higher organisms, but at lower level, these generate small quantitative genetic variations, which are much enough to change structural and function of $\mathrm{E}$ proteins in viruses. Another reason is that normally in viruses mutations occur throughout the genome but not in a single defined locus as it occurs in higher organisms. It is plausible that desirable increase in heterozygosity represent significant mean difference in amino acids and conformational changes in protein and virus infectivity. These deaccelerate the immune defense and impose deleterious effects in the host. However, artificially induced mutations may accelerate the rate of natural mutations in structural proteins and such phenotypes may remain under direct selection. Hence, artificial incorporation of new amino acids to make changes in vaccine strains might be more harmful in comparison to natural mutations, because they occur at slower rate and provide enough time to make counter defense by host. Therefore, chances are fair for generation of new genetic variations in viruses that will impart more severe deleterious effects in hosts. Further interactions of regulatory and structural genes have important implications both for evolutionary rates and for speciation. There are ways of interaction; the involvement of one regulatory gene with several structural genes and vice versa allows for several levels of regulatory interactions. Similarly, a regulatory gene may 
regulate several other regulatory genes, each of which might in turn regulate several structural genes. Therefore, changing a single gene at single site may provoke high neurovirulence if such changes are made in structural proteins. Hence, copy errors in nucleotides are not supposed to be more lethal but sudden appearing positional variations in amino acids in epitopes of virus antigens are main cause of great fear that it will lead to a yearly increase in infection and mortality rate. Both will be additive and may occur on geometrical lines. Further, overlapping populations of different genotypes are transmutating the amino acids which leads to significant structural changes in architecture of $\mathrm{E}$ and prM proteins. That is why slight changes like deletion or any small substitution mutation in epitopic region is regularly increasing both neurovirulence and intensity of acute encephalitis syndrome in various infant groups. It is clear that antigenic virus proteins involve a series of substitutions of one structural gene by another during long evolution. Virtually these differences will be not so drastic in case of regulatory genes of viruses, but structural genes might show significant divergence in future progenies of viruses. There seems to be no role of nonessential amino acids in disease occurrence and neurovirulence generated by viruses.

\section{Conclusion}

Recent studies reveal that climate induced genotypic variations are going on in flaviviruses mainly related to encephalitis. It leads to an emergence of new mutants/variants of JE virus in endemic areas. Further, vaccine attenuated sequence alterations are significantly increasing which are not only changing the etiological features of virus but also are inducing high neurovirulence and host immune responses and affecting disease transmission in endemic and nonendemic population. These environmentally adapted new variants/mutants are proved to be more lethal than normal strains because of production of high neurovirulence and pathogenesis in human hosts mainly in various infant groups. Main reason of evolution of these new variants is incorporation of significant changes in epitopic regions of structural proteins, mainly $\mathrm{E}$ and prM.

Further, important mechanisms like mutations, recombination, and replication are playing major role in development of new genotypes and phenotypes that are more virulent than their parent strains. However, once mutational changes stabilize these lead to generation of different virus. It is also possible through recombination, which helps the virus in allocation of a particular highly cross-reactive antigenic determinant in positive and negative virulent strain accordingly. These determinants are infection prone; they induce multiple severity or pathological changes inside cells and tissues and organs. However, severe infection of encephalitis viruses causes irreversible neuronal changes in central nervous system; those results in a life-long paralysis and other neurological dysfunctions in patients.

It is a known fact that viruses not only seek mutations inside host body naturally but also change by artificial means in the laboratory by transfection methods. Besides this, vaccines strains also generate mutations in storage that are used in immunization. Therefore, due to mutations occurring in antigenic sites of viruses, there occurs a regular trend of emergence and reemergence of viral diseases of the central nervous system. More specifically, single site mutations versus multiple mutations, cluster specific reversions, or amino acid substitutions occurred in neutralizing antigenic sites or $\mathrm{N}^{\prime}$ glycosylation sites of structural proteins are well known established facts of formation of new variants. But few other methods like rearrangements, reversions, additions, deletions, and duplications occurring in native viral strains of JEV including other flaviviruses are also possible playing its role in formation of new variants. In addition, changes in gene order and virus specific NS and $\mathrm{S}$ proteins and $\mathrm{pH}$ induced rearrangements in the envelope glycoprotein gene are also assisting in formation of antibody resistant mutants with variable genetic stability and molecular plasticity. More specifically, microevolution of new lethal amino acid sequences with in the E protein in ecological, vaccine strains have significantly increased the severity of pathological effects in patients, and such isolates are found to be under directional evolution and/or coevolution.

In addition, ecoclimatic, demographic, host and vector density, and clinical reasons are responsible for advent of new antibody resistant JE virus strains mainly in endemic areas. However, both molecular and ecological forces are considered as real cause of endemic expansion, disease transmission, and prevalence of Japanese encephalitis. As smaller changes occurring through deletions, inversions or transpositions in genome are the most significant evolutionary events. However, comparison of nucleotide and amino acid sequences of $\mathrm{E}$ and prM genes and proteins of present day virus with few important strains sequenced in the past could help to reveal the evolutionary history or phylogeny of flaviviruses. However, deletions may affect phylogenetic reconstruction of gene order in natural strains and impose negative-positive genomic plasticity. This is the main reason that viruses maintain virulence and pathogenesis more updated according to incubation or environmental conditions prevailing. However, due to their short genome, chances of assimilation of new sequences from other viruses are lesser and lesser, but at the same time, they can easily assimilate host and vector sequences just after single recombination. However, intragroup modifications through genetic mechanisms may occur more promptly for adjusting gene order and genome. In addition, viruses may adopt all these changes accordingly in response to a drug or any vaccine. However, main purpose of genetic modifications or transfer or mutation in a gene(s) may lead to an increase in antigenicity. Thus, viruses become able to bear a significant genetic load for carrying new harmful genes that assist them to cause severe neuropathogenesis. If all nonessential genes, which have no role in virus replication and establishment of infection, are ablated from the main chain, there will be no effect on neurovirulence, antigenicity, and virus survival.

It is understandable that antigenic sites in flaviviruses are quite flexible due to assimilation of new changes/mutations through recombination inside various hosts. Virus is not only acquiring changes through mutations and recombination but 
also repairing of errors versus destruction of corrections artificially in epitopes of virus antigens during replication and multiplication as well. This is the main reason why virus population possesses enough genetic variations, which are instrumental in incorporating changes in the genome myriad ways. Further, specific molecular corrections are being made in virus genome and viruses associating proteins (VAPs) or structural protein could significantly stop attachment of viruses to the host receptors. It will also stop virus entry inside host cells. Therefore, it could work as controlling point for clinicians, but practically it is very hard to achieve by using pharmaceuticals. Further, there are other possibilities that nonadaptive strains could eliminate themselves because new genotype may not possess required variations and remain exclusively out from positive and favorable gene recombination. Hence, a phyletic evolution versus spontaneous evolution is going on in flaviviruses that will generate different antibody resistant JEV mutants/variants in future. Further, molecular changes established within the virus may result in enhancement of neurovirulence and death rate in various infant groups. Therefore, it is an all sided alarm to have a complete program on vector control and immunization by using potential vaccine therapy for controlling the JE virus in India and other Southeast Asian countries.

\section{Abbreviations}

JEV: Japanese encephalitis virus

NS: Nonstructural proteins

CSF: Cerebrospinal fluid

VLPs: Virus like particles

VAPs: Virus associating proteins

MAbs: Monoclonal antibodies

WNV: West Nile virus

NLP: Nucleocapsid-like particles

JGMV: Johnson grass mosaic virus

TCR: T-cell receptor

CTL: Cytotoxic lymphocytes

NCPs: Neural progenitor cells

CNS: Central nervous system.

\section{Conflict of Interests}

The author has no conflict of interests. The author is responsible for the content and writing of the paper.

\section{References}

[1] J. Arroyo, F. Guirakhoo, S. Fenner, Z.-X. Zhang, T. P. Monath, and T. J. Chambers, "Molecular basis for attenuation of neurovirulence of a yellow fever virus/Japanese encephalitis virus chimera vaccine (ChimeriVax-JE)," Journal of Virology, vol. 75, no. 2, pp. 934-942, 2001.

[2] A. Sarkar, A. Banik, B. K. Pathak, S. K. Mukhopadhyay, and S. Chatterjee, "Envelope protein gene based molecular characterization of Japanese encephalitis virus clinical isolates from West Bengal, India: a comparative approach with respect to SA14-142 live attenuated vaccine strain," BMC Infectious Diseases, vol. 13, no. 1, p. 368, 2013.
[3] Z. Zhao, T. Date, Y. Li et al., "Characterization of the E-138 (Glu/Lys) mutation in Japanese encephalitis virus by using a stable, full-length, infectious cDNA clone," Journal of General Virology, vol. 86, no. 8, pp. 2209-2220, 2005.

[4] A. Padhi and B. Verghese, "Detecting molecular adaptation at individual codons in the glycoprotein gene of the geographically diversified infectious hematopoietic necrosis virus, a fish rhabdovirus," Virus Research, vol. 132, no. 1-2, pp. 229-236, 2008.

[5] W. R. Jiang, A. Lowe, S. Higgs, H. Reid, and E. A. Gould, "Single amino acid codon changes detected in louping ill virus antibody-resistant mutants with reduced neurovirulence," Journal of General Virology, vol. 74, no. 5, pp. 931-935, 1993.

[6] M. Ciarlet, Y. Hoshino, and F. Liprandi, "Single point mutations may affect the serotype reactivity of serotype G11 porcine rotavirus strains: a widening spectrum?" Journal of Virology, vol. 71, no. 11, pp. 8213-8220, 1997.

[7] J. Du, Q. Zhang, Q. Tang et al., "Characterization of human rabies virus vaccine strain in China," Virus Research, vol. 135, no. 2, pp. 260-266, 2008.

[8] Y. Yu, "Phenotypic and genotypic characteristics of Japanese encephalitis attenuated live vaccine virus SA14-14-2 and their stabilities," Vaccine, vol. 28, no. 21, pp. 3635-3641, 2010.

[9] S. Vijaysri, G. Jentarra, M. C. Heck, A. A. Mercer, C. J. McInnes, and B. L. Jacobs, "Vaccinia viruses with mutations in the E3L gene as potential replication-competent, attenuated vaccines: intra-nasal vaccination," Vaccine, vol. 26, no. 5, pp. 664-676, 2008.

[10] J. M. Ngunjiri, G. M. Buchek, K. N. Mohni, M. J. Sekellick, and P. I. Marcus, "Influenza virus subpopulations: exchange of lethal $\mathrm{H} 5 \mathrm{~N} 1$ virus NS for H1N1 virus NS triggers de novo generation of defective-interfering particles and enhances interferoninducing particle efficiency," Journal of Interferon \& Cytokine Research, vol. 33, no. 3, pp. 99-107.

[11] J.-J. Liang, C.-L. Liao, J.-T. Liao, Y.-L. Lee, and Y.-L. Lin, “A Japanese encephalitis virus vaccine candidate strain is attenuated by decreasing its interferon antagonistic ability," Vaccine, vol. 27, no. 21, pp. 2746-2754, 2009.

[12] D. E. Griffin, "Emergence and re-emergence of viral diseases of the central nervous system," Progress in Neurobiology, vol. 91, no. 2, pp. 95-101, 2009.

[13] M. E. B. Moret, A. C. Siepel, J. Tang, and L. Tao, "Inversion medians outperform breakpoint medians in phylogengy reconstruction from gene-order datavolume," in Proceedings of the 2nd Workshop on Algorithms in Bioinformatics (WABI '02), pp. 521-536, Lecture Notes in Computer Science.

[14] B. M. E. Moret, J. Tang, L.-S. Wang, and T. Warnow, "Steps toward accurate reconstructions of phylogenies from geneorder data," Journal of Computer and System Sciences, vol. 65, no. 3, pp. 508-525, 2003.

[15] D. Sankoff, C. Zheng, A. Muñoz et al., "Issues in the reconstruction of gene order evolution," Journal of Computer Science and Technology, vol. 25, no. 1, pp. 10-25, 2009.

[16] P. C. McMinn, E. Lee, S. Hartley, J. T. Roehrig, L. Dalgarno, and R. C. Weir, "Murray Valley encephalitis virus envelope protein antigenic variants with altered hemagglutination properties and reduced neuroinvasiveness in mice," Virology, vol. 211, no. 1, pp. 10-20, 1995.

[17] T. Zhang, Z. Wu, J. Du et al., "Anti- Japanese-encephalitisviral effects of kaempferol and daidzin and their RNA-binding characteristics," PLoS ONE, vol. 7, no. 1, Article ID e30259, 2012.

[18] W. Chen, H. Kawano, R. Men, D. Clark, and C.-J. Lai, "Construction of intertypic chimeric dengue viruses exhibiting type 
3 antigenicity and neurovirulence for mice," Journal of Virology, vol. 69, no. 8, pp. 5186-5190, 1995.

[19] J.-J. Hung, M.-T. Hsieh, M.-J. Young, C.-L. Kao, C.-C. King, and W. Chang, "An external loop region of domain II of dengue virus type 2 envelope protein is involved in serotypes specific binding to mosquito but not mammalian cells," Journal of Virology, vol. 78, no. 1, pp. 378-388, 2004.

[20] H. Hasegawa, M. Yoshida, T. Shiosaka, S. Fujita, and Y. Kobayashi, "Mutations in the envelope protein of Japanese encephalitis virus affect entry into cultured cells and virulence in mice," Virology, vol. 191, no. 1, pp. 158-165, 1992.

[21] D. Yoo and D. Deregt, "A single amino acid change within antigenic domain II of the spike protein of bovine coronavirus confers resistance to virus neutralization," Clinical and Diagnostic Laboratory Immunology, vol. 8, no. 2, pp. 297-302, 2001.

[22] D. Cecilia and E. A. Gould, "Nucleotide changes responsible for loss of neuroinvasiveness in Japanese encephalitis virus neutralization-resistant mutants," Virology, vol. 181, no. 1, pp. 70-77, 1991.

[23] J. T. Roehrig, A. J. Johnson, A. R. Hunt, R. A. Bolin, and M. C. Chu, "Antibodies to dengue 2 virus E-glycoprotein synthetic peptides identify antigenic conformation," Virology, vol. 177, no. 2, pp. 668-675, 1990.

[24] S. L. Allison, J. Schalich, K. Stiasny, C. W. Mandl, and F. X. Heinz, "Mutational evidence for an internal fusion peptide in flavivirus envelope protein E," Journal of Virology, vol. 75, no. 9, pp. 42684275, 2001.

[25] S. Aktas and A. R. Samuel, "Identification of antigenic epitopes on the foot and mouth disease virus isolate 01Manisa/Turkey/69 using monoclonal antibodies," OIE Revue Scientifique et Technique, vol. 19, no. 3, pp. 744-753, 2000.

[26] J. Fayolle, B. Verrier, R. Buckland, and T. Fabian Wild, "Characterization of a natural mutation in an antigenic site on the fusion protein of measles virus that is involved in neutralization," Journal of Virology, vol. 73, no. 1, pp. 787-790, 1999.

[27] M. Arakawa, T. Yamashiro, G.-I. Uechi, M. Tadano, and A. Nishizono, "Construction of human Fab $(\gamma 1 / \kappa)$ library and identification of human monoclonal Fab possessing neutralizing potency against Japanese encephalitis virus," Microbiology and Immunology, vol. 51, no. 6, pp. 617-625, 2007.

[28] J. Schlender, B. Bossert, U. Buchholz, and K.-K. Conzelmann, "Bovine respiratory syncytial virus nonstructural proteins NS1 and NS2 cooperatively antagonize alpha/beta interferoninduced antiviral response," Journal of Virology, vol. 74, no. 18, pp. 8234-8242, 2000.

[29] B. A. Watkins, M. S. Reitz Jr., C. A. Wilson, K. Aldrich, A. E. Davis, and M. Robert- Guroff, "Immune escape by human immunodeficiency virus type 1 from neutralizing antibodies: evidence for multiple pathways," Journal of Virology, vol. 67, no. 12, pp. 7493-7500, 1993.

[30] X. Wu, T. Zhou, S. O’Dell, R. T. Wyatt, P. D. Kwong, and J. R. Mascola, "Mechanism of human immunodeficiency virus type 1 resistance to monoclonal antibody b12 that effectively targets the site of CD4 attachment," Journal of Virology, vol. 83, no. 21, pp. 10892-10907, 2009.

[31] S. Sato, E. Yuste, W. A. Lauer et al., "Potent antibody-mediated neutralization and evolution of antigenic escape variants of simian immunodeficiency virus strain SIVmac239 in vivo," Journal of Virology, vol. 82, no. 19, pp. 9739-9752, 2008.

[32] G. V. Quinnan Jr., P. Zhang, M. Dong et al., "Neutralizing antibody responses in macaques induced by human immunodeficiency virus type 1 monovalent or trivalent envelope glycoproteins," PLoS ONE, vol. 8, no. 3, Article ID e59803, 2013.

[33] A. K. Dey, K. B. David, N. Ray et al., "N-terminal substitutions in HIV-1 gp41 reduce the expression of non-trimeric envelope glycoproteins on the virus," Virology, vol. 372, no. 1, pp. 187-200, 2008.

[34] Y. Li, B. Cleveland, I. Klots et al., "Removal of a single N-linked glycan in human immunodeficiency virus type 1 gp120 results in an enhanced ability to induce neutralizing antibody responses," Journal of Virology, vol. 82, no. 2, pp. 638-651, 2008.

[35] J. Graff, Y.-H. Zhou, U. Torian et al., "Mutations within potential glycosylation sites in the capsid protein of hepatitis E virus prevent the formation of infectious virus particles," Journal of Virology, vol. 82, no. 3, pp. 1185-1194, 2008.

[36] G. R. Risatti, L. G. Holinka, I. Fernandez Sainz, C. Carrillo, Z. $\mathrm{Lu}$, and M. V. Borca, "N-linked glycosylation status of classical swine fever virus strain Brescia E2 glycoprotein influences virulence in swine," Journal of Virology, vol. 81, no. 2, pp. 924933, 2007.

[37] T. Slater-Handshy, D. A. Droll, X. Fan, A. M. Di Bisceglie, and T. J. Chambers, "HCV E2 glycoprotein: mutagenesis of Nlinked glycosylation sites and its effects on E2 expression and processing," Virology, vol. 319, no. 1, pp. 36-48, 2004.

[38] B. J. Willett, E. L. McMonagle, N. Logan, A. Samman, and M. J. Hosie, "A single site for N-linked glycosylation in the envelope glycoprotein of feline immunodeficiency virus modulates the virus-receptor interaction," Retrovirology, vol. 5, article 77, 2008.

[39] P. B. Das, H. L. X. Vu, P. X. Dinh et al., "Glycosylation of minor envelope glycoproteins of porcine reproductive and respiratory syndrome virus in infectious virus recovery, receptor interaction, and immune response," Virology, vol. 410, no. 2, pp. 385394, 2011.

[40] R. Eichler, O. Lenz, W. Garten, and T. Strecker, "The role of single $\mathrm{N}$-glycans in proteolytic processing and cell surface transport of the Lassa virus glycoprotein GP-C," Virology Journal, vol. 3, article 41, 2006.

[41] S. Samal, S. K. Khattar, S. Kumar, P. L. Collins, and S. K. Samal, "Coordinate deletion of N-glycans from the heptad repeats of the fusion $\mathrm{F}$ protein of newcastle disease virus yields a hyperfusogenic virus with increased replication, virulence, and immunogenicity," Journal of Virology, vol. 86, no. 5, pp. 25012511, 2012.

[42] P. J. Lech, G. J. Tobin, R. Bushnell et al. et al., "Epitope dampening monotypic measles virus hemagglutinin glycoprotein results in resistance to cocktail of monoclonal antibodies," PLoS ONE, vol. 8, no. 1, Article ID e52306, 2013.

[43] A. K. I. Falconar and F. Martinez, "The NS1 glycoprotein can generate dramatic antibody-enhanced dengue viral replication in normal out-bred mice resulting in lethal multi-organ disease," PLoS ONE, vol. 6, no. 6, Article ID e21024, 2011.

[44] C. L. Gardner, G. D. Ebel, K. D. Ryman, and W. B. Klimstra, "Heparan sulfate binding by natural eastern equine encephalitis viruses promotes neurovirulence," Proceedings of the National Academy of Sciences of the United States of America, vol. 108, no. 38, pp. 16026-16031, 2011.

[45] J. W. Yewdell, "Monoclonal antibodies specific for discontinuous epitopes direct refolding of influenza A virus hemagglutinin," Molecular Immunology, vol. 47, no. 5, pp. 1132-1136, 2010.

[46] M. Ciarlet, M. Hidalgo, M. Gorziglia, and F. Liprandi, "Characterization of neutralization epitopes on the VP7 surface protein 
of serotype G11 porcine rotaviruses," Journal of General Virology, vol. 75, no. 8, pp. 1867-1873, 1994.

[47] F. Schmeisser, R. Friedman, J. Besho, V. Lugovtsev, J. Soto et al., "Neutralizing and protective epitopes of the 2009 pandemic influenza H1N1 hemagglutinin," Influenza and Other Respiratory Viruses, vol. 7, no. 3, pp. 480-490, 2013.

[48] K. Matsui, G. D. Gromowski, L. Li, A. J. Schuh, J. C. Lee, and A. D. T. Barrett, "Characterization of dengue complexreactive epitopes on dengue 3 virus envelope protein domain III," Virology, vol. 384, no. 1, pp. 16-20, 2009.

[49] G. D. Gromowski, N. D. Barrett, and A. D. T. Barrett, "Characterization of dengue virus complex-specific neutralizing epitopes on envelope protein domain III of dengue 2 virus," Journal of Virology, vol. 82, no. 17, pp. 8828-8837, 2008.

[50] J. Humberd, K. Boyd, and R. G. Webster, "Emergence of influenza A virus variants after prolonged shedding from pheasants," Journal of Virology, vol. 81, no. 8, pp. 4044-4051, 2007.

[51] T. Kiener, Q. Jia, X. Lim et al., "Characterization and specificity of the linear epitope of the enterovirus 71 VP2 protein," Virology Journal, vol. 9, article 55, 2012.

[52] S.-S. Chiou, W. D. Crill, L.-K. Chen, and G.-J. J. Chang, "Enzyme-linked immunosorbent assays using novel Japanese encephalitis virus antigen improve the accuracy of clinical diagnosis of flavivirus infections," Clinical and Vaccine Immunology, vol. 15, no. 5, pp. 825-835, 2008.

[53] R. Kim and J. T. Guo, "Systematic analysis of short internal indels and their impact on protein folding," BMC Structural Biology, vol. 10, no. 24, 2010.

[54] V. Debat, A. Debelle, and I. Dworkin, "Plasticity, canalization, and developmental stability of the Drosophila wing: joint effects of mutations and developmental temperature," Evolution, vol. 63, no. 11, pp. 2864-2876, 2009.

[55] S. Rits-Volloch, G. Frey, S. C. Harrison, and B. Chen, "Restraining the conformation of HIV-1 gp120 by removing a flexible loop," EMBO Journal, vol. 25, no. 20, pp. 5026-5035, 2006.

[56] K. Kaneko and C. Furusawa, "An evolutionary relationship between genetic variation and phenotypic fluctuation," Journal of Theoretical Biology, vol. 240, no. 1, pp. 78-86, 2006.

[57] V. A. Sharma, E. Kan, Y. Sun et al., "Structural characteristics correlate with immune responses induced by HIV envelope glycoprotein vaccines," Virology, vol. 352, no. 1, pp. 131-144, 2006.

[58] A. B. Reams and E. L. Neidle, "Genome plasticity in Acinetobacter: new degradative capabilities acquired by the spontaneous amplification of large chromosomal segments," Molecular Microbiology, vol. 47, no. 5, pp. 1291-1304, 2003.

[59] E. B. Flanagan, T. R. Schoeb, and G. W. Wertz, "Vesicular stomatitis viruses with rearranged genomes have altered invasiveness and neuropathogenesis in mice," Journal of Virology, vol. 77, no. 10, pp. 5740-5748, 2003.

[60] W. V. Corapi, R. J. Darteil, J.-C. Audonnet, and G. E. Chappuis, "Localization of antigenic sites of the S glycoprotein of feline infectious peritonitis virus involved in neutralization and antibody-dependent enhancement," Journal of Virology, vol. 69, no. 5, pp. 2858-2862, 1995.

[61] B. Harmon and L. Ratner, "Induction of the G $\alpha \mathrm{q}$ signaling cascade by the human immunodeficiency virus envelope is required for virus entry," Journal of Virology, vol. 82, no. 18, pp. 9191-9205, 2008.
[62] T. P. Monath, "Japanese encephalitis vaccines: current vaccines and future prospects," Current Topics in Microbiology and Immunology, vol. 267, pp. 105-138, 2002.

[63] D. E. Purdy and G. J. Chang, "Secretion of noninfectious dengue virus-like particles and identification of amino acids in the stem region involved in intracellular retention of envelope protein," Virology, vol. 333, no. 2, pp. 239-250, 2005.

[64] M. Saini and S. Vrati, "A Japanese encephalitis virus peptide present on Johnson grass mosaic virus-like particles induces virus-neutralizing antibodies and protects mice against lethal challenge," Journal of Virology, vol. 77, no. 6, pp. 3487-3494, 2003.

[65] P. Bach, E. Kamphuis, B. Odermatt, G. Sutter, C. J. Buchholz, and U. Kalinke, "Vesicular stomatitis virus glycoprotein displaying retrovirus-like particles induce a type I IFN receptor-dependent switch to neutralizing IgG antibodies," Journal of Immunology, vol. 178, no. 9, pp. 5839-5847, 2007.

[66] B. He, X. Qiao, P. J. Klasse et al., "HIV-1 envelope triggers polyclonal Ig class switch recombination through a CD40independent mechanism involving BAFF and C-type lectin receptors," Journal of Immunology, vol. 176, no. 7, pp. 3931-3941, 2006.

[67] P. E. Stanhope, A. Y. Liu, W. Pavlat, P. M. Pitha, M. L. Clements, and R. F. Siliciano, "An HIV-1 envelope protein vaccine elicits a functionally complex human CD4+ T cell response that includes cytolytic T lymphocytes," Journal of Immunology, vol. 150, no. 10, pp. 4672-4686, 1993.

[68] E. W. Hewitt, S. S. Gupta, and P. J. Lehner, "The human cytomegalovirus gene product US6 inhibits ATP binding by TAP," EMBO Journal, vol. 20, no. 3, pp. 387-396, 2001.

[69] A. Sen-Majumdar, I. L. Weissman, G. Hansteen, J. Marian, E. K. Waller, and M. Lieberman, "Radiation leukemia virusinduced thymic lymphomas express a restricted repertoire of $\mathrm{T}$-cell receptor $\mathrm{V} \beta$ gene products," Journal of Virolog $y$, vol. 68, no. 2, pp. 1165-1172, 1994.

[70] G. B. Athas, B. Choi, S. Prabhu, P. A. Lobelle-Rich, and L. S. Levy, "Genetic determinants of feline leukemia virus-induced multicentric lymphomas," Virology, vol. 214, no. 2, pp. 431-438, 1995.

[71] P. J. Fischinger, "Pathogenesis and virus content of lymphomas induced by pure ecotropic graffi murine leukemia virus," International Journal of Radiation Oncology Biology Physics, vol. 11, no. 2, pp. 241-251, 1985.

[72] P. Salahuddin and A. U. Khan, "Identification of mutations at the antigenic and glycosylation sites in hemagglutinin protein of H5N1 strain," Bioinformation, vol. 4, no. 1, pp. 30-35, 2009.

[73] J. Li, Y. Wang, Y. Liang et al., "Fine antigenic variation within $\mathrm{H} 5 \mathrm{~N} 1$ influenza virus hemagglutinin's antigenic sites defined by yeast cell surface display," European Journal of Immunology, vol. 39, no. 12, pp. 3498-3510, 2009.

[74] R. Rong, B. Li, R. M. Lynch et al., "Escape from autologous neutralizing antibodies in acute/early subtype C HIV-1 infection requires multiple pathways," PLoS Pathogens, vol. 5, no. 9, Article ID e1000594, 2009.

[75] L. Tomé, S. Frabasile, C. Candia et al., "Selection and characterization of human respiratory syncytial virus escape mutants resistant to a polyclonal antiserum raised against the F protein," Archives of Virology, vol. 157, no. 6, pp. 1071-1080, 2012.

[76] S. L. Highlander, D. J. Dorney, P. J. Gage et al., "Identification of mar mutations in herpes simplex virus type 1 glycoprotein $B$ which alter antigenic structure and function in virus penetration," Journal of Virology, vol. 63, no. 2, pp. 730-738, 1989. 
[77] S. D. Thompson and A. Portneri, "Localization of functional sites on the hemagglutinin-neuraminidase glycoprotein of Sendai virus by sequence analysis of antigenic and temperaturesensitive mutants," Virology, vol. 160, no. 1, pp. 1-8, 1987.

[78] W. L. Gorman, C. Pridgen, and A. Portner, "Glycosylation of the hemagglutinin-neuraminidase glycoprotein of human parainfluenza virus type 1 affects its functional but not its antigenic properties," Virology, vol. 183, no. 1, pp. 83-90, 1991.

[79] B. M. Hause, D. L. Stine, Z. Sheng et al., "Migration of the swine influenza virus $\delta$-cluster hemagglutinin $\mathrm{N}$-linked glycosylation site from N142 to N144 results in loss of antibody crossreactivity," Clinical and Vaccine Immunology, vol. 19, no. 9, pp. 1457-1464, 2012.

[80] J. Kimura Kuroda and K. Yasui, “Topographical analysis of antigenic determinants on envelope glycoprotein V3 (E) of Japanese encephalitis virus, using monoclonal antibodies," Journal of Virology, vol. 45, no. 1, pp. 124-132, 1983.

[81] F. X. Heinz, "Epitope mapping of flavivirus glycoproteins," Advances in Virus Research, vol. 31, pp. 103-168, 1986.

[82] C. W. Mandl, F. Guirakhoo, H. Holzmann, F. X. Heinz, and C. Kunz, "Antigenic structure of the flavivirus envelope protein $\mathrm{E}$ at the molecular level, using the tick-borne encephalitis virus as a model," Journal of Virology, vol. 63, no. 2, pp. 564-571, 1989.

[83] F. L. Chu, H. L. Wen, G. H. Hou et al., "Role of N-linked glycosylation of the human parainfluenza virus type 3 hemagglutininneuraminidase protein," Virus Research, vol. 174, no. 1-2, pp. 137147, 2013.

[84] Y.-M. A. Lee, Y. Cui, J. König et al., "Identification and functional characterization of the natural variant MRP3-Arg1297His of human multidrug resistance protein 3 (MRP3/ABCC3)," Pharmacogenetics, vol. 14, no. 4, pp. 213-223, 2004.

[85] K. Stiasny, S. L. Allison, A. Marchler-Bauer, C. Kunz, and F. X. Heinz, "Structural requirements for low-pH-induced rearrangements in the envelope glycoprotein of tick-borne encephalitis virus," Journal of Virology, vol. 70, no. 11, pp. 81428147, 1996.

[86] Y. Modis, S. Ogata, D. Clements, and S. C. Harrison, "Structure of the dengue virus envelope protein after membrane fusion," Nature, vol. 427, no. 6972, pp. 313-319, 2004.

[87] Y. Chen, T. Maguire, R. E. Hileman et al., "Dengue virus infectivity depends on envelope protein binding to target cell heparan sulfate," Nature Medicine, vol. 3, no. 8, pp. 866-871, 1997.

[88] Y. Zhang, W. Zhang, S. Ogata et al., "Conformational changes of the flavivirus E glycoprotein,” Structure, vol. 12, no. 9, pp. 16071618, 2004.

[89] T. Toda, K. Kuwahara, N. Kondo et al., "Dynamic appearance of antigenic epitopes effective for viral neutralization during membrane fusion initiated by interactions between HIV-1 envelope proteins and CD4/CXCR4," Immunobiology, vol. 217, no. 9, pp. 864-872, 2012.

[90] M. Akram, M. Idrees, A. Hussain et al., "Characterization of Hepatitis $\mathrm{C}$ virus genotype 3a hypervariable region 1 in patients achieved rapid virological response to alpha interferon and Ribavirin Combination therapy," Virology Journal, vol. 8, article 253, 2011.

[91] T. J. Chambers, C. S. Hahn, R. Galler, and C. M. Rice, "Flavivirus genome organization, expression, and replication," Annual Review of Microbiology, vol. 44, pp. 649-688, 1990.

[92] C. Lin, S. M. Amberg, T. J. Chambers, and C. M. Rice, "Cleavage at a novel site in the NS4A region by the yellow fever virus NS2B-3 proteinase is a prerequisite for processing at the downstream 4A/4B signalase site," Journal of Virology, vol. 67, no. 4, pp. 2327-2335, 1993.

[93] C. M. Rice, E. M. Lenches, and S. R. Eddy, "Nucleotide sequence of yellow fever virus: implications for flavivirus gene expression and evolution," Science, vol. 229, no. 4715, pp. 726-733, 1985.

[94] C. M. Rice, E. G. Strauss, and J. H. Strauss, "Structure of the flavivirus genome," in The Togaviridae and Flaviviridae, S. Schlesinger and M. J. Schlesinger, Eds., pp. 279-326, Plenum Press, New York, NY, USA, 1986.

[95] H. Sumiyoshi, C. Mori, I. Fuke et al., "Complete nucleotide sequence of the Japanese encephalitis virus genome RNA," Virology, vol. 161, no. 2, pp. 497-510, 1987.

[96] T. Yamashita, H. Unno, Y. Mori et al., "Crystal structure of the catalytic domain of Japanese encephalitis virus NS3 helicase/nucleoside triphosphatase at a resolution of $1.8 \AA$," Virology, vol. 373, no. 2, pp. 426-436, 2008.

[97] Y.-Q. Deng, J.-X. Dai, G.-H. Ji et al., "A broadly flavivirus cross-neutralizing monoclonal antibody that recognizes a novel epitope within the fusion loop of e protein," PLoS ONE, vol. 6, no. 1, Article ID e16059, 2011.

[98] G. W. Wertz, V. P. Perepelitsa, and L. A. Ball, "Gene rearrangement attenuates expression and lethality of a nonsegmented negative strand RNA virus," Proceedings of the National Academy of Sciences of the United States of America, vol. 95, no. 7, pp. 3501-3506, 1998.

[99] Z. Q. Wang, Y. Yu, X. H. Zhang, J. Qin, and E. Floyd, “Gene expression profile in human skeletal muscle cells infected with human adenovirus type 36," Journal of Medical Virology, vol. 84, no. 8, pp. 1254-1266, 2012.

[100] C.-M. Hogerkorp, Y. Nishimura, K. Song, M. A. Martin, and M. Roederer, "The simian immunodeficiency virus targets central cell cycle functions through transcriptional repression in vivo," PLoS ONE, vol. 6, no. 10, Article ID e25684, 2011.

[101] C.-K. Chuang and W.-J. Chen, "Experimental evidence that RNA recombination occurs in the Japanese encephalitis virus," Virology, vol. 394, no. 2, pp. 286-297, 2009.

[102] A. López-Bueno, M. G. Mateu, and J. M. Almendral, "High mutant frequency in populations of a DNA virus allows evasion from antibody therapy in an immunodeficient host," Journal of Virology, vol. 77, no. 4, pp. 2701-2708, 2003.

[103] S. S. Athavale, W. Ouyang, M. P. McPike, B. S. Hudson, and P. N. Borer, "Effects of the nature and concentration of salt on the interaction of the HIV-1 nucleocapsid protein with SL3 RNA," Biochemistry, vol. 49, no. 17, pp. 3525-3533, 2010.

[104] R. Levitz, R. Wattier, P. Phillips et al., "Induction of IL-6 and CCL5 (RANTES) in human respiratory epithelial (A549) cells by clinical isolates of respiratory syncytial virus is strain specific," Virology Journal, vol. 10, no. 9, pp. 1901743-1901422, 2012.

[105] C.-F. Yang, H.-Y. Chen, J. Jorba et al., "Intratypic recombination among lineages of type 1 vaccine-derived poliovirus emerging during chronic infection of an immunodeficient patient," Journal of Virology, vol. 79, no. 20, pp. 12623-12634, 2005.

[106] A. McGoldrick, A. J. Macadam, G. Dunn et al., "Role of mutations G-480 and C-6203 in the attenuation phenotype of sabin type 1 poliovirus," Journal of Virology, vol. 69, no. 12, pp. 7601-7605, 1995.

[107] M.-M. Georgescu, F. Delpeyroux, M. Tardy-Panit et al., "High diversity of poliovirus strains isolated from the central nervous system from patients with vaccine-associated paralytic 
poliomyelitis," Journal of Virology, vol. 68, no. 12, pp. 8089-8101, 1994.

[108] L. M. Shulman, Y. Manor, J. Alfandari, D. R. Kilpatrick, and T. Halmut, "Rapid evolution by recombination of OPV strains in immunized children in an urban Bedouin community," Program and Abstracts of the Annual Meeting of the Israeli Society of Microbiology, Haifa, Israel, 2004.

[109] V. I. Agol, "Recombination and other genomic rearrangements in picornaviruses," Seminars in Virology, vol. 8, no. 2, pp. 77-84, 1997.

[110] S. Guillot, V. Caro, N. Cuervo et al., "Natural genetic exchanges between vaccine and wild poliovirus strains in humans," Journal of Virology, vol. 74, no. 18, pp. 8434-8443, 2000.

[111] N. S. Cuervo, S. Guillot, N. Romanenkova et al., "Genomic features of intertypic recombinant sabin poliovirus strains excreted by primary vaccinees," Journal of Virology, vol. 75, no. 13, pp. 5740-5751, 2001.

[112] K. H. Eckels, Y. Yong-Xin, D. R. Dubois, N. J. Marchette, D. W. Trent, and A. J. Johnson, "Japanese encephalitis virus liveattenuated vaccine, Chinese strain SA14-14-2; Adaptation to primary canine kidney cell cultures and preparation of a vaccine for human use," Vaccine, vol. 6, no. 6, pp. 513-518, 1988.

[113] R. C. Gualano, M. J. Pryor, M. R. Cauchi, P. J. Wright, and A. D. Davidson, "Identification of a major determinant of mouse neurovirulence of dengue virus type 2 using stably cloned genomic-length cDNA," Journal of General Virology, vol. 79, no. 3, pp. 437-446, 1998.

[114] A. Maeda, R. Murata, M. Akiyama et al., "A PCR-based protocol for the generation of a recombinant West Nile virus," Virus Research, vol. 144, no. 1-2, pp. 35-43, 2009.

[115] J. Li, Y. Wang, Y. Liang et al., "Fine antigenic variation within $\mathrm{H} 5 \mathrm{~N} 1$ influenza virus hemagglutinin's antigenic sites defined by yeast cell surface display," European Journal of Immunology, vol. 39, no. 12, pp. 3498-3510, 2009.

[116] K. Matsui, G. D. Gromowski, L. Li, A. J. Schuh, J. C. Lee, and A. D. T. Barrett, "Characterization of dengue complexreactive epitopes on dengue 3 virus envelope protein domain III," Virology, vol. 384, no. 1, pp. 16-20, 2009.

[117] M. Igarashi, K. Ito, R. Yoshida, D. Tomabechi, H. Kida, and A. Takada, "Predicting the antigenic structure of the pandemic (H1N1) 2009 influenza virus hemagglutinin," PLoS ONE, vol. 5, no. 1, Article ID e8553, 2010.

[118] L. Badam, "In vitro antiviral activity of indigenous Glycyrrhizin, Licorice and Glycyrrhizic Acid (Sigma) on Japanese Encephalitis Virus," Journal of Communicable Diseases, vol. 29, no. 2, pp. 91-99, 1997.

[119] B. Gabrielsen, T. P. Monath, J. W. Huggins et al., "Antiviral (RNA) activity of selected Amaryllidaceae isoquinoline constituents and synthesis of related substances," Journal of Natural Products, vol. 55, no. 11, pp. 1569-1581, 1992.

[120] W. C. Chen, S. Y. Wang, C. C. Chiu et al., "Lucidone suppresses hepatitis $\mathrm{C}$ virus replication by Nrf2-mediated heme oxygenase1 induction," Antimicrobial Agents and Chemotherapy, vol. 57, no. 3, pp. 1180-1191, 2013.

[121] M. M. Alfajaro, H. J. Kim, J. G. Park et al., "Anti-rotaviral effects of Glycyrrhiza uralensis extract in piglets with rotavirus diarrhea," Virology Journal, vol. 18, no. 9, p. 310, 2012.

[122] F. R. Chang, C. T. Yen, M. Ei-Shazly et al., "Anti-human coronavirus (anti-HCoV) triterpenoids from the leaves of Euphorbia neriifolia," Natural Product Communications, vol. 7, no. 11, pp. 1415-1417, 2012.
[123] L. Mišurcová, S. Škrovánková, D. Samek, J. Ambrožová, and L. Machů, "Health benefits of algal polysaccharides in human nutrition," Advances in Food and Nutrition Research, vol. 66, pp. 75-145, 2012.

[124] S. Jahn, B. Seiwert, S. Kretzing, G. Abraham, R. Regenthal, and U. Karst, "Metabolic studies of the Amaryllidaceous alkaloids galantamine and lycorine based on electrochemical simulation in addition to in vivo and in vitro models," Analytica Chimica Acta, vol. 756, pp. 60-72.

[125] G. C. Wang, T. Li, F. Y. Deng, Y. L. Li, and W. C. Ye, "Five new phenolic glycosides from Hedyotis scandens," Bioorganic \& Medicinal Chemistry Letters, vol. 23, no. 5, pp. 1379-1382, 2012.

[126] T. Rosen, "Green tea catechins: biologic properties, proposed mechanisms of action, and clinical implications," Journal of Drugs in Dermatology, vol. 11, no. 11, pp. 55-60, 2012.

[127] G. C. Wang, X. L. Zhang, Y. F. Wang, G. Q. Li, W. C. Ye, and Y. L. $\mathrm{Li}$, "Four new dilignans from the roots of Wikstroemia indica," Chem Pharm Bull, vol. 60, no. 7, pp. 920-923, 2012.

[128] A. H. Hamdy, W. S. Mettwally, M. A. El Fotouh et al., "Bioactive phenolic compounds from the Egyptian Red Sea seagrass, Thalassodendron ciliatum," Zeitschrift für Naturforschung, vol. 67, no. 5-6, p. 291, 2012.

[129] L. C. Faccin-Galhardi, K. Aimi Yamamoto, S. Ray, B. Ray, R. E. Carvalho Linhares, and C. Nozawa, "The in vitro antiviral property of Azadirachta indica polysaccharides for poliovirus," Journal of Ethnopharmacology, vol. 142, no. 1, pp. 86-90, 2012.

[130] K. Kajimura, Y. Takagi, N. Ueba et al., "Protective effect of Astragali Radix by oral administration against Japanese encephalitis virus infection in mice," Biological and Pharmaceutical Bulletin, vol. 19, no. 9, pp. 1166-1169, 1996.

[131] M. Chen, L. Gan, S. Lin et al., "Alkaloids from the root of Isatis indigotica," Journal of Natural Products, vol. 75, no. 6, Article ID 300283, pp. 1167-1176, 2012.

[132] S. A. Marathe, A. A. Datey, and D. Chakravortty, "Herbal cocktail as anti-infective: promising therapeutic for the treatment of viral diseases," Recent Patents on Anti-Infective Drug Discovery, vol. 7, no. 2, pp. 123-132, 2012.

[133] H. J. Lee, Y. N. Lee, H.-N. Youn et al., "Immunology, health, and disease, anti-influenza virus activity of green tea by-products in vitro and efficacy against influenza virus infection in chickens," Poultry Science, vol. 91, no. 1, pp. 66-73, 2012.

[134] S. Mansouri, M. Kutky, and K. A. Hudak, "Pokeweed antiviral protein increases HIV-1 particle infectivity by activating the cellular mitogen activated protein kinase pathway," PLOS ONE, vol. 7, no. 5, Article ID e36369, 2012.

[135] K. R. Reddy, S. H. Belle, M. W. Fried et al., "Rationale, challenges, and participants in a Phase II trial of a botanical product for chronic hepatitis C," Clinical Trials, vol. 9, no. 1, pp. 102-112, 2012.

[136] Y.-W. Sun, G.-M. Liu, H. Huang, and P.-Z. Yu, "Chromone derivatives from Halenia elliptica and their anti-HBV activities," Phytochemistry, vol. 75, pp. 169-176, 2012.

[137] T. T. Dao, T. T. Dang, P. H. Nguyen, E. Kim, P. T. Thuong, and W. K. Oh, "Xanthones from Polygala karensium inhibit neuraminidases from influenza A viruses," Bioorganic and Medicinal Chemistry Letters, vol. 22, no. 11, pp. 3688-3692, 2012.

[138] A. B. Cecílio, D. B. de Faria, C. O. Pde et al., "Screening of Brazilian medicinal plants for antiviral activity," Journal of Ethnopharmacology, vol. 141, no. 3, pp. 975-981, 2012.

[139] S. K. Kim, T. S. Vo, and D. H. Ngo, "Potential application of marine algae as antiviral agents in medicinal foods," Advances in Food and Nutrition Research, vol. 64, pp. 245-254, 2011. 
[140] S. L. Alcaraz-Estrada, E. D. Reichert, and R. Padmanabhan, "Construction of self-replicating subgenomic West Nile virus replicons for screening antiviral compounds," Methods in Molecular Biology, vol. 1030, pp. 283-299, 2013.

[141] S. P. J. Whelan, J. N. Barr, and G. W. Wertz, "Transcription and replication of nonsegmented negative-strand RNA viruses," Current Topics in Microbiology and Immunology, vol. 283, pp. 61-119, 2004.

[142] K. K.-S. Ng, J. J. Arnold, and C. E. Cameron, "Structurefunction relationships among RNA-dependent RNA polymerases," Current Topics in Microbiology and Immunology, vol. 320, pp. 137-156, 2008.

[143] C. Ferrer-Orta, A. Arias, R. Agudo et al., "The structure of a protein primer-polymerase complex in the initiation of genome replication," EMBO Journal, vol. 25, no. 4, pp. 880-888, 2006.

[144] M. R. Beard and K. J. Helbig, "Control of HCV replication: when size does not matter," Hepatology, vol. 47, no. 3, pp. 1092-1094, 2008.

[145] A. Salonen, T. Ahola, and L. Kääriäinen, "Viral RNA replication in association with cellular membranes," Current Topics in Microbiology and Immunology, vol. 285, pp. 139-173, 2004.

[146] K. J. Helbig, N. S. Eyre, E. Yip et al., "The antiviral protein viperin inhibits hepatitis $C$ virus replication via interaction with nonstructural protein 5A," Hepatology, vol. 54, no. 5, pp. 15061517, 2011.

[147] B. P. Wellensiek, R. Ramakrishnan, B. P. Bashyal, Y. Eason, A. A. Gunatilaka, and N. Ahmad, "Inhibition of HIV-1 replication by secondary metabolites from endophytic fungi of desert plants," The Open Virology Journal, vol. 26, no. 7, pp. 72-80, 1874.

[148] Y. Xie, B. Huang, K. Yu, F. Shi, T. Liu, and W. Xu, "Caffeic acid derivatives: a new type of influenza neuraminidase inhibitors," Bioorganic \& Medicinal Chemistry Letters, vol. 23, no. 12, pp. 3556-3560, 2013.

[149] P. Faral-Tello, S. Mirazo, C. Dutra, A. Pérez et al., "Cytotoxic, virucidal, and antiviral activity of South American plant and algae extracts," The Scientific World Journal, vol. 2012, Article ID 174837, 5 pages, 2012.

[150] S.-F. Wu, C.-K. Lin, Y.-S. Chuang et al., "Anti-hepatitis C virus activity of 3-hydroxy caruilignan C from Swietenia macrophylla stems," Journal of Viral Hepatitis, vol. 19, no. 5, pp. 364-370, 2012.

[151] T. T. Puck, A. Garen, and J. Cline, "The mechanism of virus attachment to host cells. I. The role of ions in the primary reaction," The Journal of experimental medicine, vol. 93, no. 1, pp. 65-88, 1951.

[152] T. T. Puck and H. H. Lee, "Mechanism of cell wall penetration by viruses. II. Demonstration of cyclic permeability change accompanying virus infection of Escherichia coli B cells," The Journal of experimental medicine, vol. 101, no. 2, pp. 151-175, 1955.

[153] M. A. Brindley, R. Suter, I. Schestak, G. Kiss, E. R. Wright, and R. K. Plemper, "A stabilized headless measless virus attachment protein stalk efficiently triggers membrane fusion," Journal of Virology, vol. 87, no. 21, pp. 11693-11703, 2013.

[154] A. D. Regan and G. R. Whittaker, "Entry of rhabdovirus in to animal cells," Advances in Experimental Medicine and Biology, vol. 790, pp. 167-177, 2013.

[155] C. L. Jolly and Q. J. Sattentau, "Attachment factors," Advances in Experimental Medicine and Biology, vol. 790, pp. 1-23, 2013.

[156] C.-H. Chen, Y.-L. Lin, Y.-K. Liu et al., "Liposome-based polymer complex as a novel adjuvant: enhancement of specifc antibody production and isotype switch," International Journal of Nanomedicine, vol. 7, pp. 607-621, 2012.
[157] K. Boonnak, B. M. Slike, G. C. Donofrio, and M. A. Marovich, "Human Fc $\gamma$ RII cytoplasmic domains differentially influence antibody-mediated dengue virus infection," The Journal of Immunology, vol. 190, no. 11, pp. 5659-5665, 2013.

[158] W. W. S. I. Rodrigo, X. Jin, S. D. Blackley, R. C. Rose, and J. J. Schlesinger, "Differential enhancement of dengue virus immune complex infectivity mediated by signaling-competent and signaling-incompetent human Fc $\gamma$ RIA (CD64) or Fc $\gamma$ RIIA (CD32)," Journal of Virology, vol. 80, no. 20, pp. 10128-10138, 2006.

[159] K. R. Chan, S. L.-X. Zhang, H. C. Tan et al., "Ligation of Fc gamma receptor IIB inhibits antibody-dependent enhancement of dengue virus infection," Proceedings of the National Academy of Sciences of the United States of America, vol. 108, no. 30, pp. 12479-12484, 2011.

[160] A. A. Khromykh, A. N. Varnavski, P. L. Sedlak, and E. G. Westaway, "Coupling between replication and packaging of flavivirus RNA: evidence derived from the use of DNA-based full-length CDNA clones of kunjin virus," Journal of Virology, vol. 75, no. 10, pp. 4633-4640, 2001.

[161] R. M. Kinney and C. Y.-H. Huang, "Development of new vaccines against dengue fever and Japanese encephalitis," Intervirology, vol. 44, no. 2-3, pp. 176-197, 2001.

[162] A. Takano, K. Yoshii, Y. Omori-Urabe, K. Yokozawa, H. Kariwa, and I. Takashima, "Construction of a replicon and an infectious cDNA clone of the Sofjin strain of the Far-Eastern subtype of tick-borne encephalitis virus," Archives of Virology, vol. 156, no. 11, pp. 1931-1941, 2011.

[163] S. Li, L. Zhang, Y. Wang et al., "An infectious full-length cDNA clone of duck Tembusu virus, a newly emerging flavivirus causing duck egg drop syndrome in China," Virus Research, vol. 171, no. 1, pp. 238-241, 2013.

[164] C. Bahuon, P. Desprès, N. Pardigon et al., "IS-98-ST1 West Nile virus derived from an infectious cDNA clone retains neuroinvasiveness and neurovirulence properties of the original virus," PLoS ONE, vol. 7, no. 10, 2012.

[165] K. Yoshii, M. Igarashi, K. Ito, H. Kariwa, M. R. Holbrook, and I. Takashima, "Construction of an infectious cDNA clone for Omsk hemorrhagic fever virus, and characterization of mutations in NS2A and NS5," Virus Research, vol. 155, no. 1, pp. 61-68, 2011.

[166] R. Suzuki, L. de Borba, C. N. Duarte dos Santos, and P. W. Mason, "Construction of an infectious cDNA clone for a Brazilian prototype strain of dengue virus type 1: characterization of a temperature-sensitive mutation in NS1," Virology, vol. 362, no. 2, pp. 374-383, 2007.

[167] V. P. Mishin, F. Cominelli, and V. F. Yamshchikov, "A 'minimal' approach in design of flavivirus infectious DNA," Virus Research, vol. 81, no. 1-2, pp. 113-123, 2001.

[168] M. Zeng, L.-L. Jia, Y.-X. Yu et al., "Construction of infectious Japanese encephalitis virus clone based on the cDNA template of the attenuated live vaccine production strain SA14-14-2," Chinese Journal of Experimental and Clinical Virology, vol. 19, no. 1, pp. 9-11, 2005.

[169] R. Sriburi, P. Keelapang, T. Duangchinda et al., "Construction of infectious dengue 2 virus cDNA clones using high copy number plasmid," Journal of Virological Methods, vol. 92, no. 1, pp. 71-82, 2001.

[170] A. A. Khromykh and E. G. Westaway, "Completion of Kunjin virus RNA sequence and recovery of an infectious RNA trancribed from stably cloned full-length cDNA," Journal of Virology, vol. 68, no. 7, pp. 4580-4588, 1994. 
[171] E. P. Kelly, B. Puri, W. Sun, and B. Falgout, "Identification of mutations in a candidate dengue 4 vaccine strain 341750 PDK20 and construction of a full-length cDNA clone of the PDK20 vaccine candidate," Vaccine, vol. 28, no. 17, pp. 3030-3037, 2010.

[172] S.-Y. Pu, R.-H. Wu, C.-C. Yang et al., "Successful propagation of flavivirus infectious cDNAs by a novel method to reduce the cryptic bacterial promoter activity of virus genomes," Journal of Virology, vol. 85, no. 6, pp. 2927-2941, 2011.

[173] T. S. Gritsun and E. A. Gould, "Infectious transcripts of tick-borne encephalitis virus, generated in days by RT-PCR," Virology, vol. 214, no. 2, pp. 611-618, 1995.

[174] A. A. Khromykh, A. N. Varnavski, P. L. Sedlak, and E. G. Westaway, "Coupling between replication and packaging of flavivirus RNA: evidence derived from the use of DNA-based full-length CDNA clones of kunjin virus," Journal of Virology, vol. 75, no. 10, pp. 4633-4640, 2001.

[175] C. M. Rice, A. Grakoui, R. Galler, and T. J. Chambers, "Transcription of infectious yellow fever RNA from full-length cDNA templates produced by in vitro ligation," The New Biologist, vol. 1, no. 3, pp. 285-296, 1989.

[176] S.-I. Yun, S.-Y. Kim, C. M. Rice, and Y.-M. Lee, "Development and application of a reverse genetics system for Japanese encephalitis virus," Journal of Virology, vol. 77, no. 11, pp. 64506465, 2003.

[177] H. Sumiyoshi, C. H. Hoke, and D. W. Trent, "Infectious Japanese encephalitis virus RNA can be synthesized from in vitro-ligated cDNA templates," Journal of Virology, vol. 66, no. 9, pp. 54255431, 1992.

[178] R. M. Kinney, S. Butrapet, G.-J. J. Chang et al., "Construction of infectious cDNA clones for dengue 2 virus: strain 16681 and its attenuated vaccine derivative, strain PDK-53," Virology, vol. 230, no. 2, pp. 300-308, 1997.

[179] V. Yamshchikov, V. Mishin, and F. Cominelli, "A new strategy in design of (+)RNA virus infectious clones enabling their stable propagation in E. coli," Virology, vol. 281, no. 2, pp. 272-280, 2001.

[180] C. S. Schmaljohn and C. D. Blair, "Clonal analysis of mammalian cell cultures persistently infected with Japanese encephalitis virus," Journal of Virology, vol. 31, no. 3, pp. 816822, 1979.

[181] K.-N. Tsai, S.-F. Tsang, C.-H. Huang, and R.-Y. Chang, "Defective interfering RNAs of Japanese encephalitis virus found in mosquito cells and correlation with persistent infection," Virus Research, vol. 124, no. 1-2, pp. 139-150, 2007.

[182] W. Chen, H. Kawano, R. Men, D. Clark, and C.-J. Lai, "Construction of intertypic chimeric dengue viruses exhibiting type 3 antigenicity and neurovirulence for mice," Journal of Virology, vol. 69, no. 8, pp. 5186-5190, 1995.

[183] M. Bray and C.-J. Lai, "Construction of intertypic chimeric dengue viruses by substitution of structural protein genes," Proceedings of the National Academy of Sciences of the United States of America, vol. 88, no. 22, pp. 10342-10346, 1991.

[184] D. K. Toukam, M. Tenbusch, A. Stang, V. Temchura et al., "Targeting antibody responses to the membrane proximal external region of the envelope glycoprotein of human immunodeficiency virus," PLoS ONE, vol. 7, no. 5, Article ID e38068, 2012.

[185] P. Bach, E. Kamphuis, B. Odermatt, G. Sutter, C. J. Buchholz, and U. Kalinke, "Vesicular stomatitis virus glycoprotein displaying retrovirus-like particles induce a type I IFN receptor-dependent switch to neutralizing IgG antibodies," Journal of Immunology, vol. 178, no. 9, pp. 5839-5847, 2007.
[186] M. P. Ramanathan, M. A. Kutzler, Y.-C. Kuo et al., "Coimmunization with an optimized IL15 plasmid adjuvant enhances humoral immunity via stimulating B cells induced by genetically engineered DNA vaccines expressing consensus JEV and WNV E DIII," Vaccine, vol. 27, no. 32, pp. 4370-4380, 2009.

[187] A. W. Lifland, J. Jung, E. Alonas, C. Zurla, J. E. Crowe Jr., and P. J. Santangelo, "Human respiratory syncytial virus nucleoprotein and inclusion bodies antagonize the innate immune response mediated by MDA5 and MAVS," Journal of Virology, vol. 86, no. 15, pp. 8245-8258, 2012.

[188] D. Li, J.-L. Chen, H. Zhang et al., "Improvement of the immunity of pig to Hog cholera vaccine by recombinant plasmid with porcine interleukin-6 gene and CpG motifs," Vaccine, vol. 29, no. 22, pp. 3888-3894, 2011.

[189] T. J. Pitcher, G. D. Gromowski, D. W. C. Beasley, and A. D. T. Barrett, "Conservation of the DENV-2 type-specific and DEN complex-reactive antigenic sites among DENV-2 genotypes," Virology, vol. 422, no. 2, pp. 386-392, 2012.

[190] N. L. Davis, K. W. Brown, G. F. Greenwald et al., "Attenuated mutants of Venezuelan equine encephalitis virus containing lethal mutations in the PE2 cleavage signal combined with a second-site suppressor mutation in E1," Virology, vol. 212, no. 1, pp. 102-110, 1995.

[191] R. O. Jimenez and B. A. L. Da Fonseca, "Recombinant plasmid expressing a truncated dengue-2 virus E protein without coexpression of prM protein induces partial protection in mice," Vaccine, vol. 19, no. 6, pp. 648-654, 2000.

[192] K. V. Pugachev, J. Schwaiger, N. Brown et al., "Construction and biological characterization of artificial recombinants between a wild type flavivirus (Kunjin) and a live chimeric flavivirus vaccine (ChimeriVax-JE)," Vaccine, vol. 25, no. 37-38, pp. 66616671, 2007.

[193] Z. Wu, Y. Xue, B. Wang, J. Du, and Q. Jin, "Broad-spectrum antiviral activity of RNA interference against four genotypes of Japanese encephalitis virus based on single microrna polycistrons," PLoS ONE, vol. 6, no. 10, Article ID e26304, 2011.

[194] F. Guirakhoo, Z.-X. Zhang, T. J. Chambers et al., "Immunogenicity, genetic stability, and protective efficacy of a recombinant, chimeric yellow fever-Japanese encephalitis virus (ChimeriVax- JE) as a live, attenuated vaccine candidate against Japanese encephalitis," Virology, vol. 257, no. 2, pp. 363-372, 1999.

[195] T. P. Monath, K. Soike, I. Levenbook et al., "Recombinant, chimaeric live, attenuated vaccine (ChimeriVax) incorporating the envelope genes of Japanese encephalitis (SA14-14-2) virus and the capsid and nonstructural genes of yellow fever (17D) virus is safe, immunogenic and protective in non-human primates," Vaccine, vol. 17, no. 15-16, pp. 1869-1882, 1999.

[196] C. C. Maier, S. Delagrave, Z.-X. Zhang et al., "A single M protein mutation affects the acid inactivation threshold and growth kinetics of a chimeric flavivirus," Virology, vol. 362, no. 2, pp. 468-474, 2007.

[197] T. J. Chambers, A. Nestorowicz, P. W. Mason, and C. M. Rice, "Yellow fever/Japanese encephalitis chimeric viruses: construction and biological properties," Journal of Virology, vol. 73, no. 4, pp. 3095-3101, 1999.

[198] C.-J. Lai and T. P. Monath, "Chimeric flaviviruses: novel vaccines against dengue fever, tick-borne encephalitis, and Japanese encephalitis," Advances in Virus Research, vol. 61, pp. 469-509, 2003. 
[199] M. B. Appaiahgari and S. Vrati, "IMOJEV: a yellow fever virusbased novel Japanese encephalitis vaccine," Expert Review of Vaccines, vol. 9, no. 12, pp. 1371-1384, 2010.

[200] G.-J. J. Chang, A. R. Hunt, and B. Davis, "A single intramuscular injection of recombinant plasmid DNA induces protective immunity and prevents Japanese encephalitis in mice," Journal of Virology, vol. 74, no. 9, pp. 4244-4252, 2000.

[201] Y. Yu, "Phenotypic and genotypic characteristics of Japanese encephalitis attenuated live vaccine virus SA14-14-2 and their stabilities," Vaccine, vol. 28, no. 21, pp. 3635-3641, 2010.

[202] L. M. Shulman, Y. Manor, D. Sofer et al., "Neurovirulent vaccine-derived polioviruses in sewage from highly immune populations," PLoS ONE, vol. 1, no. 1, article e69, 2006.

[203] W. Shang, J. Liu, J. Yang, Z. Hu, and X. Rao, "Dengue virus-like particles: construction and application," Applied Microbiology and Biotechnology, vol. 94, no. 1, pp. 39-46, 2012.

[204] K. Yoshii, A. Goto, K. Kawakami, H. Kariwa, and I. Takashima, "Construction and application of chimeric virus-like particles of tick-borne encephalitis virus and mosquito-borne Japanese encephalitis virus," Journal of General Virology, vol. 89, no. 1, pp. 200-211, 2008.

[205] H. Yamaji and E. Konishi, "Production of Japanese encephalitis virus-like particles in insect cells," Bioengineered, vol. 4, no. 6, pp. 438-442, 2013.

[206] H. Yamaji, M. Nakamura, M. Kuwahara, Y. Takahashi, and T. Katsuda E Konishi, "Efficient production of Japanese encephalitis virus-like particles by recombinant lepidopteran insect cells," Applied Microbiology and Biotechnology, vol. 97, no. 3, pp. 10711079, 2013.

[207] N. V. Petukhova, P. A. Ivanov, and A. I. Migunov, "Virus-like particles-a new strategy for production of vaccines against influenza virus," Voprosy Virusologii, vol. 58, no. 2, pp. 10-14, 2013.

[208] Y. X. Tang, L. F. Jiang, J. M. Zhou et al., "Induction of virus-neutralizing antibodies and $\mathrm{T}$ cell responses by dengue virus type 1 virus-like particles prepared from Pichia pastoris," Chinese Medical Journal, vol. 125, no. 11, pp. 1986-1992, 2012.

[209] L. Lazo, L. Gil, C. López, I. Valdés et al., "A vaccine formulation consisting of nucleocapsid-like particles from Dengue-2 and the fusion protein P64k-domain III from Dengue-1 induces a protective immune response against the homologous serotypes in mice," Acta Tropica, vol. 124, no. 2, pp. 107-112, 2012.

[210] E. A. Teunissen, M. de Raad, and E. Mastrobattista, "Production and biomedical applications of virus-like particles derived from polyomaviruses," Journal of Controlled Release, vol. 3659, no. 13, pp. 0168-211], 2013.

[211] D. Chandran, P. V. Shahana, G. S. Rani, P. Sugumar, C. R. Shankar, and V. A. Srinivasan, "Display of neutralizing epitopes of Canine parvovirus and a T-cell epitope of the fusion protein of Canine distemper virus on chimeric tymovirus-like particles and its use as a vaccine candidate both against Canine parvo and Canine distemper," Vaccine, vol. 28, no. 1, pp. 132-139, 2009.

[212] M. N. Jagadish, S. J. Edwards, M. B. Hayden et al., "Chimeric potyvirus-like particles as vaccine carriers," Intervirology, vol. 39, no. 1-2, pp. 85-92, 1996.

[213] U. Arora, P. Tyagi, S. Swaminathan, and N. Khanna, "Chimeric Hepatitis B core antigen virus-like particles displaying the envelope domain III of dengue virus type 2," Journal of Nanobiotechnology, vol. 10, no. 30, pp. 1477-3155, 2012.

[214] A. E. Calvert, C. Y. Huang, C. D. Blair, and J. T. Roehrig, "Mutations in the West Nile prM protein affect VLP and virion secretion in vitro," Virology, vol. 433, no. 1, pp. 35-44, 2012.
[215] A. J. Chua, C. Vituret, M. L. Tan et al., "A novel platform for virus-like particle-display of flaviviral envelope domain III: induction of Dengue and West Nile virus neutralizing antibodies," Virology Journal, vol. 10, p. 129, 2013.

[216] L. Gil, L. Bernardo, A. Pavón et al. et al., "Recombinant nucleocapsid-like particles from dengue- 2 induce functional serotype-specific cell-mediated immunity in mice," Journal of General Virology, vol. 93, no. 6, pp. 1204-1214, 2012.

[217] A. S. Kolaskar and U. Kulkarni-Kale, "Prediction of threedimensional structure and mapping of conformational epitopes of envelope glycoprotein of Japanese encephalitis virus," Virology, vol. 261, no. 1, pp. 31-42, 1999.

[218] T. P. Monath, G. A. Myers, R. A. Beck et al., "Safety testing for neurovirulence of novel live, attenuated flavivirus vaccines: infant mice provide an accurate surrogate for the test in monkeys," Biologicals, vol. 33, no. 3, pp. 131-144, 2005.

[219] T. P. Monath, I. Levenbook, K. Soike et al., "Chimeric yellow fever virus 17D-Japanese encephalitis virus vaccine: doseresponse effectiveness and extended safety testing in rhesus monkeys," Journal of Virology, vol. 74, no. 4, pp. 1742-1751, 2000.

[220] N. Witthajitsomboon, A. Chen, S. Lorroengsil, M. Sällberg, and S. Pantuwatana, "Cloning and expression of envelope protein of Thai genotype I strain KE-093 of Japanese encephalitis virus," Southeast Asian Journal of Tropical Medicine and Public Health, vol. 41, no. 6, pp. 1359-1367, 2010.

[221] F. J. May, L. Li, C. T. Davis, S. E. Galbraith, and A. D. T. Barrett, "Multiple pathways to the attenuation of West Nile virus in South-East Texas in 2003," Virology, vol. 405, no. 1, pp. 8-14, 2010.

[222] E. Ryu, "Attenuation of Japanese encephalitis virus by brain passage of guinea pigs," International Journal of Zoonoses, vol. 3, no. 2, pp. 145-150, 1976.

[223] E. Domingo, E. Martinez-Salas, and F. Sobrino, “The quasispecies (extremely heterogeneous) nature of viral RNA genome populations: biological relevance-a review," Gene, vol. 40, no. 1, pp. 1-8, 1985.

[224] L. Kinnunen, A. Huovilainen, T. Poyry, and T. Hovi, "Rapid molecular evolution of wild type 3 poliovirus during infection in individual hosts," Journal of General Virology, vol. 71, no. 2, pp. 317-324, 1990.

[225] L. M. Shulman, R. Handsher, C.-F. Yang et al., "Resolution of the pathways of poliovirus type 1 transmission during an outbreak," Journal of Clinical Microbiology, vol. 38, no. 3, pp. 945-952, 2000.

[226] O. M. Kew, M. N. Mulders, G. Y. Lipskaya, E. E. Da Silva, and M. A. Pallansch, "Molecular epidemiology of polioviruses," Seminars in Virology, vol. 6, no. 6, pp. 401-414, 1995.

[227] L. M. Shulman, Y. Manor, R. Handsher et al., "Molecular and antigenic characterization of a highly evolved derivative of the type 2 oral poliovaccine strain isolated from sewage in Israel," Journal of Clinical Microbiology, vol. 38, no. 10, pp. 3729-3734, 2000.

[228] L. M. Shulman, Y. Manor, D. Sofer et al., "Neurovirulent vaccine-derived polioviruses in sewage from highly immune populations," PLoS ONE, vol. 1, no. 1, article e69, 2006.

[229] K. H. Eckels, Y. Yong-Xin, D. R. Dubois, N. J. Marchette, D. W. Trent, and A. J. Johnson, "Japanese encephalitis virus liveattenuated vaccine, Chinese strain SA14-14-2; Adaptation to primary canine kidney cell cultures and preparation of a vaccine for human use," Vaccine, vol. 6, no. 6, pp. 513-518, 1988. 
[230] P. S. Shah, M. Tanaka, A. H. Khan et al., "Molecular characterization of attenuated Japanese encephalitis live vaccine strain ML-17," Vaccine, vol. 24, no. 4, pp. 402-411, 2006.

[231] R. M. Kinney, S. Butrapet, G.-J. J. Chang et al., "Construction of infectious cDNA clones for dengue 2 virus: strain 16681 and its attenuated vaccine derivative, strain PDK-53," Virology, vol. 230, no. 2, pp. 300-308, 1997.

[232] S. S. Whitehead, K. A. Hanley, J. E. Blaney Jr., L. E. Gilmore, W. R. Elkins, and B. R. Murphy, "Substitution of the structural genes of dengue virus type 4 with those of type 2 results in chimeric vaccine candidates which are attenuated for mosquitoes, mice, and rhesus monkeys," Vaccine, vol. 21, no. 2730, pp. 4307-4316, 2003.

[233] K. V. Pugachev, F. Guirakhoo, D. W. Trent, and T. P. Monath, "Traditional and novel approaches to flavivirus vaccines," International Journal for Parasitology, vol. 33, no. 5-6, pp. 567-582, 2003.

[234] S.-S. Chiou and W.-J. Chen, "Mutations in the NS3 gene and 3/-NCR of Japanese encephalitis virus isolated from an unconventional ecosystem and implications for natural attenuation of the virus," Virology, vol. 289, no. 1, pp. 129-136, 2001.

[235] S. P. Hong, W.-D. Yoo, R. Putnak, K. H. Eckels, H. M. Rho, and S.-O. Kim, "Nucleotide sequence of envelope protein of Japanese encephalitis virus SA14-14-2 adapted to Vero cells," Mitochondrial DNA, vol. 12, no. 5-6, pp. 437-442, 2001.

[236] S. Nitayaphan, J. A. Grant, G.-J. J. Chang, and D. W. Trent, "Nucleotide sequence of the virulent SA-14 strain of Japanese encephalitis virus and its attenuated vaccine derivative, SA-1414-2," Virology, vol. 177, no. 2, pp. 541-552, 1990.

[237] H. Ni, G.-J. J. Chang, H. Xie, D. W. Trent, and A. D. T. Barrett, "Molecular basis of attenuation of neurovirulence of wild-type Japanese encephalitis virus strain SA14," Journal of General Virology, vol. 76, no. 2, pp. 409-413, 1995.

[238] S. P. Hong, W.-D. Yoo, R. Putnak, K. H. Eckels, H. M. Rho, and S.-O. Kim, "Nucleotide sequence of envelope protein of Japanese encephalitis virus SA14-14-2 adapted to Vero cells," Mitochondrial DNA, vol. 12, no. 5-6, pp. 437-442, 2001.

[239] H. Ni and A. D. T. Barrett, "Attenuation of Japanese encephalitis virus by selection of its mouse brain membrane receptor preparation escape variants," Virology, vol. 241, no. 1, pp. 30-36, 1998.

[240] J. X. Cao, H. Ni, M. R. Wills et al., "Passage of Japanese encephalitis virus in HeLa cells results in attenuation of virulence in mice," Journal of General Virology, vol. 76, no. 11, pp. 2757-2764, 1995.

[241] A. J. Schuh, H. Guzman, R. B. Tesh, and A. D. Barrett, "Genetic diversity of Japanese encephalitis virus isolates obtained from the indonesian archipelago between 1974 and 1987," VectorBorne and Zoonotic Diseases, vol. 13, no. 7, pp. 479-488, 2013.

[242] S. K. Pujhari, S. Prabhakar, R. K. Ratho, M. Modi, M. Sharma, and B. Mishra, "A novel mutation (S227T) in domain II of the envelope gene of Japanese encephalitis virus circulating in North India," Epidemiology and Infection, vol. 139, no. 6, pp. 849-856, 2011.

[243] K. Dutta, A. Nazmi, and A. Basu, "Chemotherapy in Japanese encephalitis: are we there yet?" Infectious Disorders, vol. 11, no. 3, pp. 300-314, 2011.

[244] X. Wu, T. Zhou, S. O’Dell, R. T. Wyatt, P. D. Kwong, and J. R. Mascola, "Mechanism of human immunodeficiency virus type 1 resistance to monoclonal antibody b12 that effectively targets the site of CD4 attachment," Journal of Virology, vol. 83, no. 21, pp. 10892-10907, 2009.
[245] I. Kurane, K. Shibasaki, A. Kotaki, Y. Hijioka, and T. Takasaki, "The effect of precipitation on the transmission of Japanese encephalitis (JE) virus in nature: a complex effect on antibodypositive rate to JE virus in sentinel pigs," International Journal of Environmental Research and Public Health, vol. 10, no. 5, pp. 1831-1844, 1831.

[246] S. M. Upadhyayula, S. Rao Mutheneni, H. K. Nayanoori, A. Natarajan, and P. Goswami, "Impact of weather variables on mosquitoes infected with Japanese encephalitis virus in Kurnool district, Andhra Pradesh," Asian Pacific Journal of Tropical Medicine, vol. 5, no. 5, pp. 337-341, 2012.

[247] F. Rodhain, "Japanese encephalitis: a fast-changing viral disease," Bulletin de la Société de Pathologie Exotique, vol. 103, no. 3, pp. 135-154, 2010.

[248] D. E. Impoinvil, T. Solomon, W. W. Schluter et al., "The spatial heterogeneity between Japanese encephalitis incidence distribution and environmental variables in Nepal," PLOS ONE, vol. 6, no. 7, Article ID e22192, 2011.

[249] Centers for Disease Control and Prevention (CDC), "Japanese encephalitis surveillance and immunization-Asia and the Western pacific," MMWR Morbidity and Mortality Weekly Report, vol. 62, no. 33, pp. 658-662, 2013.

[250] R. Kumari, K. Kumar, A. Rawat, G. Singh, N. K. Yadav, and L. S. Chauhan, "First indigenous transmission of Japanese Encephalitis in urban areas of National Capital Territory of Delhi, India," Tropical Medicine \& International Health, vol. 18, no. 6, pp. 743-749, 2013.

[251] L.-J. Xu, R. Liu, S. Ye, H. Ling, and C.-M. Zhu, "Genomic analysis of a newly isolated of Japanese encephalitis virus strain, CQ11-66, from a pediatric patient in China," Virology Journal, vol. 10, no. 101, 2013.

[252] H. Wang, Y. Li, X. Liang, and G. Liang, "Japanese encephalitis in mainland China," Japanese Journal of Infectious Diseases, vol. 62, no. 5, pp. 331-336, 2009.

[253] K. Morita, "Molecular epidemiology of Japanese encephalitis in East Asia," Vaccine, vol. 27, no. 50, pp. 7131-7132, 2009.

[254] A. T. Pyke, D. T. Williams, D. J. Nisbet et al., "The appearance of a second genotype of Japanese encephalitis virus in the Australasian region," American Journal of Tropical Medicine and Hygiene, vol. 65, no. 6, pp. 747-753, 2001.

[255] Y.-Y. Chen, Y.-C. Fan, W.-C. Tu et al., "Japanese encephalitis virus genotype replacement, Taiwan, 2009-2010," Emerging Infectious Diseases, vol. 17, no. 12, pp. 2354-2356, 2011.

[256] M. A. F. Mohammed, S. E. Galbraith, A. D. Radford et al., "Molecular phylogenetic and evolutionary analyses of Muar strain of Japanese encephalitis virus reveal it is the missing fifth genotype," Infection, Genetics and Evolution, vol. 11, no. 5, pp. 855-862, 2011.

[257] A. J. Schuh, M. J. Ward, A. J. L. Brown, and A. D. T. Barrett, "Phylogeography of Japanese encephalitis Virus: genotype Is associated with climate," PLOS Neglected Tropical Diseases, vol. 7, no. 8, 2013

[258] M. H. Li, S. H. Fu, W. X. Chen, H. Y. Wang, Y. H. Guo et al., "Genotype v Japanese encephalitis virus is emerging," PLOS Neglected Tropical Diseases, vol. 5, no. 7, 2011.

[259] E. O. Erra, H. H. Askling, S. Yoksan et al., "Cross-protective capacity of Japanese encephalitis (JE) vaccines against circulating heterologous JE virus genotypes," Clinical Infectious Diseases, vol. 56, no. 2, pp. 267-270, 2013. 

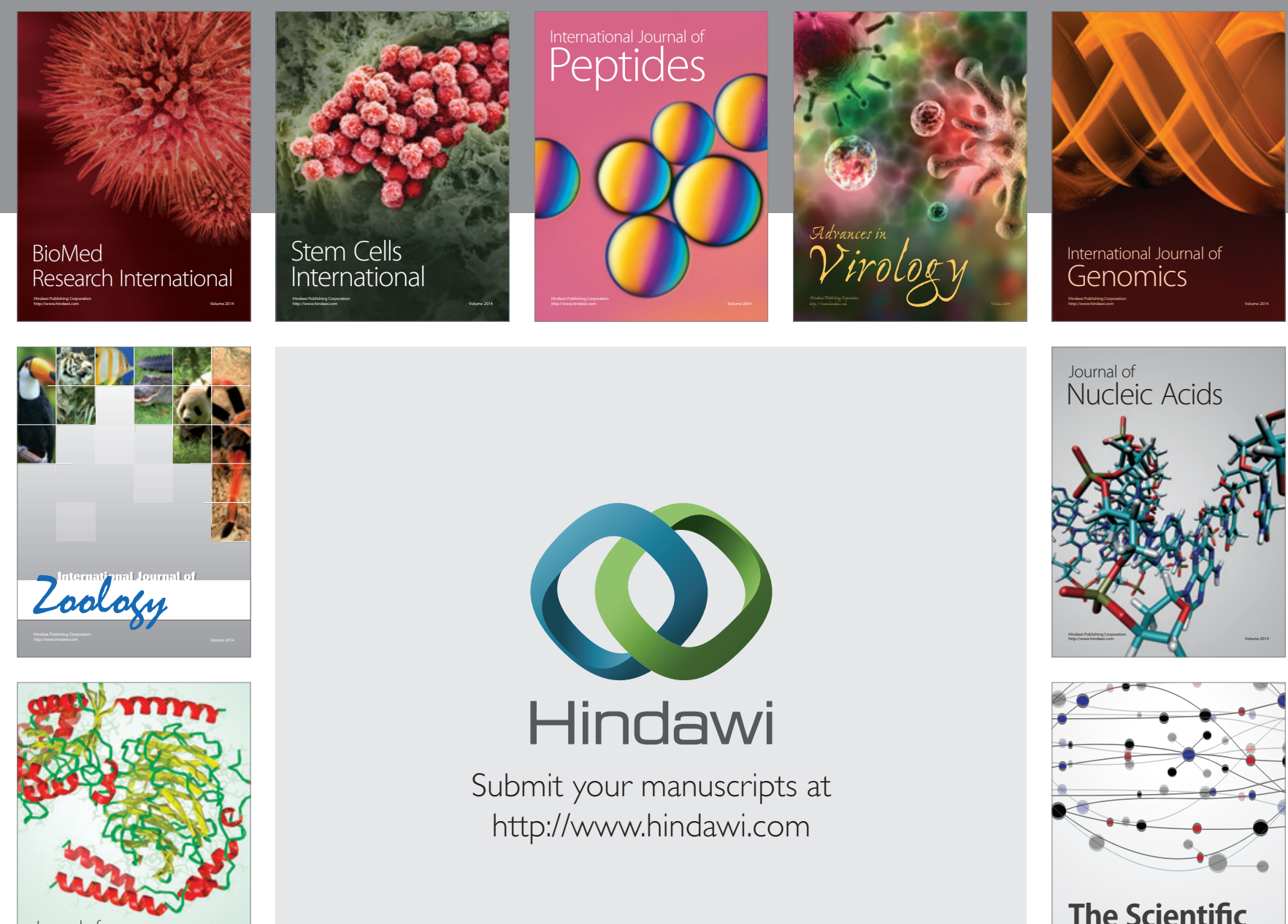

Submit your manuscripts at

http://www.hindawi.com

Journal of
Signal Transduction
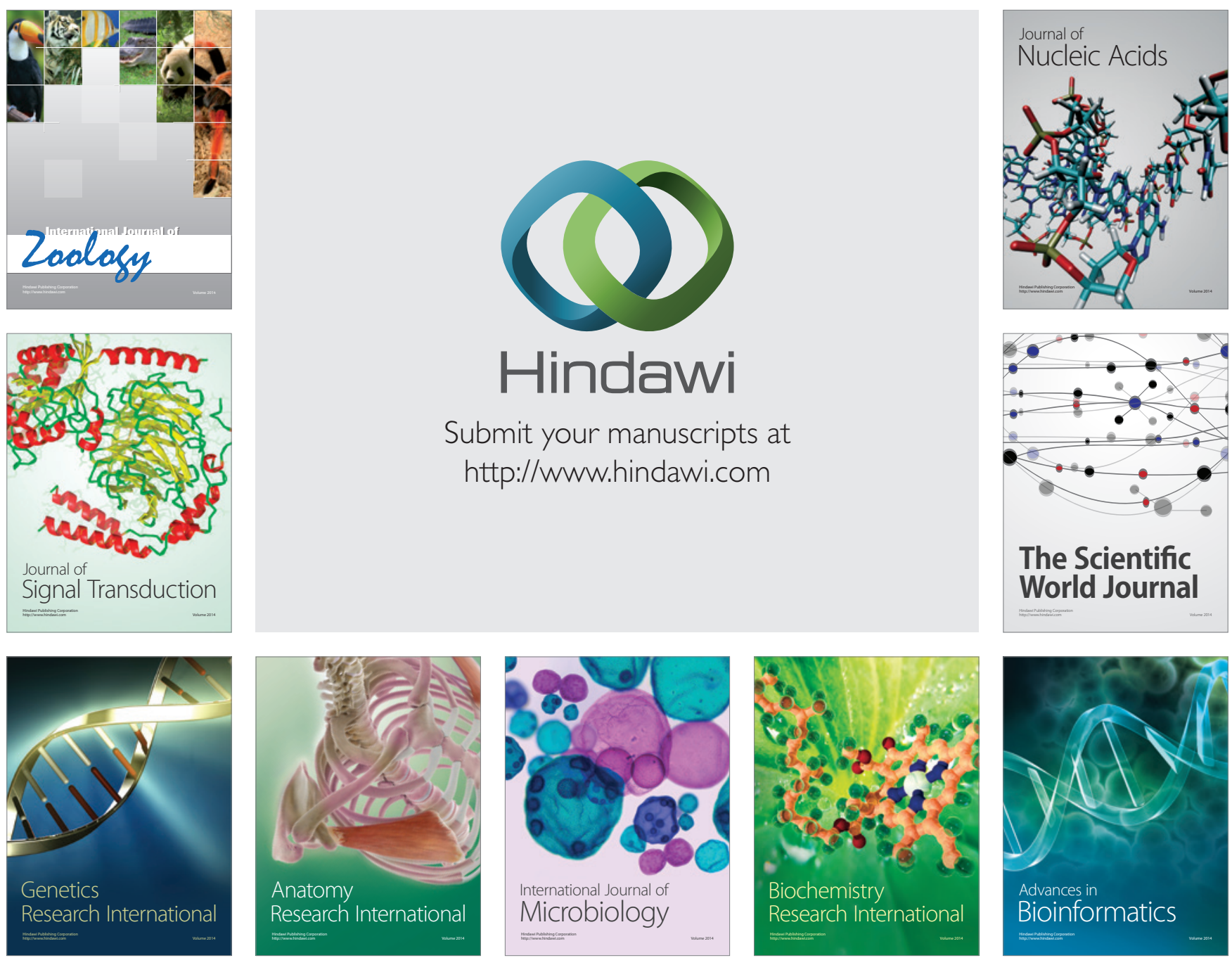

The Scientific World Journal
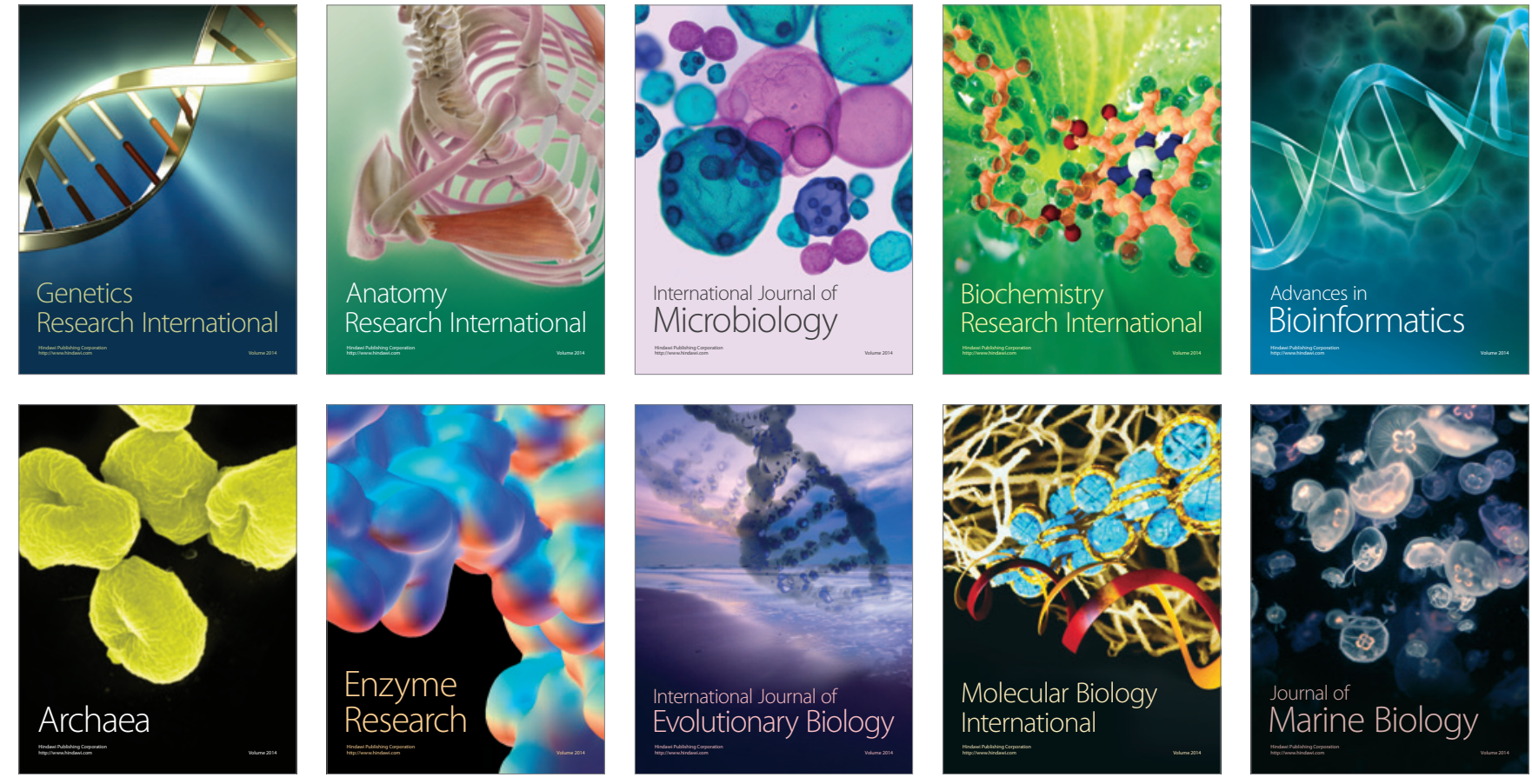